OECDpublishing

WHAT FUTURE

FOR SCIENCE,

TECHNOLOGY AND

INNOVATION AFTER

COVID-19?

OECD SCIENCE, TECHNOLOGY AND INDUSTRY

POLICY PAPERS

April 2021 No. 107 
This paper was approved and declassified by written procedure by the Committee for Scientific and Technological Policy (CSTP) on 11 December 2019 and prepared for publication by the OECD Secretariat.

Note to Delegations:

This document is also available on ONE M\&P under the reference code:

DSTI/STP/TIP(2020)7/FINAL

This document, as well as any data and any map included herein, are without prejudice to the status of or sovereignty over any territory, to the delimitation of international frontiers and boundaries and to the name of any territory, city or area.

The statistical data for Israel are supplied by and under the responsibility of the relevant Israeli authorities. The use of such data by the OECD is without prejudice to the status of the Golan Heights, East Jerusalem and Israeli settlements in the West Bank under the terms of international law.

Note by Turkey

The information in this document with reference to "Cyprus" relates to the southern part of the Island. There is no single authority representing both Turkish and Greek Cypriot people on the Island. Turkey recognises the Turkish Republic of Northern Cyprus (TRNC). Until a lasting and equitable solution is found within the context of the United Nations, Turkey shall preserve its position concerning the "Cyprus issue".

Note by all the European Union Member States of the OECD and the European Union

The Republic of Cyprus is recognised by all members of the United Nations with the exception of Turkey. The information in this document relates to the area under the effective control of the Government of the Republic of Cyprus.

(C) OECD 2021

The use of this work, whether digital or print, is governed by the Terms and Conditions to be found at http://www.oecd.org/termsandconditions. 


\title{
What future for science, technology and innovation after COVID-19?
}

\author{
Caroline Paunov and Sandra Planes-Satorra, OECD
}

\begin{abstract}
The COVID-19 crisis may bring lasting socioeconomic changes, also affecting science, technology and innovation (STI). This paper discusses the effects that the COVID-19 crisis could have on the future of STI and its policies, building on lessons learned from past crises, an analysis of diverse sources of early data and insights from expert discussions in international policy fora. Factors shaping the future of STI include the unequal effects of the crisis on R\&D spending across sectors, the accelerated adoption of digital tools and techniques, and changes in the openness and inclusiveness of research and innovation ecosystems. The paper also explores how STI policy could experience fundamental changes as resilience, environmental sustainability and inclusiveness become more prominent objectives on policy agendas. This includes experimentation with new data and digital tools for policy purposes and unconventional policy approaches, which could spur the adoption of new and more effective STI policies.
\end{abstract}

Keywords: science, technology and innovation (STI); STI policy; resilience; COVID-19; future developments; innovative (digital) policy tools and approaches; OECD countries

JEL codes: O30, I23, H12

Acknowledgements: The authors are grateful to Hunter McGuire for excellent research assitance, Blandine Serve and Fabien Verger for their statistical support, and to Randy Holden for his editorial support. For their participation in interviews conducted in connection with this paper, the authors would like to thank Daniele Archibugi (Italian National Research Council), José Argudo, Robert Shaw and James Gardiner (Innovate UK), Susana Borrás (Copenhagen Business School), Franz Haas (CureVac), Chris Hale (Ipsos Mori), Roland Sommer (Plattform Industrie 4.0, Austria) and Caroline Wagner (Ohio State University). The paper greatly benefitted from the virtual workshops and expert discussions organized by the OECD Working Party on Innovation and Technology Policy (TIP) in 2020. The authors would like to specifically thank the speakers of TIP talks organized in October and November 2020: Jakob Edler (Fraunhofer Institute for Systems and Innovation Research), Kathryn Funk (PubMed Central), Sebastian Kohlmeier (Allen Institute for Artificial Intelligence), David Legg (Innovate UK), Josh Lerner (Harvard University), Göran Marklund (VINNOVA, Sweden), Byeongwon Park (STEPI, Korea), Fortunato de la Peña (Department of Science and Technology, Republic of the Philippines), Jerry Sheehan (National Library of Medicine, United States), Axel Sommer (Sommerrust), Reinhilde Veugelers (KU Leuven), and Sacha WunschVincent (WIPO). Comments received from TIP delegates and experts, including the detailed comments from Jerry Sheehan, Kai Husso and Ana Correia, are gratefully acknowledged. 


\section{Table of contents}

Executive summary 5

Determinants of the future impacts of COVID-19 on STI 5

Possible long-term implications of the COVID-19 crisis for STI 5

Introduction 8

1. Factors determining lasting impacts of COVID-19 on STI 9

1.1. The uncertain evolution of the pandemic 9

1.2. Impacts on STI of changing societal preferences and policy directions $\quad 10$

2. Lasting impacts of the COVID-19 crisis on science, technology and innovation 14

2.1. The challenges ahead for STI spending: What lessons from past shocks? 14

2.2. Will digitalisation accelerate with the COVID-19 pandemic? What would be the implications for STI? $\quad 20$

2.3. Will STI ecosystems be more open and agile?

2.4. Will global collaborations in STI increase? 28

2.5. Will STI be more or less inclusive at social, industrial and territorial levels? 30

3. Will the goals of STI policy change? 35

3.1. Towards a more directional role for STI policy 35

3.2. How can STI policy support the transition towards environmentally
sustainable futures?

3.3. How can STI policy support future inclusiveness? $\quad 38$

3.4. How can STI policy help build greater resilience? $\quad 41$

3.5. Open questions on the new policy goals 45

4. New ways of conducting STI policy 46

4.1. New data and better data analytics tools for STI policy 46

4.2. Alternative policy approaches: Strategic foresight, systems transformation, and tracking applications $\quad 50$

4.3. New governance models and the importance of civil society engagement 53

4.4. Implementation challenges for new policy tools 55

5. Conclusion: What speed and directions for innovation in the future? 56

$\begin{array}{ll}\text { References } & 58\end{array}$ 


\section{Executive summary}

The COVID-19 pandemic and its impacts on socio-economic activities as a result of the national and global management of the pandemic may result in lasting changes, including for the science, technology and innovation (STI). It may also affect the purpose, design and execution of STI policies.

\section{Determinants of the future impacts of COVID-19 on STI}

The severity and duration of the pandemic will shape the long-term impacts of COVID-19 on STI. As of March 2021 - one year after the start of the COVID-19 crisis - the future evolution of the pandemic remained uncertain but expected to differ across countries and regions. While some, particularly in the Asia-Pacific region, returned to a degree of economic normalcy in the latter half of 2020, others were facing rising infection rates. A few countries were rolling out vaccination campaigns, but most others struggled to access and distribute vaccines. The effectiveness of existing vaccines against new COVID-19 variants was also uncertain.

The implications of a prolonged crisis on STI ecosystems is mixed. Longer duration may result in new ways of operating (e.g. more flexible work arrangements, intensive use of digital tools, increased automation) becoming more embedded and efficient. However, a longer period of economic shock would reduce the financial means for businesses to transform STI processes and for government to support STI. Under this scenario, the risks of widening gaps in terms of innovation performance across and within countries, as well as across firms and research institutions, become central policy concerns. Some firms, entrepreneurs and researchers may be permanently excluded from participating in STI.

\section{Possible long-term implications of the COVID-19 crisis for STI}

\section{Challenges for future STI funding}

Insights from past crises, in particular the 2008-09 global financial crisis, point to two upcoming challenges for future STI spending:

- Business expenditure on R\&D (BERD) and innovation are both typically procyclical as declines in demand and resulting declines in firm revenues reduce funds available to invest in STI. The increased demand for a number of health and digital tools and services since the onset of the pandemic, however, point to highly unequal dynamics across sectors. High demand for new solutions to address the pandemic and ways to operate in contexts of social distancing incentivised investments in STI in those sectors and is likely to lead to a very different evolution of R\&D expenditures compared to the 2008-09 global financial crisis.

- Public funding of STI may change in the years to come because of high levels of public debt. At the same time, the success of STI contributions in addressing the current pandemic may provide fresh impetus for enhanced policy support for STI. Funding available for STI, including for universities and public research institutions, may not decrease and even increase as a result. Cuts in funding for universities and research institutions will have lasting effects if they cause a brain drain of researchers from countries most affected by funding cuts. 


\section{Greater adoption of digital technologies and tools, big data analytics and AI}

The wide uptake of digital technology applications as well as big data analytics and AI tools during the COVID-19 crisis may result in the following:

- an increase in digital innovations to respond to growing demand for digital applications, ranging from e-health services to virtual conferencing and machine learning for research;

- more scientific conferences, training and research collaboration activities may be held virtually, with possible impacts on the productivity of STI;

- higher productivity of research and innovation activities as a result of the widespread adoption of better digital tools and the use of AI techniques; and

- wider business adoption of automation and other technologies and practices (e.g. 3D printing, blockchain, cybersecurity) to increase resilience to future shocks.

Adoption of these technologies and tools that is widespread and lasting greatly depends on a range of factors, including different STI actors' access to infrastructures, digital security and privacy conditions, and policy actions.

\section{The openness, inclusiveness and agility of STI ecosystems}

The rapid implementation of open science and open data initiatives -including platforms to share research publications and data created to support COVID-19 research- may prove a catalyst for the wider adoption of open science and data initiatives, but a number of wellknown challenges will need to be addressed.

The prominence STI gained during the COVID-19 crisis offers opportunities for greater inclusion in STI ecosystems by attracting talent from groups that have been historically underrepresented, such as women and minorities. The large number of crowdsourcing challenges launched between March and May 2020 following the unexpected outbreak of COVID-19, which left billions of people confined to their homes, may also result in more diverse participation in innovation compared to the past. More disadvantaged groups, however, were disproportionately affected by the COVID-19 crisis and may struggle to contribute to the post-pandemic STI ecosystem.

The effects of COVID-19 also threaten to widen the gap between leading firms, sectors and research institutions that thrived during the crisis and others, particularly those that were more severely hit, more liquidity-constrained, and less able to benefit from digital tools.

Efforts undertaken to mobilise the STI system to provide quick responses to the pandemic may boost that system's agility. Changes could include reduced regulatory barriers for health innovations, such as more rapid vaccine approval processes, and quicker ways to publish research findings, such as the wider use of preprints. The feasibility of extending these across all areas of STI and the associated downsides will shape wider adoption.

\section{The global nature of STI ecosystems}

Opportunities and policy support for international co-operation may be reinforced in an effort to optimise an efficient global STI system, benefiting from national specialisations and capacities, especially in the health field.

However, public budget constraints stemming from the crisis, restrictions on international mobility, and countries' concerns over building national technological capacities in view of possible international future shocks - as well as geopolitical tensions - could negatively affect international co-operation in STI. 


\section{Possible changes in future STI policy objectives}

The COVID-19 crisis may change STI policy by affecting the direction STI policy takes. Resilience, environmental sustainability and inclusiveness goals may gain in importance in the recovery as the crisis sheds new light on the relevance of these goals. The crisis raised both new opportunities and new challenges in achieving them. Inclusiveness, for instance, was challenged as educational programmes were severely interrupted, while flexible work arrangements may pave the way for new ways of including more people in the STI workforce. At the same time, difficult recoveries may detract from those goals. The pandemic also demonstrated that government can shape directionality of STI efforts by soliciting solutions to address the COVID-19 crisis. The crisis also provided for extensive experimentation on how to best do so that may be applied to other areas in the future.

The COVID-19 crisis provides momentum for STI to play more important roles in building more environmentally sustainable, inclusive and resilient futures. Greening principles, for instance, have been integrated as part of the massive recovery packages that are implemented to support economic recovery. Similarly, recovery programmes can provide for STI that steers towards more resilience and inclusiveness.

Building resilience to crises became a new policy priority to which STI can critically contribute by developing solutions to prevent or mitigate the effects of crises such as future pandemics, shocks related to global warming or cyberattacks. STI can also contribute by better anticipating shocks and providing agility to countries in times of crisis (notably through the ability to develop solutions quickly).

New futures for STI policies add new complexities. Crafting STI policy for more inclusive, resilient and sustainable futures requires understanding complementarities and trade-offs between these objectives and growth in the recovery. The selection of priority fields - i.e. research/technology areas, sectors or missions - for STI policy support also requires careful consideration: if the absolute amount of funding for STI is not increased, providing more support to new priority fields reduces the funding for others.

\section{New data, tools and policy approaches shaping the evidence base for and governance of STI policy}

New tools for STI policy may increase in importance following the unprecedented use of real-time granular data (e.g. mobility data, pulse surveys) and big data visualisation and analysis tools during the pandemic. These may in turn render STI policy responses more agile, targeted and ultimately more effective.

Unconventional policy approaches that could gain ground over the coming years include embedding strategic foresight in policy making, i.e. the structured and explicit exploration of multiple futures in order to inform decision-making. Systems approaches, which take into account the interconnections in socio-economic processes, aim to formulate policies taking into account their impacts on the entire system rather than on a single component or process. This requires, for instance, when it comes to advancing the transition towards green mobility, investing in relevant R\&D, adapting city infrastructures, establishing efficient public transportation services and increasing public awareness about its benefits.

Reflections on new governance models involving intergovernmental co-operation and relations with the media will also figure in revisited STI policy agendas. The wider engagement of civil society institutions in STI policy may also be further embraced, particularly in view of achieving important societal transformations. 


\section{Introduction}

The COVID-19 pandemic and the national and global management of the crisis may result in lasting changes for science, technology and innovation (STI). Examples of such changes could include the widespread use of digital tools such as virtual conferencing for collaborative research, and artificial intelligence (AI) to optimise research processes. The pandemic may also become a catalyst for more open science and the increased engagement of civil society in STI efforts. Undesirable effects of the COVID-19 shock to STI actors could include a reduction in the diversity of STI systems if the early-career researchers, SMEs, early-stage start-ups and sectors more severely disrupted by the crisis are permanently left behind.

STI policy itself may be ready for fundamental change if resilience, environmental sustainability and inclusiveness emerge as important priorities on policy agendas for the recovery. Changes in the public's views on the role of STI in achieving socio-economic goals and on the role of government in building new futures may foster this change. In addition, the impact of STI policy may change with more experimentation with digital tools and new governance models, which has played a significant and positive role during the COVID-19 pandemic.

This paper looks at the possible long-term effects of the COVID-19 crisis on STI. First it reflects on the main factors shaping long-term changes (section 1) and explores five dimensions of future impact: funding for STI; adoption of digital technologies and AI in research and innovation processes; and the future openness, inclusiveness and global nature of STI systems (section 2). Second, it discusses possible future directions for STI policies, and how they can contribute to "bouncing forward" towards more sustainable, inclusive and resilient futures (section 3). Third, it explores changes in STI policy approaches as a result of the pandemic, including the potential for using new digital tools for policy following experimentation with such tools during the pandemic (section 4).

The paper is released jointly with the paper "Science, technology and innovation in the time of COVID-19" (Paunov and Planes-Satorra, 2021 $\left.{ }_{[1]}\right)$, and constitutes a background paper to the OECD Science, Technology and Innovation Outlook 2021 (OECD, $2021_{[2]}$ ).

The analysis builds on several expert interviews, country policy information collected through the OECD Survey on STI Policy Responses to COVID-19 ("STIP COVID-19 Watch") and an extensive review of the published analyses on these questions. It also benefits from insights from the webinar organised by the OECD New Approaches to Economic Challenges (NAEC) Initiative on "Building resilient systems in the 21st century" (23 April 2020); the workshop "STI readiness and response in times of global emergencies: The Covid-19" (1 April 2020); and the series of webinars ${ }^{1}$ organised by the OECD Committee for Scientific and Technological Policy (CSTP). Insights from the workshops "Science, technology and innovation in times of Covid-19: What policy responses for the recovery?" (17 and 24 June 2020) and "What role for science, technology and innovation in building resilience?" (9 December 2020), as well as from the series of expert webinars ${ }^{2}$ organised by the OECD Working Party on Innovation and Technology Policy (TIP) also were invaluable.

The analysis also builds on previous CSTP and TIP work on the 2008-09 crisis (OECD, $2012_{[3]}$; Guellec and Wunsch-Vincent, 2009 $\left.{ }_{[4]}\right)$, and the work on digital innovation (OECD, 2019 $[5]$; Paunov and Planes-Satorra, 2019 ${ }_{[6]}$; Paunov et al., 2019 $\left.9_{[7]}\right)$; knowledge transfer and co-creation between industry and science (OECD, 2019 $\left.{ }_{[8]}\right)$; open science (OECD, $2015_{[9]}$; Dai, Shin and Smith, 2018 $\left.{ }_{[10]}\right)$; and systems innovation (OECD, 2015 $\left.5_{[11]}\right)$. 


\section{Factors determining lasting impacts of COVID-19 on STI}

\subsection{The uncertain evolution of the pandemic}

The COVID-19 crisis marks a global crisis of large magnitude with an evolution of the pandemic and measures taken to contain the spread of the virus of heterogeneous nature across countries over time. The IMF projects the COVID-19 crisis to result in a loss in global GDP of USD 22 trillion by 2025 - a figure that is roughly the equivalent of the GDP of the United States in 2020 in current USD (IMF, 2021 $1_{[12]}$ ). The initial shock of the COVID-19 pandemic led to widespread containment measures in March/April 2020, and a broadly symmetrical economic shock in most countries, with a gradual relaxation in the second and third quarters of 2020. This generalized shock has become less symmetrical as the pandemic has evolved. Some countries, particularly in the Asia-Pacific region, returned to a degree of economic normalcy in the latter half of 2020, while in Europe and the Americas, high caseloads continued to be a challenge through the end of the year. Nonetheless, containment measures were often less restrictive to facilitating economic activity compared to the March/April 2020 lockdown.

At the time of release of this report in March 2021, the future evolution of the COVID-19 pandemic remained uncertain. On the one hand, there were positive developments with progress in vaccination in some countries, including Israel, the United Kingdom and the United States. Initial evidence from Israel that vaccination campaigns would reduce infection and death rates from COVID-19 held the promise of an end to the pandemic. On the other hand, several countries struggled with rising infection rates and the expansion of vaccinations to the full population, while new more infectious and deadlier COVID-19 variants posed new threats with a possibly larger increase in infections. Uncertainty regarding the effectiveness of existing vaccines against new variants raised the possibility that the pandemic could not be contained in the foreseeable future. At the end of March 2021, the global death toll of the pandemic stood at over 2.7 million (Johns Hopkins University, 2021 $\left.1_{[13]}\right)$.

There was also variety in the measures governments implemented to contain the virus, including what restrictions were set to economic activity and travelling, the extent to which school closures were implemented, and the use of curfews. The way these containment measures were implemented and how different industry and social actors were considered also differed across countries. These measures and the uncertainty about the efficacy of restrictions have prevented the return to pre-crisis activities involving social interactions and travel in particular. The uneven course of the crisis suggests that these impacts will differ both between and within countries.

This uncertainty also puts a strain on potential recovery in spite of the robust performance of STI across several dimensions in the early months of the pandemic (Paunov and PlanesSatorra, $\left.2021_{[1]}\right)$. Policy makers were confronted with the challenge of reconciling the objectives of keeping the economy (including STI systems) operating to avoid immediate and longer-term negative impacts of the crisis (such as losses in terms of STI systems' performance and capabilities), while containing the spread of the virus to avoid excess deaths. There was a progressive recovery of trade and economic activity after the first lockdown period in early 2020 , with massive recovery packages implemented across the developed world that partly mitigated the economic shock of the pandemic, at least in its initial period. The renewed increase in global COVID-19 cases up until early 2021, however, challenged again the trade-off of not affecting economic activity as the pandemic spurred. 
The implications of a prolonged crisis on STI ecosystems is mixed. Longer duration may result in new ways of operating (e.g. more flexible work arrangements, intensive use of digital tools, increased automation) becoming more embedded and efficient. However, a longer period of economic shock would reduce the financial means for businesses to transform STI processes and for government to support STI and invest in socio-technical transitions to more resilient, sustainable and inclusive futures. Under this scenario, the risks of widening gaps in terms of innovation performance across and within countries, as well as across firms and research institutions, become central policy concerns. Some firms, entrepreneurs and researchers may be permanently excluded from participating in STI in the future, independently of changes adopted. The many uncertainties as to future developments also likely affect business investments in longer-term projects where the outcome depends on the evolution of the pandemic.

\subsection{Impacts on STI of changing societal preferences and policy directions}

The pandemic and the restrictions implemented to contain it are affecting the everyday life of millions of people around the world. The prolonged experience with the pandemic can change social preferences and consequently policy directions, with implications for STI and STI policy.

Previous health threats, such as the 2003 SARS and 2014 Ebola outbreaks and the 1918 Spanish flu, illustrate the extent to which such crises can shape future policy directions. After the 1918 Spanish flu, which according to estimates killed at least 50 million people, many governments across the world introduced public healthcare systems and created or strengthened their health ministries. The precursor of today's World Health Organization was also established in 1919 in consequence (Spinney, 2020 ${ }_{[14]}$ ). The Coalition for Epidemic Preparedness Innovations (CEPI), which has engaged in the global co-ordination of vaccine development for COVID-19, was formed in the aftermath of the 2014-15 Ebola outbreak in West Africa to support the development of vaccines to improve the world's preparedness to future infectious diseases.

Possible changes in social preferences with implications for STI and STI policies relate to the three areas outlined below (Figure 1).

Figure 1. Social preferences affecting STI policy

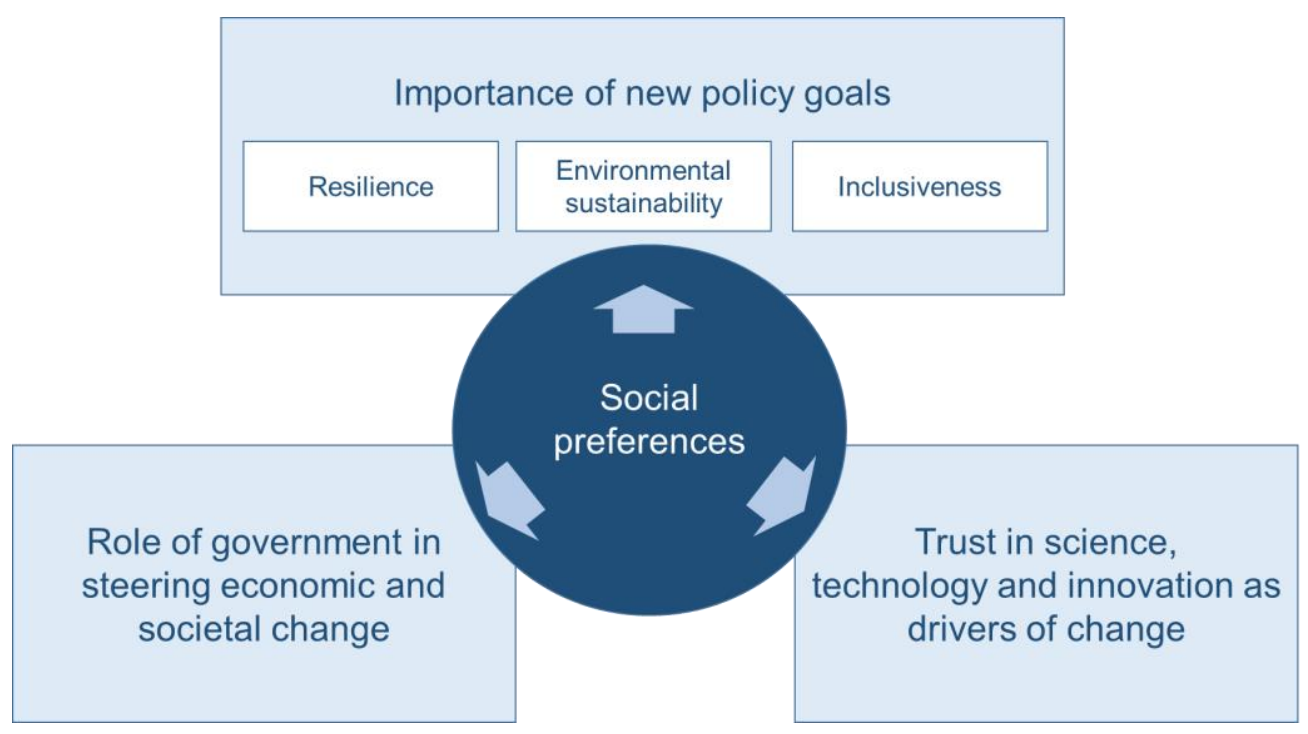




\subsubsection{Resilience, environmental sustainability and inclusiveness as policy goals}

Social preferences for implementing STI policies to meet resilience, environmental sustainability and inclusiveness goals may change.

First, the experience of the COVID-19 shock may increase public support for building more resilience to future unexpected shocks. The attention to resilience - the ability to anticipate, absorb, recover from and adapt to disruption - is not surprising in view of the high socioeconomic costs of lockdown and "social distancing" measures implemented as the only options to save lives, in a context where solutions (vaccines and treatments) were not available and health systems were under extreme pressure. The shortages and rising costs of critical medical equipment (e.g. masks, ventilators and disinfectants) during the first months of the pandemic also highlighted both the possible fragility of global supply chains and the benefits from diversified global production processes (OECD, 2020 $\left.0_{[15]}\right)$.

The COVID-19 crisis exposed the vulnerabilities that result from growing complexity and global interdependence across systems (including economic, social, financial, public health, environmental, cyber); these make failures in one system rapidly cascade to others (Hynes et al., 2020[16]). In the case of COVID-19, the localised outbreak of coronavirus led in a matter of weeks to a global pandemic and a resulting socio-economic crisis of unprecedented nature. Already the 2008-09 financial crisis had shown how problems in a national financial sector could escalate into a global economic recession that gave rise to social and political crises as well (Hynes, Lees and Müller, 2020 $\left.{ }_{[17]}\right)$. The austerity measures implemented in the decade that followed led to decreased investment in healthcare systems and consequently their capacity to address the COVID-19 shock. Localised shocks such as the Fukushima nuclear accident of 2011 and natural catastrophes had already illustrated the vulnerabilities of local systems to unexpected shocks. The COVID-19 pandemic being a global symmetric shock, however, made the vulnerabilities of global systems (incl. global supply chains) much more evident and challenging to address, requiring strengthened STI efforts in this area.

Second, the COVID-19 crisis may also raise public awareness of the need to tackle climate change and environmental degradation as key policy priorities, as they could generate future shocks with catastrophic consequences. The COVID-19 shock has shown the pain a crisis of global reach can inflict on societies and economies - and the environmental crisis could be the next one. The pandemic has incidentally resulted in some short-term positive environmental impacts, including drastic reductions in levels of air pollution and greenhouse gas emissions, allowing citizens to experience the advantages of clean air, particularly in urban areas (Shakil et al., 2020 $0_{[18]}$ ). More public awareness of the risks posed by climate change and damage to the environment, as well as the increased civil society engagement and voice in global causes experienced during the COVID-19 crisis, may impel a tighter policy focus on environmental objectives (see Section 3.2).

Third, inclusiveness challenges were also exacerbated with the 2020 COVID-19 crisis, which may increase societal demands for inclusiveness to gain ground in policy agendas. At the individual level, those in more vulnerable positions were hit hardest, including students from disadvantaged backgrounds, early-career and women researchers, and entrepreneurs. Firms in low-R\&D-intensive service sectors (in particular the tourism, entertainment and services requiring in-person interactions), and manufacturing firms reliant on global supply chains (e.g. automotive, aerospace), were highly disrupted, while digital services saw an increase in demand. Differences were also observed across regions, depending on their sectoral composition, the severity of local outbreaks of COVID-19, and the subsequent restrictions implemented (Paunov and Planes-Satorra, 2021 $1_{[1]}$ ). 
However, there is also the possibility that the crisis will slow down policy actions aimed at achieving resilience, environmental sustainability and inclusiveness. In a period of recovery, governments may focus on deploying stimulus packages primarily to support jobs and economic growth. As outlined in the OECD green growth and inclusive growth strategies, there are paths allowing for the pursuit of sustainable and inclusive futures, without compromising economic growth $\left(\right.$ OECD, 2011 $\left.{ }_{[19]}\right)$. Nonetheless, there are also trade-offs with COVID-19, particularly for those economies deeply hit by the crisis and with limited resources to invest in sustainable futures, particularly if polluting sectors play an important role in the economy. Also, while inclusiveness and diversity are key components of robust growth, policy in the recovery may focus on large players with proven potential for enhancing national competitiveness. There may also be trade-offs between the goals of environmental sustainability, inclusiveness and resilience. For instance, where resilience is pursued by building excess capacities, the result will be more production volumes than was previously the case, contrary to sustainability objectives. The pandemic also highlighted the core role of health research and services to enhance resilience to future health shocks. More investments in health, however, may reduce available investments for other objectives such as pursuing environmental sustainability.

\subsubsection{Public trust in the role of government and STI}

Social preferences regarding the role governments and STI should play in the economy and in society may change, with ramifications for the future of STI policy. Differences may also arise within countries, if preferences diverge significantly across social groups and affect social cohesion.

First, the pandemic may shape public trust in the role of government because social distancing measures implemented by government has impacts on people's everyday lives, notably lockdown measures and travel restrictions. In turn, the large death toll caused by the uncontrolled spread of the virus, and the saturation of public health systems due to high numbers of hospitalisations (in particular in intensive care units), puts high pressure on government action. Consequently, the way the public perceives government actions undertaken in the context of COVID-19 is likely to influence views on the role governments should play in "steering" the economy in the recovery towards new goals, as outlined above. Public opinion may shift with regards to the perceived need for government action on markets and the division of tasks across government and markets.

Important shapers of the public trust in government actions include the following:

- international factors such as the effectiveness of global governance structures in coordinating global responses to the crisis, and the role of international research collaborations in finding solutions to the pandemic;

- the perceived effectiveness of national governments in managing the COVID-19 pandemic - e.g. through restrictions implemented and their effectiveness in controlling the spread of the virus, and communication of science advice to the public;

- the severity of the socio-economic impacts of the crisis - for example the degree to which the economy relies on sectors largely unaffected by the crisis, and impacts on inclusiveness.

Tensions among different layers of government and with citizens regarding the restriction measures deemed necessary to apply and the spread of misinformation on social media could reduce citizens' trust in government action. Evidence from an EU survey conducted in September 2020 shows that citizens' perceptions of public authorities' capacity to take 
the right decisions to overcome the socio-economic impacts differ significantly across countries (Figure 2).

\section{Figure 2. Citizens' trust in national governments capacity to take the right measures to overcome} the economic and social impact of the COVID-19 crisis

\section{EU Regional and Local Barometer 2020}

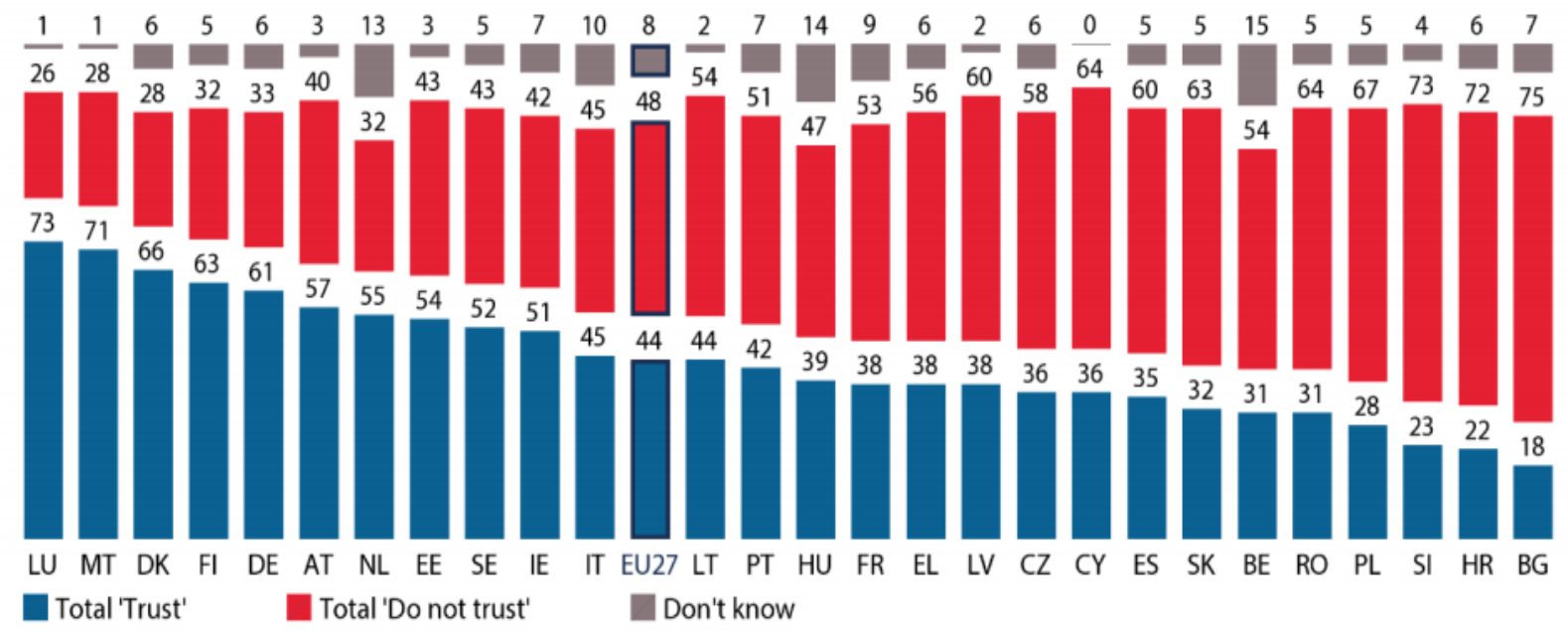

Note: The question of the survey was: please indicate how much you trust that your national government is taking, and will take in the future, the right measures to overcome the economic and social impact of the coronavirus crisis.

Source: European Committee of the Regions (2020[20]), based on a survey conducted online by Kantar, between 3 September and 17 September 2020, among 26381 respondents in the 27 Member States.

Second, public views on the role of STI could also change. With the COVID-19 crisis, STI has been at the forefront as provider of sound evidence-based advice on addressing COVID-19 and of long-lasting solutions to COVID-19, including vaccines, treatments, and innovative (often digital) solutions to address "social distancing".

However, the lack of fast and effective solutions; the spread of misinformation on social media; the diversity in scientific views regarding the virus, its possible evolution and best approaches to dealing with it; and the linkages between science advice and sometimes unpopular confinement measures all pose risks regarding the evolution of public perceptions of STI.

Possible changes in societal preferences for the role of government and trust in STI with regard to its policies have important implications. If governments are given a stronger policy mandate to "steer", then STI policy may play a more proactive role in shaping future developments. This could be reflected in ambitious mission-oriented projects that engage stakeholders from across the STI system (see Section 3 below). If government is not supported in those actions and STI less appreciated, then the scope and engagement of future STI policy may be much more reduced. 


\section{Lasting impacts of the COVID-19 crisis on science, technology and innovation}

This section discusses possible lasting changes brought on by the COVID-19 crisis for STI across five dimensions: 1) public and private funding for STI; 2) the wider digitalisation of STI and STI policies; 3) the openness and agility of STI; 4) international collaboration in STI; and 5) the inclusiveness of STI at social, industrial and territorial levels.

\subsection{The challenges ahead for STI spending: What lessons from past shocks?}

This section discusses what to expect in terms of the future evolution of STI spending, drawing on lessons from past shocks - including in particular the 2008-09 financial crisis, as the latter has been the most analysed in terms of its shocks for innovation.

\subsubsection{Business $R \& D$ and the business cycle similarities and differences between the COVID-19 crisis and the global financial crisis}

Business R\&D expenditure (BERD) moves in parallel with GDP, slowing markedly in times of economic downturn such as the 2001-02 recession and 2008-09 global financial crisis, as shown in Figure 3. Other indicators of innovation follow the same trend, as illustrated by the historical evolution of Patent Cooperation Treaty (PCT) patent and trademark applications (Figure 4). The procyclical nature of business innovation investments is due to decreased demand and subsequent liquidity constraints faced by firms during economic crises, as well as to growing market uncertainties. The latter result in businesses making fewer risky investments as is the case of investments in innovation.

Figure 3. The impact of the business cycle on business R\&D investments, OECD countries

\section{Annual growth rate}

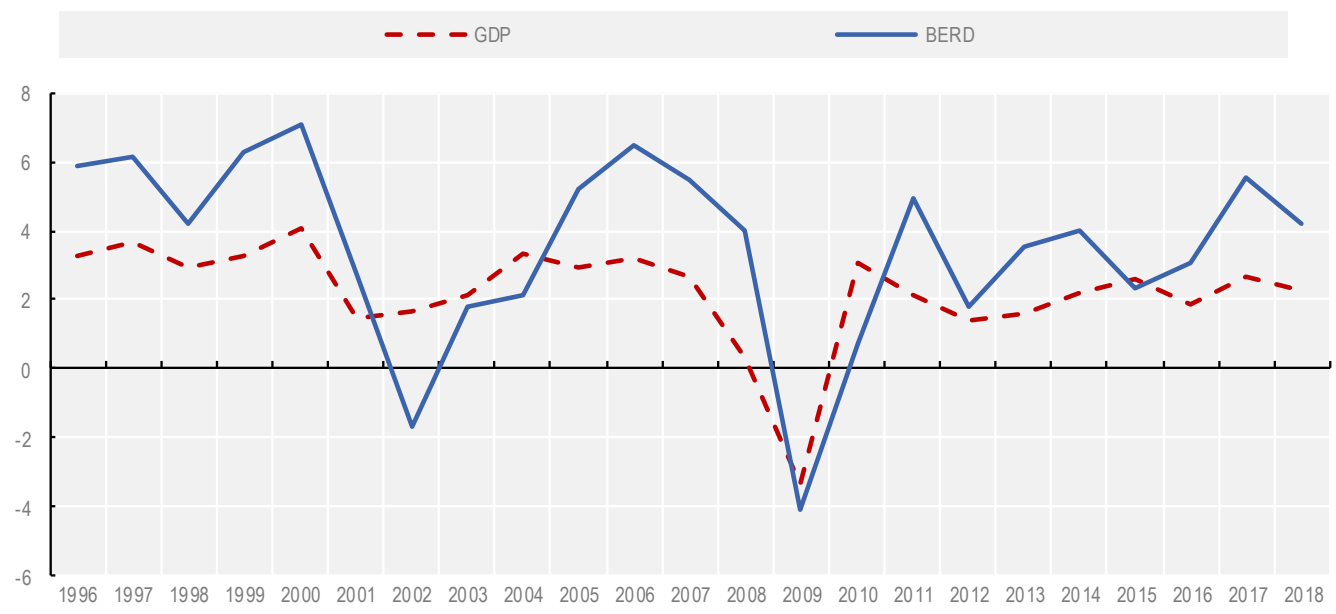

Source: OECD Science, Technology and Innovation Outlook (2021), based on "Main Science and Technology Indicators", OECD Science, Technology and R\&D Statistics (database), https://doi.org/10.1787/data-00182-en and OECD (2020) "National Accounts at a Glance", OECD National Accounts Statistics (database), https://doi.org/10.1787/data-00369-en (accessed on 11 May 2020). 
Figure 4. US gross domestic product and trademark applications at the USPTO, 1999-2012

\section{Comparing cycles, by type of trademarks, percentage deviation from the long-term trend}

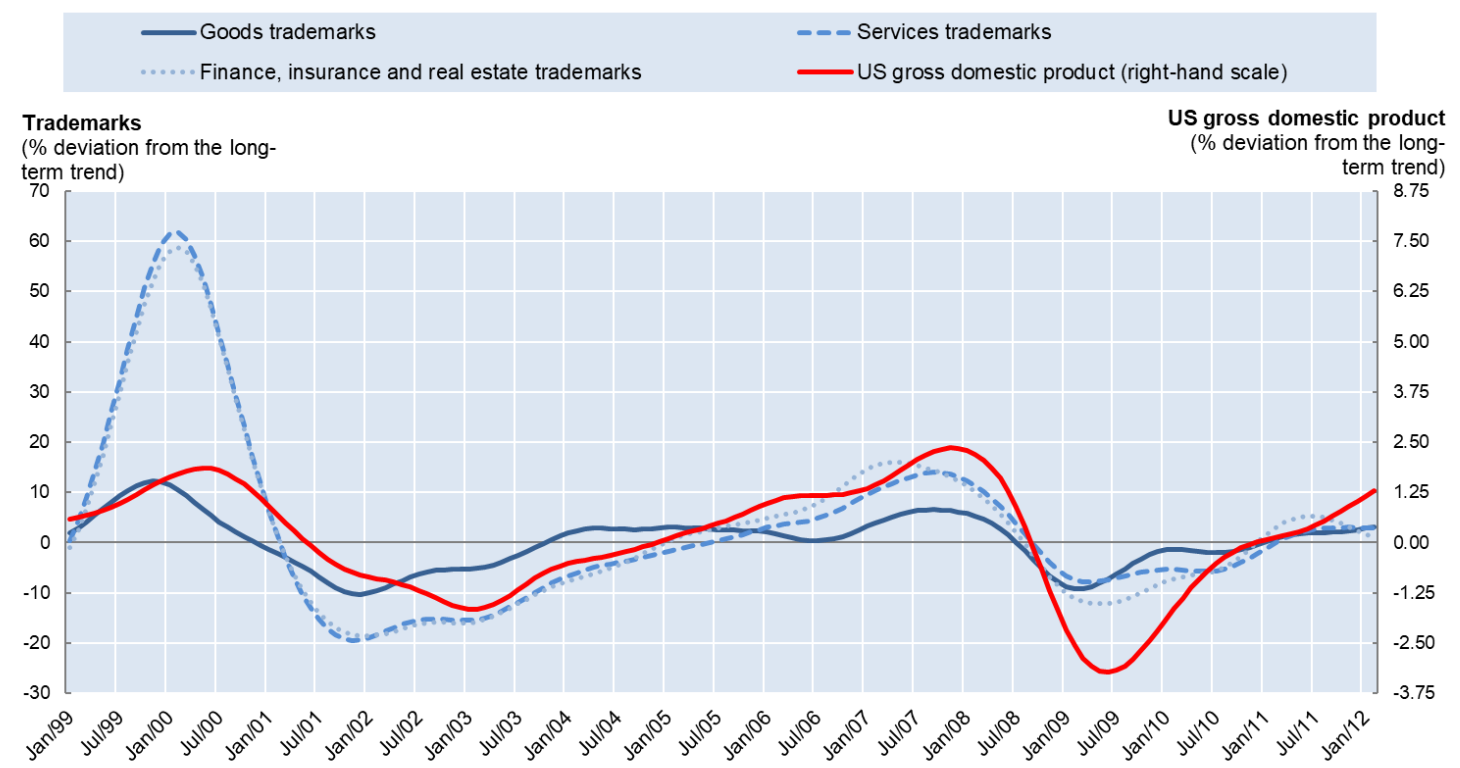

Note: Goods (resp. services) trademarks represent trademark applications designating only good (resp. services) classes; finance, insurance and real estate trademarks represent trademark applications designating class 036 of the Nice Classification. The US gross domestic product is based on the series of seasonally adjusted GDP, expenditure approach, in volume (chained volume estimates) contained in the OECD Quarterly National Accounts Database (June 2012). Raw GDP and trademark applications series were treated using the OECD's Composite Leading Indicators methodology. Monthly data were used for trademark applications and quarterly data for GDP, converted to a monthly frequency via linear interpolation and aligned with the mid-quarter month. This treatment removes seasonal patterns and trends (using the Hodrick-Prescott filter) in order to extract the cyclical pattern. The cyclical pattern presented on the graph is expressed as a percentage deviation from the long-term trend. Considering the filters applied, the remaining cycles are those with a period of between 18 months and 10 years. The analysis was performed on series from January 1990 to February 2012 for trademark applications and to January 2012 for GDP. For more information on the methodology, see OECD (2008), OECD System of Composite Leading Indicators, OECD, Paris, www.oecd.org/dataoecd/26/39/41629509.pdf. The graph shows a peak around 2004 for the trademark series which does not correspond to the economic activity. It corresponds to the accession of the United States to the Madrid Agreement in November 2003, which facilitated the filing procedure for foreign applications.

Source: OECD (2012[21]), based on USPTO, Trademark Electronic Search System, June 2012; Trademark Electronic Search System (TESS), June 2012; OECD, Quarterly National Accounts Database, June 2012

The major concern with declines in business $R \& D$ and innovation investments is their lasting impact on firms' and consequently economies' innovation performance: if highly trained researchers and innovators lose their jobs, firms might subsequently be unable (or take a long time) to return to previously attained innovation paths. Lower business investments also affect research activities conducted by research or higher education institutions, as fewer collaborative or contract research activities are undertaken.

Evidence from the 2008-09 financial crisis shows that in the aftermath of the crisis the return to pre-crisis levels of business $R \& D$ and innovation was not straightforward. In some countries, such as Canada, Japan and Spain, it took several years to return to the pre-crisis levels of business R\&D investment, while in others the levels of investment remained quite stable (e.g. Australia, Germany, France, United Kingdom) or increased significantly (e.g. the People's Republic of China, Estonia, Hungary, Ireland, Korea). This was due to a 
number of factors, including differences in the intensity of the 2008-09 crisis and in the characteristics of countries' innovation systems.

The analysis of the COVID-19 crisis and the 2008-09 financial crisis points to differences in the evolution of business R\&D and innovation expenditures. First, both the COVID-19 and the 2008-09 crises were characterised by market uncertainty and important decreases in demand, but to different extents. Compared to the 2008-09 crisis, the COVID-19 shock of early 2020 led to a short-lived downturn followed by a temporary recovery in the third quarter of 2020. In a number of countries - including Australia, China, Korea, Japan and New Zealand - low infection rates allowed for a return to pre-COVID-19 conditions for most of 2020 while other countries however were severely affected by new waves of the pandemic. The prospect of "living with the pandemic", with caseloads and containment policies that varied over time, presented firms with considerable uncertainty. A study based on an April 2020 survey of 6,000 German businesses found that those firms that anticipated the shutdown to last four months or longer were more likely to implement costly and permanent measures, in particular layoffs and the cancelation of investment projects (Buchheim et al., 2020 [22]).

Second, both crises share possible impacts on business innovation from market uncertainty and decreases in demand, but differ in how they affected supply conditions for business innovation. The 2008-09 crisis' impacts were driven by impacts on firms' access to finance as the financial system was affected by the shock. By contrast, the impacts of COVID-19 on the supply of business innovation are primarily due to the implementation of lockdown and social distancing measures, resulting in locked laboratories and research facilities, reduced productivity of researchers with childcare duties as schools were closed, and limited opportunities for young researchers to connect. The supply chain shock that affected products with value chains based in China during the first months of $2020-$ including automotive product and electronics - was short-lived, as production resumed with an easing of lockdown measures.

Third, the impact of the two crises on financial markets has been substantively different. The 2008-09 crisis was characterized by a liquidity crunch that impacted access to credit (Brunnermeier, 2009 [23]). The COVID-19 crisis has featured comparatively high liquidity, buoyed in part by expansionary fiscal policy, with stimulus spending reaching $15 \%$ of GDP in OECD countries as of February 2021; and an accommodative monetary policy, with central banks implementing a variety of measures to lower interest rates and increase liquidity (Elgin, Basbug and Yalaman, 2020 [24]; Byrne, Kraemer and Gunter, 2020[25]). The European Central Bank, US Federal Reserve, and Bank of Japan grew their balance sheets by USD 2.9 trillion (EUR 2.5 trillion), USD 3.0 trillion, and USD 1.2 trillion (JPY 133 trillion) respectively between March 2020 and March 2021 (European Central Bank, 2021 [26]; Federal Reserve Board, 2021 [27]; Bank of Japan, 2021 [28]). Stock markets were especially buoyant in 2020, with key indices like the S\&P 500, a stock market index that measures the stock performance of 500 large companies listed on stock exchanges in the United States, reaching all-time highs in 2020 after a sharp dip early in the crisis (Nasdaq, $\left.2021_{[29]}\right)$. The growth in technology stocks played an important role in this evolution (Goedhart, Koller and Stumpner, 2020[30]).

This easy access to liquidity has, however, also resulted in emerging vulnerabilities. Corporate indebtedness was already on the rise before the crisis, increasing by $13 \%$ between 2008 and 2019 relative to global output (OECD, 2020[31]). Corporations took advantage of low interest rates and high liquidity to borrow in the face of declining revenues due to the crisis. Although these have thus far proved resilient, high corporate indebtedness is a medium-term risk for solvency, especially for SMEs (IMF, 2020 ${ }_{[32]}$ ). Without 
restructuring assistance, the crisis' debt overhang presents an insolvency risk that may endure even after the COVID-19 crisis ends (Demmou et al., 2021 [33]).

A final and important difference is that demand for business innovation and sectoral products was highly unequal, differently from the more generalised 2008-09 slowdown.

\subsubsection{Unequal evolution of demand and its impact on future aggregate business innovation}

The COVID-19 crisis may not result in a similar slowdown in aggregate business innovation to the one seen in 2008-09 due to the increase in demand for certain innovations, notably in the fields of health and digital services. The health sector experienced an increase in demand for vaccines, effective treatments and various health products to solve the pandemic. The lockdown and social distancing measures also led to increased demand for digital tools for work (work-from-home applications), exchanges (virtual meeting tools), research (big data analytics) and the provision of virtual services (digital health, online learning, online shopping and entertainment). Data from world's top R\&D investing companies show that those in the digital sector increased their R\&D expenditures between April and September 2020 compared to the same period in 2019 (e.g. Facebook by around $34 \%$, Apple by $16 \%$ and Microsoft by $12 \%$ ) (OECD, 2021 $\left.1_{[2]}\right)$. The increased demand for products from these sectors provided those companies with the financial resources to engage in those R\&D investments. Trading and investment banking also experienced important increases in revenues (Fitter and Kelly, 2020[34]). In countries where sectors with sustained revenues and demand for innovation account for an important share of total value added, increases in BERD in these sectors may compensate the effects of declines in other sectors in aggregate levels.

By contrast, the shock hit a number of other sectors more severely. This included other R\&D-intensive activities affected by the demand shocks associated with the first wave of COVID-19; examples are manufacturing sectors producing durable and investment products (e.g. automotive and machinery) and the aerospace sector due to the implementation of travelling restrictions. For instance, Boeing reduced its R\&D investments by more than $25.2 \%$ between April and September 2020 compared to the same period in 2019, and Daimler reduced them by $9.8 \%$ (OECD, 2021 $\left.{ }_{[2]}\right)$. In countries where such sectors account for an important share of total value added, the decline in BERD may be particularly strong. Service sectors hit hardest by lockdowns and social distancing measures - in particular tourism, travel, leisure industries, professional services and retail - have historically had a low propensity to invest in $R \& D$, and thus the slowdown in those sectors may have weaker impacts on aggregate business R\&D investments. Importantly, the difficulty in measuring innovation investments in such sectors may result in underestimation of foregone innovation investments. We discuss those unequal effects in section 2.5.2 on industrial inclusiveness.

Finally, the unequal recovery of demand across sectors and countries will also shape the evolution of business innovation. Some manufacturing sectors (e.g. automotive, aerospace, electronics) were highly affected as the COVID-19 crisis first hit in March/April 2021, as demand for durables dropped. Demand for many durables, however, recovered across the OECD and even more so in Asia, including China, where fewer COVID-19 infections resulted in the widespread lifting of containment measures in April and May 2020 except for localized lockdowns in virus hotspots. The site of the first COVID-19 outbreak, Wuhan, exited its lockdown in June 2020. Japan and Korea avoided strict national lockdowns in 2020 (Chen et al., 2021 ${ }_{[35]}$ ). Robust growth in China of nearly $18 \%$ across the last 3 quarters of 2020 (for a net annual GDP increase of $2.3 \%$ on the previous year) (OECD, 2021 [36]) also boosted sales for those producers active on the Chinese market, as was, for instance, 
the case of Daimler, a maker of trucks and luxury cars (Daimler, 2021 $1_{[37]}$ ). Services sectors such as restauration, tourism and entertainment were much affected by restrictions on movement and social distancing, with in many OECD countries several months of closures of services and barriers to travelling. This is likely to affect the financial means for those firms to invest in innovations often provided by other sectors in the future.

\subsubsection{Public resources for $S T I$ will be under pressure in the future}

Public funding for R\&D in response to the COVID-19 shock will also shape STI developments in the longer term. Support for R\&D given the crisis has so far been similarly strong to support provided in the 2008-09 financial crisis. To illustrate those commitments, in March 2020 the UK Government confirmed its plans to more than double public spending on R\&D over the next five years, reaching GBP 22 billion by 2024-25 (Stokstad, $\left.2020_{[38]}\right)$. The Action Plan for Science and Innovation in Spain, launched in July 2020, commits EUR 1.06 billion to the Spanish science and innovation system in 2020-21 with the aim of boosting the recovery (Spanish Government, 2020[39]). As part of the Korean New Deal to restart economic growth, in September 2020 the Korean government announced plans to increase its R\&D spending by KRW 3 trillion (USD 2.6 billion), or $12 \%$, in 2021 (Korean Ministry of Economy and Finance, 2021 ${ }_{[40]}$ ). In October 2020, Australia's government announced AUD 1 billion (USD 776 million) of new funding for universities in 2020-21 to protect its academic research sector from long-term damage due to the crisis (Australian Government, 2020 [41] $)$. Sweden's government also put forward a plan in December 2020 to spend an additional SEK 13.65 billion (USD 1.61 billion) on research and innovation between 2021 and 2024 (Swedish Government, 2020[42]).

The current strong support for STI could be sustained in the future in view of the recognition of its importance. Stronger endorsement and recognition of STI could lead to significant increases in public R\&D. One domain that may benefit from such investments is health-related STI, especially investments to prepare for future pandemics in response to the shock. More R\&D investments may also be obtained in other sectors (e.g. industry 4.0 and robotics or $5 \mathrm{G}$ ) that are equally identified as strategic also in the interests of being better prepared to future shocks.

The mid- to longer-term trends in public R\&D investments will also depend on the size of the public budget available. The recovery packages adopted in 2020 and 2021 by most developed countries, coupled with the sharp decline in output and government revenue, increased public debt ratios across the world (Figure 5). The ratio approached $98 \%$ of global GDP by the end of 2020, placing it at the highest level since 1945 (Figure 6) (IMF, $2020_{[43]}$ ). According to IMF data, global fiscal support in 2020 reached nearly USD 14 trillion, comprising USD 7.8 trillion in additional spending or foregone revenue and USD 6 trillion in equity injections, loans and guarantees (IMF, 2021 $\left.1_{[44]}\right)$. In the United States alone, the fiscal response to COVID-19 based on legislation enacted as of December 2020 amounted to nearly USD 5 trillion - significantly above the USD 1.8 trillion of fiscal stimulus and other economic support enacted between 2008 and 2012 to respond to the financial crisis (Committee for a Responsible Federal Budget, 2020 $0_{[46]}$ ). Countries with elevated public debt and financing constraints are likely to implement contractionary fiscal policies in the medium term, which could reduce the amount of public funding invested in STI. 
Figure 5. Contribution to the change in global government debt and deficits, 2007-20

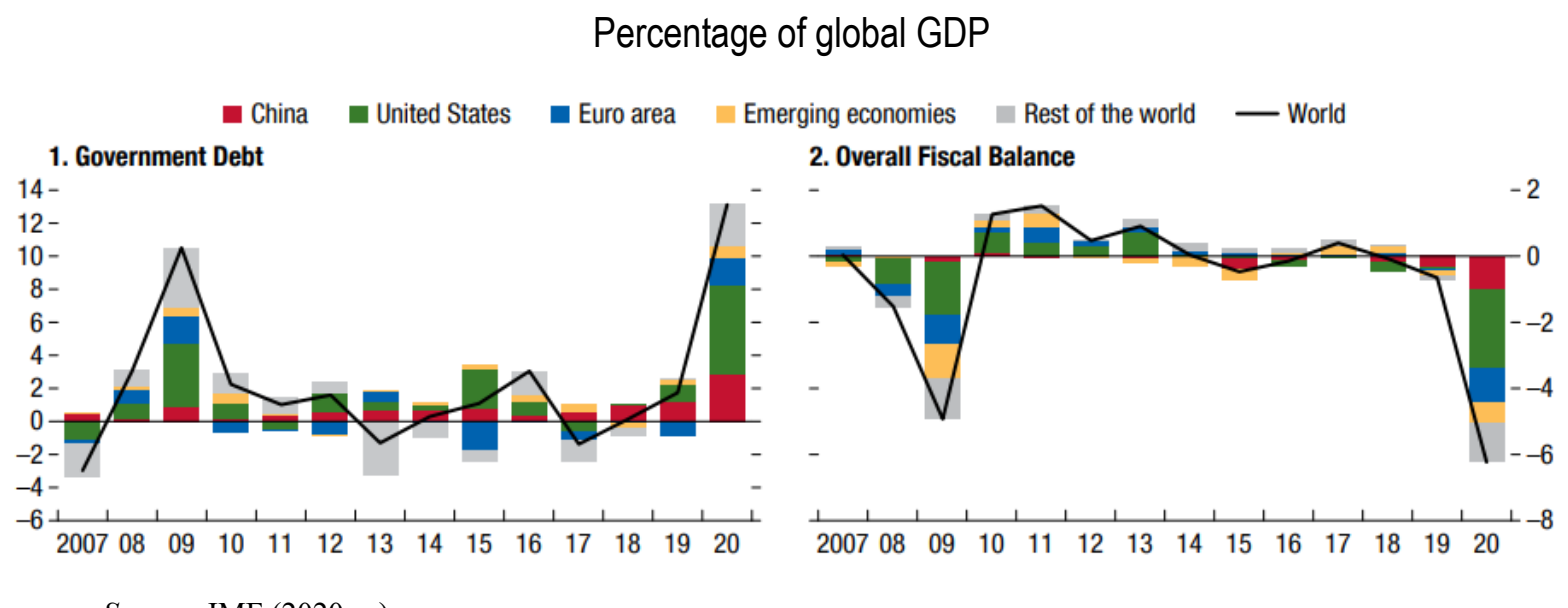

Source: IMF $\left(2020_{[43]}\right)$.

Figure 6. Historical patterns of general government debt

Percent of GDP

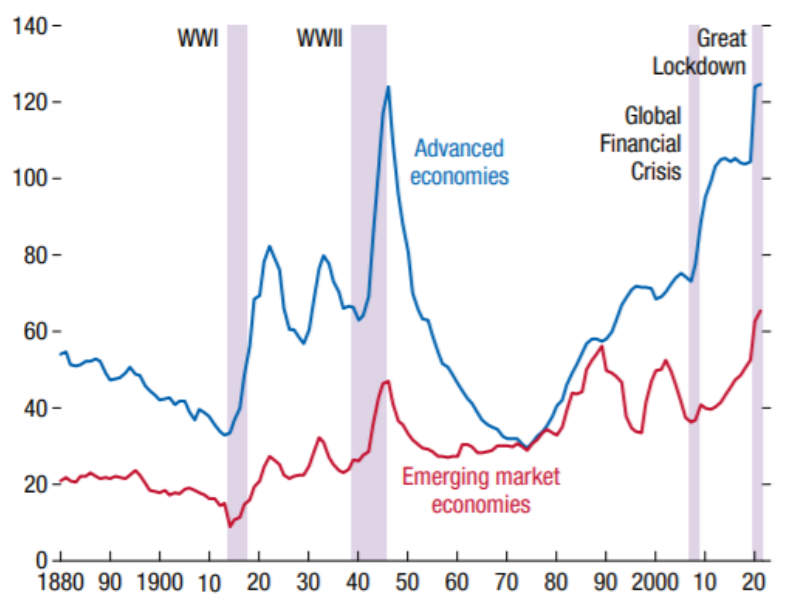

Source: IMF (2020[47]).

\subsubsection{Financial constraints could challenge public research institutions and raise risks of brain drain}

Even if the role of STI is recognised, the level of public spending during the COVID-19 crisis may require important cuts in the coming years and affect funding for research and innovation. Such cuts characterised the evolution of public $R \& D$ funding in the years following the 2008-09 crisis (OECD, 2012 $2_{[21]}$ ). Although public spending on research and innovation was protected after 2008 until approximately 2010 (measured by government budget appropriations or outlays for R\&D - GBAORD), in the following years many countries experienced declines. In the case of Greece, Latvia, Romania and Spain, these were severe (Izsak et al., 2013 [48]).

Public budgetary constraints resulting from the COVID-19 crisis could affect public universities and research institutions in the mid- to longer-term. Evidence collected by the European University Association shows that following the 2008-09 crisis university funding in Europe was at its lowest in 2012, four years after the start of the crisis 
(Eastermann, 2020[49]). The extent of such funding declines will also depend on the evolution of student intake, philanthropic donations and research contracts for those institutions for which those revenues were an important source of income. The evolution will depend on the duration of the COVID-19 crisis and the nature of restrictions. Income from research contracts will depend on the dynamics of business innovation, while philanthropic donations will be affected by the evolution of societal priorities and the role of research institutions in addressing those.

Reduced future funding can result in durable negative impacts on scientific production, breakthroughs, and translation of scientific outcomes into solutions as these are very hard to reverse in the mid-term, as national science capacities are built progressively and rely essentially on people. Future funding cuts would also result in limited recruitment as well as terminations of contracts of academic staff; and reduced contributions to reskilling activities and support to the local communities (e.g. provision of continuing education, open conferences). The outcomes are possibly particularly detrimental as research activities were strongly affected by the 2020 COVID-19 crisis. Social distancing rules affected many research activities, industry funding was often disrupted and young researchers found themselves unable to build networks to support progress in research and innovation (Paunov and Planes-Satorra, 2021 $1_{[1]}$ ).

Moreover, the gap in research capacities may increase further in a context of limited financial resources. The risk of brain drain of highly skilled workers (including scientific authors) in countries most severely affected by budget cuts arises, as experienced during the 2008-09 crisis in countries such as Greece, Italy, Portugal and Spain (Izsak et al., $\left.2013_{[48]}\right)$. The brain drain of their scientific labour force certainly affected the research base of a number of southern European countries. Greece and Spain for instance had very high rates of unemployment among highly skilled workers that persisted up until 2013, and that included employees at (public) research institutions.

The gap between leading universities and others could also widen in the future, if those with greater financial capacities are more able to lead in their respective research fields. This may reinforce reputational effects supported by digital conferencing tools that are dominated by superstar researchers, as these now address global audiences much more easily compared to when physical travelling was needed. Moreover, as online learning becomes more generalised, competition in the higher education field may also increase. Providers of online learning that do not face many of the costs of higher education institutions (e.g. infrastructure costs, research facilities, larger administration, support services, etc.) may exploit economies of scale (i.e. a single online class can potentially reach thousands of students, who can access it at any time from any location) and offer interesting training opportunities. These trends could have implications on the quality of local research institutions and their capacities to support local STI activities in the longer term. It could also subsequently affect the inclusiveness of STI, to the extent that local research capacities affect the quality of locally provided education.

\subsection{Will digitalisation accelerate with the COVID-19 pandemic? What would be the implications for STI?}

The unprecedented uptake of digital tools and $\mathrm{AI}$ in science, technology and innovation, both to respond to the COVID-19 health emergency and to keep the economy - and STI systems - operating during the crisis, may have long-lasting consequences for research and innovation (Paunov and Planes-Satorra, 2021 $1_{[1]}$ ). This section discusses possible permanent changes in STI stemming from this wider application of digital tools. It then outlines drivers and challenges for positive changes in regard to digitalisation. 


\subsubsection{Possible lasting changes for STI from digitalisation}

\section{New forms of knowledge exchange, collaboration and research processes in science and innovation}

Virtual communication and conferencing tools enabled new forms of research collaboration, knowledge exchange and the provision of training during the pandemic. These could possibly remain after the crisis and affect future dynamics of STI as follows:

- Work from home (WFH) has proved appropriate for a variety of innovation processes, and may allow for more flexible work engagements. These in turn could increase diversity in STI, enabling the higher involvement of those with care responsibilities or located in more remote areas. Possible savings from reduced office space may provide more resources to firms, including for innovation activities (OECD, 2020[50]).

- Virtual exchanges enabled by digital tools (e.g. online collaborative platforms) allow for increased circulation of scientific knowledge, facilitating global collaborations in innovation and open science. Virtual conferences, for instance, allow opening exchanges to larger and more diverse audiences than in-person meetings, and reduce transaction costs as well as the carbon footprint incurred by travel.

- Virtual training tools facilitate access to training for wider audiences, and are highly flexible. These could increase the availability of good-quality on-the-job training by making training more compatible with work commitments. They could also allow more tailored training that pools expertise across institutions, as students could participate remotely in the training offered by partner institutions.

Some evidence points to gains from the extensive experimentation with digital tools during the pandemic. While so far few firms have followed the example of GitLab, a private company that builds tools for software developers, in fully operating remotely, many may combine remote and on-site work in the future. A survey of 1080 business leaders worldwide conducted in May 2020 finds that $78 \%$ of respondents expect the amount of remote work to increase from its pre-pandemic levels, with $30 \%$ expecting the increase to be significant (HBR, 2020[51]). A survey of business executives from 1750 US firms conducted in July 2020 finds that firms anticipate tripling the number of external meetings conducted by video after the crisis compared to the pre-pandemic period (reaching nearly $50 \%$ of the total), reducing travel spending by $30 \%$ on average (Federal Reserve Bank of Atlanta, 2020 [52]). Another survey of 375 UK businesses conducted in July 2020 found that over $90 \%$ of firms that had adopted new digital technologies and practices during the pandemic expected such adoption to be permanent and have a positive impact on firm performance (Riom and Valero, $\left.2020_{[53]}\right)$.

Digital tools, applied widely during the COVID-19 period, may also make their mark on the productivity of research processes. Data from the OECD Science Flash Survey 2020, based on over 2700 responses (as of 17 March 2021) from scientists and other professionals involved in science across 94 countries, indicate that over $60 \%$ are experiencing or expect to experience an increase in the use of digital tools for research as a result of COVID-19 (OECD, 2020 [54]).

However, there are also downsides to these applications that may render them less successful in supporting STI. Virtual environments are not perfect substitutes for face-toface interactions, as building new trusted relations for future research collaborations is harder. This also poses a challenge for newcomers. The fact that large virtual scientific 
research events can easily recruit leading scholars to intervene reinforces the superstar phenomenon and reduces opportunities for others to make their mark.

The transition towards hybrid modes of operation of work, research collaboration and events (i.e. where some participants are able to join in person while others join virtually) requires careful design to succeed. Those joining virtually, which would not benefit from informal interactions that contribute to building trusted relationships, risk being less included in work processes, collaborations and events. Such exclusion could then affect the inclusiveness of new processes or result in reduced uses of virtual modes of operation altogether.

\section{Changes to the nature and impact of STI policy}

New digital tools (e.g. big data analytics) and data that are more granular may also allow for more agile, targeted and ultimately more impactful STI policy responses in the future. Governments have shown unprecedented agility in the use of digital tools during the COVID-19 crisis, most exemplified by contact tracing applications that were introduced as a way to monitor and control the spread of the disease (OECD, 2020[55]). The pandemic has also shown the extent to which policy making has changed since the 2008-09 crisis, as illustrated by the use of real-time data - such as Google's mobility statistics - and other tools to best monitor and respond to the crisis. A series of pulse surveys have also been informing STI policies. In turn, the open release of COVID-19 papers by such initiatives as the COVID-19 Open Research Dataset (CORD-19) has not only supported scientific activities but also helped identify the nature of scientific contributions to COVID-19.

Digital innovation policies may become even more important in the STI policy mix in the near future, and demands for them to address related challenges (e.g. privacy protection, increasing market concentration in the delivery of digital services, data access and sharing) may become more prominent. In the past, STI policies have played a key role in fostering digital technology adoption, including by promoting investments in key infrastructures (e.g. broadband connectivity), providing targeted support to SMEs and firms in traditional sectors (e.g. offering innovation vouchers, technical assistance, training, and demonstration facilities) and expanding digital skills and competencies (in both firms and research institutions) (OECD, 2019 [5]; Planes-Satorra and Paunov, 2019 [56]).

\section{Changing market dynamics with implications for innovation}

Innovation dynamics may change because digital innovation is fundamentally different from innovation in tangible products (Figure 7). The reduced costs of producing and handling information and knowledge and the increased fluidity change innovation dynamics (Guellec and Paunov, 2018[57]). The transformations in innovation processes can have two opposing impacts on market dynamics and income distribution (OECD, 2019 $\left.{ }_{[5]}\right)$.

On the one hand, the outcome of more digital innovation may be to facilitate market entry and competition. First, data are fluid and potentially available to all at a low marginal cost. Depending on the type of data, different companies and individuals, regardless of their location, can simultaneously exploit the same data, thus providing market opportunities for more participants. This contrasts with traditional markets for tangible goods, where inputs are available in limited quantities and at a significant cost. Second, digital platforms facilitate entrepreneurship by lowering set-up costs for newcomers, as for example in the case of e-commerce platforms (e.g. Alibaba, Amazon and eBay) on which new ventures can offer products to the global market without having to deal with additional marketing expenditures (Brynjolfsson, Hui and Liu, 2018 $8_{[58]}$ ). 
Figure 7. Innovation in the digital age and impacts on market dynamics

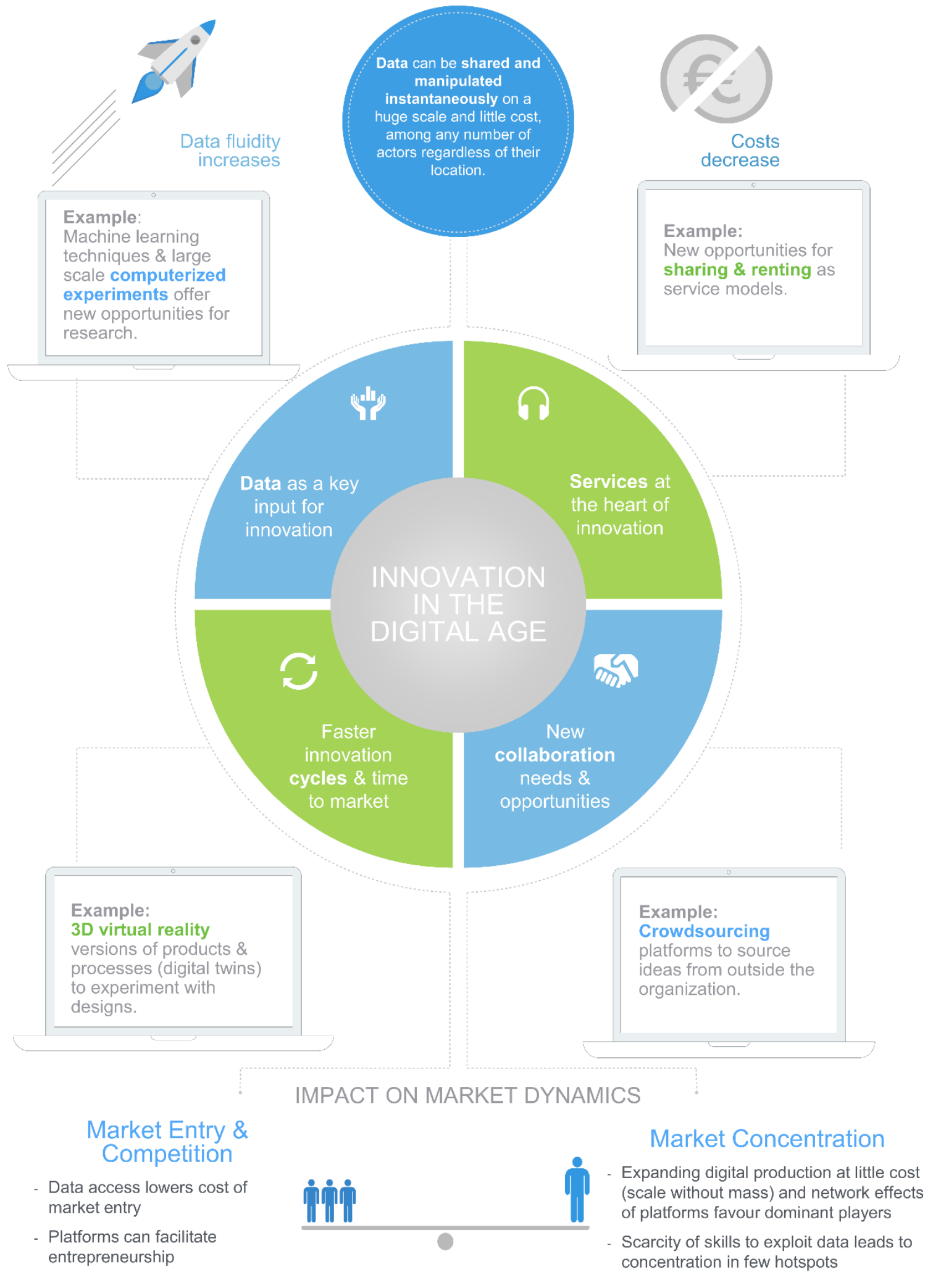

Source: OECD (2019[5]). 
On the other hand, more digital innovation may increase market concentration and distributional challenges. Several factors can be at work here. A first factor is the natural advantage of platforms - Internet-based structures in position to pool more user data can use them to offer better and more personalised services. Large aggregators of data such as Google and Amazon thus benefit from a natural advantage. In other words, several small platforms that provide fewer services, have fewer users each, and build on fewer data would be much less efficient than a single, large platform. Such economies of scale are a characteristic of natural monopolies (Tirole, 2019[59]).

A second factor arises from "scale without mass", a consequence of the increasingly intangible attributes of products. The larger the intangible component of a product, the easier it is to expand production to the entire market at little or no cost. In the extreme, as in the case of software, the cost of producing an additional unit is close to zero since no further set-up costs are involved. The much smaller number of employees of certain digital companies compared to companies in traditional industries with similar sales levels illustrates this dynamic.

A third factor is the scarcity of certain elements required for efficient exploitation of data: skills are the most important of these. Such scarcity may favour concentration of digital innovation in a few firms and geographic innovation hotspots (Paunov et al., 2019 $9_{[7]}$ ).

\subsubsection{Drivers of and challenges to accelerated digitalisation}

As a result of experiences during the COVID-19 pandemic, social preferences may shift regarding the role that digital technologies, big data analytics and AI should play in the economy and in society. If digital experiences are positive overall, demand for improved digital tools may increase, possibly generating a new wave of technological progress in this field. Negative experiences with some of these technologies could have the opposite effect.

Additional factors that could shape specific developments are the following:

- Preparing for a longer shock and possible future shocks (including a backlash against globalisation) - Preparing for a long-lasting COVID-19 crisis or other future shocks may lead to an acceleration in automation and more broadly the adoption of digital tools. The fear of possible barriers to trade and possible trends toward reshoring of production back to locations where labour is expensive may further contribute to efforts aimed at automation in businesses. If a trend of reverse globalisation develops, more innovation investments may also be devoted to spurring the cost-efficiency of 3D printing (Seric and Winkler, 2020 $0_{[60]}$ ).

- Strengthening supply chains - The importance of better managing supply chains to protect against future shocks may result in further digitalisation efforts, such as systems that track supplies and possible shortages. The COVID-19 shock could stimulate investments in the Internet of Things (IoT) and blockchain technologies to help increase the transparency and safety of, and trust in, supply chains (Khurshid, 2020 [61] $)$. IBM, an American hardware and software producer, expanded its existing blockchain solutions for supply chain verification to pair suppliers with governments and hospitals early in the crisis. In March 2021, IBM announced a partnership with Moderna, a pharmeceuticals company coanufacturing COVID-19 vaccines, to apply its blockchain-based tracking platform to the distribution of vaccine doses (McGrail, 2021 [62] $)$. If blockchain is successfully implemented to track and trace essential medical supplies (e.g. vaccines) during the crisis, this could encourage more widespread adoption in the future. 
- Providing digital security and privacy - Future adoption of digitalisation will depend on the safety of those systems. Remote work during COVID-19 made systems more vulnerable to cyber-attacks. Online scams and phishing emails have proliferated, and hospitals, research centres and critical infrastructure have been targeted for ransomware attacks by cybercriminals (Interpol, 2020 $\left.{ }_{[63]}\right)(\mathrm{OECD}$, $\left.2020_{[64]}\right)($ OECD, 2020 $[65])$. In the field of health in particular, consumers' willingness to digitalise sensitive health data may further enable innovations in digital health services, but concerns about data privacy and security could hamper those developments $\left(\mathrm{OECD}, 2020_{[66]}\right)$. Such risks increase incentives to step up the implementation of cybersecurity practices across organisations, and encourage investments in technology development in this area.

- Asymmetric adoption capacity and speed - Limitations in terms of access to infrastructure and skills and limited financial resources (particularly in view of the COVID-19 shock) could constrain digital technology adoption in research and business. The complexity of digital technology applications also affects adoption speed. For example, enterprise resource planning and customer relationship management tools can be rapidly deployed, while advanced robotic automation or the use of blockchain to track and trace supply chains can take a long time to implement (Agrawal et al., 2020[67]).

- Challenges to adoption faced by SMEs - As is the case for other technologies, not all firms (in particular SMEs and micro firms) were as flexible in adopting new digital processes during the crisis. A survey of 1500 SMEs in the United Kingdom conducted in May 2020 found that more than one in five firms struggled with wellknown challenges of technology adoption during COVID-19. This included costs, implementation time, complexity, lack of customisation of products to business needs, and insufficient skills to deal with the new technology (Be the business, $\left.2020_{[68]}\right)$. The 2018 Annual Business Survey in the USA, covering a nationally representative sample of over 850,000 firms, finds that while digitalization and the use of some cloud computing is quite widespread, advanced technology adoption (e.g. AI, robotics, augmented reality) is rare and generally skewed towards larger and older firms (Zolas et al., 2020 [69] ).

\subsection{Will STI ecosystems be more open and agile?}

The COVID-19 pandemic spread rapidly across all countries, presenting a challenge that the global STI community was called on to respond to quickly. The STI processes set in place emphasised open science modes of operating and agile STI responses (Paunov and Planes-Satorra, $\left.2021_{[1]}\right)$. This section discusses possible lasting changes to STI in terms of that openness and agility.

\subsubsection{Open science}

Open science encompasses unhindered access to scientific articles, access to data from public research, and collaborative research enabled by ICT tools and incentives. These practices enhance transparency and collaboration, reduce the risk of duplication of research efforts, and foster research and innovation that builds on the existing research base. The need to quickly find solutions to the COVID-19 health emergency generated the surge of an unprecedented number of open science initiatives. These included the sharing of research data in open platforms, open-source designs for medical equipment, the major publishers' commitment to open access to COVID-19-related publications, and the early dissemination of research manuscripts in the form of preprints (see Paunov and Planes- 
Satorra $\left(2021_{[1]}\right)$. The quick progress in implementing open science initiatives - particularly if these are shown to have accelerated solutions to the COVID-19 pandemic - may be a catalyst for the wider adoption of open science across all scientific research fields.

A number of challenges do remain to strengthening the contribution of open science to the COVID-19 response and beyond, explored in detail in OECD $\left(2020_{[70]}\right)$. A key challenge is that of making data sufficiently findable, accessible, interoperable and reusable (FAIR). Access across borders is even more difficult under data protection frameworks across OECD countries. This creates an imperative for standards on data sharing for research. Best practice experiences - for instance with regard to data sharing protocols - can help support making open science a reality. In October 2020 the National Institutes of Health (NIH) released a new policy for data management and sharing for all $\mathrm{NIH}$-funded research (Wolinetz, 2020[71]). In January 2021 the OECD Council adopted a revised recommendation aimed at enhancing global access to research data and other researchrelevant digital products from public funding (OECD, 2021 $\left.1_{[72]}\right)$.

Well-known constraints to making data and publications openly accessible for easy reuse by peers also persist and require further efforts. Incentives for scientists to release and make research data and publications available so that others can use them continue to be essential. Currently, neither good data management nor the development of high-quality data sets that can be reused is incentivised or rewarded, and career paths for data managers are unclear in an academic research system that mainly rewards publication in scientific journals. Career advancement mechanisms partly based on metrics that take into account open science or data-sharing efforts could enhance incentives in this regard (OECD, $2020_{[73]}$; Dai, Shin and Smith, 2018 $\left.{ }_{[10]}\right)$. Moreover, the costs involved in extending open science models more widely (e.g. the costs of publishing and maintaining databases) need to be taken into account.

\subsubsection{More agile STI ecosystems}

The urgency of the COVID-19 pandemic, as mentioned, led STI ecosystems to respond rapidly, adopting quicker-than-usual processes for doing so. This included the engagement of public researchers, firms and citizens in frugal innovation - which are improvised production processes to address product shortcomings in the absence of sufficient production capacities to respond to global demand (e.g. personal protective equipment and ventilators during the first months of COVID-19) (Harris et al., 2020[74]) (see Section 1.2 in Paunov and Planes-Satorra $\left(2021_{[1]}\right)$. It also included the extensive use of preprints as a mechanism to share preliminary results of COVID-19-related research more quickly to inform other research and advance the development of solutions to COVID-19. By the end of May 2020, 26\% of the COVID-19 papers listed on the NIH COVID-19 Portfolio were preprints; by comparison, the proportion of biomedical preprints vs. the published literature in PubMed stood at 3\% in 2019 (ASAPbio, 2020 $0_{[75]}$ ).

STI policy responses were also very responsive and agile to the COVID-19 crisis with the deployment of extensive immediate support packages. These supported innovators as they faced a sudden drop in revenues and/or barriers to conducting innovation activities due to lockdown measures in 2020. A range of approaches were used, including fast-track open competitions to stimulate out-of-the-box thinking and gather inputs from all parts of STI systems; hackathons (which are typically 24- to 48-hour events in which participants are provided with data with which they have to create an innovative product); matchmaking activities to accelerate the time between idea generation and commercialisation; initiatives to facilitate access to research infrastructures to accelerate COVID-19 research; and the introduction of regulatory flexibilities to accelerate the process of approval for new 
products that tackled COVID-19, while maintaining the necessary safeguards (see Section 1.1 in Paunov and Planes-Satorra $\left(2021_{[1]}\right)$.

These initiatives could inform both the future agility of STI in normal times and in response to future emergencies. The extent to which crowdsourcing, open competition and hackathons will be more widely adopted will greatly depend on their contributions to STI and on their capacity to mobilise STI ecosystems and citizens around other key societal challenges (e.g. climate change, resilience). The large-scale "matchathon" organised by the European Commission following the "EUvsVirus" hackathon in April 2020 could also be emulated in the future to support matchmaking among innovators, researchers, firms and investors so as to help bring innovative solutions to the market more quickly, particularly in response to future emergencies requiring quick action (European Commission, 2020 [76]).

Agility in the future may also result in more co-ordination across researchers, biotech companies, manufacturers and public authorities to anticipate emerging threats and provide comprehensive emergency responses. The European Commission's plans to create a European Health Emergency Preparedness and Response Authority (HERA) aims to enhance such preparedness and coordination to better respond to future health threats. The European bio-defence preparedness plan against COVID-19 variants, called "HERA incubator", aims to allow for public-private coordinated action to detect and analyse new variants, speed up regulatory approval of adapted vaccines, and ramp up production of vaccines. This initiative will prepare the ground for the creation of HERA (European Commission, 2021 $[77]$ ).

Moreover, the COVID-19 crisis may also result in renewed efforts in revising regulatory processes to speed up innovation without compromising safety. The regulatory processes around authorizing COVID-19 vaccines but also tests have been subject to wider scrutiny given the urgent need for those products. The COVID-19 crisis led some regulatory bodies to use emergency measures while others chose not to, raising the issue of what emergency procedures to apply in what circumstances in view of better preparedness of future crises. Another debate that may result in changes was about consumer privacy protection in the context of the COVID-19 crisis that also resulted, in several countries, in government agencies not being in position to share data among each other for the purposes of addressing the COVID-19 crisis more efficiently. Israel gained much visibility for its successful steps in vaccinating a large share of its population; 114 vaccination doses per 100 people in midMarch $2021^{3}$, according to Our World in Data; but also for offering Pfizer access to patient data (Our World in Data, 2021 $1_{[78]}$ ). Aggregated epidemiological data shared with Pfizer allowed monitoring and assessing the effectiveness of the Pfizer-BioNTech vaccine against symptomatic COVID-19 cases, including those caused by emerging virus variants, and the impact of vaccination on the spreading of the virus (Pfizer, 2021 ${ }_{[79]}$ ).

STI systems will also gain in agility if possible downsides from more agile processes can be reduced. One such issue is the misuse of preprints, which have not been fully validated, by media outlets that may be damaging and even result in panic. As a way to address this issue, the NIH published a guide for the use of preprints by the press. Extending such principles also to social media will be important. Another issue for policy support measures regards agreeing on the right balance between rigour in providing support and speed in times of emergencies. As was the case during the COVID-19 pandemic, providing support quickly will necessarily result in mistakes, including payments to fraudsters, while rigour may result in delays that would hurt those to be supported. 


\subsection{Will global collaborations in STI increase?}

The COVID-19 has both challenged global collaboration and demonstrated its importance. With extensive restrictions to international travel and in-person interactions, the COVID19 crisis interrupted the mobility of STI human resources (e.g. visiting researchers, staff exchanges with industry) and put on hold many international research collaborations, particularly if field work was required - except for those addressing COVID-19 (see Section 2.1 in Paunov and Planes-Satorra $\left(2021_{[1]}\right)$. Some teams efficiently utilised digital tools and continued their joint work despite the constraints. Some international conferences were also highly successful in gathering more virtual participation than was the case in inperson meetings of the past. Yet, effective networking to build new collaborations proved challenging to emulate in virtual settings.

At the same time, COVID-19 research produced important outputs that have been developed by international teams, confirming and highlighting the importance of international collaboration in tackling global challenges. Analysis of research papers on COVID-19 published from January to September 2020 shows that around half of the papers published by UK-based authors are with an international co-author. The share is of around one-third for the United States, and around one-quarter for China. Chinese collaborators account for the lion's share of co-authors for US authors, and vice versa (OECD, 2021 ${ }_{[80]}$ ). Differences emerge however, depending on the field: virology and immunology research is often conducted by international teams, while it is less the case in patient care and public health research. Evidence also suggests that international teams had often collaborated previously but also that new connections were built quickly. For instance, Bryan, Lemus and Marshall $\left(2020_{[81]}\right)$ - based on data from BioMedTracker and Pharmaprojects, two online platforms that track drug development - found that $40 \%$ of drug therapies for COVID-19 (covering January to April 2020) were developed by a team of firms and that about one-third of collaborations were new.

The future of international research collaborations is uncertain, leading the US National Science Foundation to launch a call for research aimed at better understanding the nature and scope of the future impacts of COVID-19 on international research collaborations (NSF, 2020[82]). The following factors will play a role in the future of global collaboration:

A first factor regards available possibilities for global collaboration. The duration of COVID-19-related restrictions such as restrictions to international mobility and social interactions, coupled with reduced international research funding, may hamper the start of new international research projects, and reduce the number of opportunities for collaboration that often arise from random encounters in conferences and shared facilities. At the same time, working-from-home practices have also been successfully applied to research collaborations. For instance, Albert Bourla, the CEO of Pfizer -a US-based pharmaceutical company- has discussed the "surprisingly" successful quick transition to mostly virtual collaboration that has not affected the company's cross-border research activities (Chopoorian and Gross, 2021 ${ }_{[83]}$ ). This includes collaborations with German biotechnology company BioNTech that resulted in one of the first approved COVID-19 vaccines. The ability of digital tools to enable collaborations and new networks would directly shape what is possible while the COVID-19 crisis persists. New digital experimentation may allow for more collaborations than was previously the case - probably in combination with in-person exchanges when these are again possible.

A second factor regards impacts of tension in the multilateral system on international STI collaboration. On the one hand, the current crisis may lead to a shift towards national approaches as countries look to address the COVID-19 crisis and as a number of them, especially larger economies, seek to become more resilient to future shocks. These 
tendencies could be augmented by multinational enterprises seeking to rely less on global value chains to reduce uncertainty and enhance their "resilience", which would lead to further "reshoring" of production. On the other hand, multilateral frameworks could be reinforced as the result of greater appreciation of the risks and challenges that transcend national boundaries and require co-ordinated responses, especially if transnational actors in the governmental and private sectors succeed in leading the fight against the pandemic.

A third factor is about how STI policies will support international collaboration. STI policies can support international co-operation in STI that benefits from national research and innovation specialisations and capacities. In view of the COVID-19 experience, specific emphasis may be set in the future on building strong international platforms to share data about infectious diseases, launch international funding schemes for research and development of vaccines and treatments for emerging diseases, or establish a global disease prevention and control system. Global.health is an example of global data repository and visualisation platform launched in February 2021 to enable open access to real-time epidemiological anonymised data on about 24 million individual cases of COVID-19 infections around the world. Each of the cases contains data on up to 40 variables including on pre-existing conditions, location, symptoms, hospitalisation, and patient demographics. The repository is the result of a collaborative effort by technologists and researchers from 7 academic institutions in the United States and Europe, and the technical and financial support from Google and the Rockefeller Foundation. The database aims to help researchers monitor the spread of new variants and the effects of vaccines in the coming months, and to set a standard for the rapid reporting of case-level data in future epidemics (Maxmen, 2021 ${ }_{[84]}$ ).

Moreover, an ambitious proposal put forward by Italy in response to the OECD Survey on STI Policy Responses to COVID-19 was to have a one-stop-shop created by national governments, to be co-funded by a multilateral initiative (such as the Global Fund to Fight AIDS, Tuberculosis and Malaria) with an open-ended list of topics, including development of technologies to support the preparedness, resilience and quality of health systems. This co-operation could extend beyond the field of health to include collaborations to tackle other global challenges, such as climate change. Increasing policy attention to strengthening countries' resilience to possible future crises may also stimulate international collaboration in research and innovation towards this common goal (see Section 3.4).

However, public budget constraints stemming from the COVID-19 crisis could result in policies supporting national STI actors as a priority, while reducing incentives for international collaborations.

Countries may also decide to direct efforts at building national and transnational (regional) safeguards against future shocks, at the expense of global collaborative efforts and responses. This could involve, for instance, investments to ensure national or regional selfsufficiency in the production of essential goods (such as food and health supplies) to avoid shortages in the case of future crises similar to those experienced with key medical equipment during the first months of COVID-19. The crisis may also amplify demands for "access to" key technologies, such as 5G communications and artificial intelligence, in view of concerns over national security, the risk of future dependencies on foreign technology suppliers, and concerns over global monopolies and their potential detrimental impact on technological progress. Strategic alliances with a number of chosen countries may be sought in STI in view of shared values and the reciprocity of benefits and costs in such collaborations. 


\subsection{Will STI be more or less inclusive at social, industrial and territorial levels?}

\subsubsection{Social inclusiveness}

The COVID-19 crisis creates opportunities and challenges the social inclusiveness of STI systems - defined as the extent to which individuals, independently of their socio-economic background, gender, age, ethnic origin, religion or place of residence, have the capacity and the opportunity to participate in R\&D and innovation activities and to benefit from $R \& D$ and innovation. The future can be both more and less inclusive depending on the direction of developments and policy choices.

One opportunity arises from the high public visibility of science during the COVID-19 crisis which creates opportunities to increase the diversity of talent engaged in STI. More students may be attracted to pursue scientific career paths after the pandemic. In turn, if appropriate policy support measures are in place, groups that are currently underrepresented in STI ecosystems, including women and minority groups, may engage in STI activities (see examples of policies to support social inclusiveness in STI systems in Planes-Satorra and Paunov (2017 [85]).

Another opportunity emerges from more flexible work arrangements as the COVID-19 crisis led to extensive practice in remote working. More flexible ways to participate in STI rather than the rigid full-time work arrangements may particularly allow involving women with young children more in labour markets, also as part of the STI workforce. Should more work operate remotely, those located in remote areas may have more opportunities to engage in research and innovation networks at a distance, while firms located in those areas may also be able to access talent more widely. Some restrictions to complete mobility however are likely to remain, as hybrid working models -where employees combine working in the office some days per week and work remotely the rest of the time-are likely to become more common than fully remote work.

Nonetheless, the COVID-19 crisis also poses a number of threats to future inclusiveness in STI systems. A first one is related to ensuring acquisition of skills at all stages -from primary school to graduate education and on-the-job training- needed to contribute to the future STI ecosystem. If financial difficulties stemming from the crisis disproportionally affect families of students from disadvantaged backgrounds, then the pandemic may exacerbate rather than reduce unequal participation in STI ecosystems. These students may not complete their degrees or obtain lower grades than would otherwise have been the cases and consequently not be in position to pursue higher levels of education and training to participate in the STI workforce of the future. Considering a scenario where in 2020 and 2021 public investment in education declined by $25 \%$ and parental income by $5 \%$, researchers at the US Federal Reserve calculated that in 2045 there would be $2.7 \%$ fewer college-educated workers, and 3.8\% more workers without a high school diploma, than in the baseline scenario (Fernald, Li and Ochse, 2021 ${ }_{[86]}$ ). Even farther upstream, the extensive closures of education facilities poses a particular threat to those students from disadvantaged groups, potentially reducing for the next decade the pool of students from disadvantaged backgrounds available to engage in STI careers. Existing evidence suggests that school closure for just one third of an academic year has an impact on student skill attainment and could decrease long-run GDP by as much as $2.6 \%$ by 2100 (Hanushek and Woessmann, 2020[87]).

Hysteresis is a term in labour economics that describes skill loss due to long-term unemployment. Hysteresis in education refers to the long-term impact of school closures on students' outcomes (OECD, 2020 $\left.{ }_{[88]}\right)$. Although the negative impacts of hybrid or online learning are thought to be minimal on students who attend class regularly, even a temporary 
withdrawal from education reduces students' lifetime prospects for educational attainment, employment and income. Estimates based on the OECD Survey of Adult Skills indicate that the loss of one year of schooling would decrease a child's future income by $7.7 \%$ on average (Hanushek and Woessmann, 2020[87]). Rising absenteeism due to the crisis has been most prevalent among children from lower-income households, whose home environments or limited access to digital equipment affect their ability to engage with school in an online setting. The crisis requires effective action to ensure that educational hysteresis does not reinforce social inequalities by disproportionally affecting students from disadvantaged households.

Moreover, the well-known challenge of reskilling is accentuated in the context of the COVID-19 crisis as it may accelerate change in industry - notably with digitalisation as mentioned above. According to ILO estimates, global employment losses in 2020 were of around 144 million relative to the level in 2019 (or a loss of 4.3\% globally, including rising inactivity and unemployment); young workers were particularly hard hit, with an employment loss of $8.7 \%$ and almost all of those affected withdrawing from the labour force (ILO, 2021 $\left.{ }_{[89]}\right)$. Changing demands for skillsets in the workforce after COVID-19 may leave some of these workers without jobs to return to. Already before the pandemic, the World Economic Forum had estimated, based on employer surveys, that $54 \%$ of workers would require significant re- and upskilling by 2022 (World Economic Forum, $\left.2018_{[90]}\right)$. This figure may rise because of the COVID-19 pandemic. Evidence from the 2008 financial crisis indicates that skill requirements rose, and remained high, because the recession accelerated plans for automation and capital investment (Hershbein and Kahn, $\left.2018_{[91]}\right)$. This requires finding efficient ways to invest in reskilling that involves all.

Another threat is that the effect of the COVID-19 crisis results in a permanent exclusion of disadvantaged groups. Women researchers, especially those with young children and with elderly care responsibilities, were found to devote less time to research activities during lockdown, which can negatively affect their research career progression if disruptions continue for an extended period (see Section 2.3 in Paunov and Planes-Satorra, 2021 ${ }_{[1]}$ ) (Myers et al., 2020[92]; Vincent-Lamarre, Sugimoto and Larivière, 2020[93]). Opportunities to reconnect following the crisis may not be as easy and lost years of career development may permanently put a bar on career advancement. Gender disparities in research careers could also widen.

The challenges for the young generation of the STI workforce are also important. Young researchers, including $\mathrm{PhD}$ students and postdocs, may face more challenges to enter the STI workforce under stable conditions, as they often have fixed-term contracts and new positions may become scarcer - although differences are likely to emerge across scientific fields. Failure to fully set up their careers and build networks may permanently reduce their possibilities to make their mark in STI, possibly reducing the rate of progress as dominant researchers are less challenged than would have been the case otherwise. In addition, digital forums, unlike in-person meetings, may reinforce the "superstar" phenomenon in science as leading scholars are prioritised speakers. Limited opportunities to "get known" may affect publishing opportunities and thereby reduce future career opportunities for researchers outside of top institutions.

\subsubsection{Industrial inclusiveness}

\section{Impacts of sectoral differences}

The 2020 COVID-19 crisis was highly unequal in its impacts across leading innovationintensive sectors and other sectors of the economy (Figure 8) (see section 2.3 of Paunov 
and Planes-Satorra $\left(2021_{[1]}\right)$ for a detailed discussion). The unequal impacts across sectors may affect STI ecosystems in the following ways.

\section{Figure 8. COVID-19 is especially threatening for several sectors}

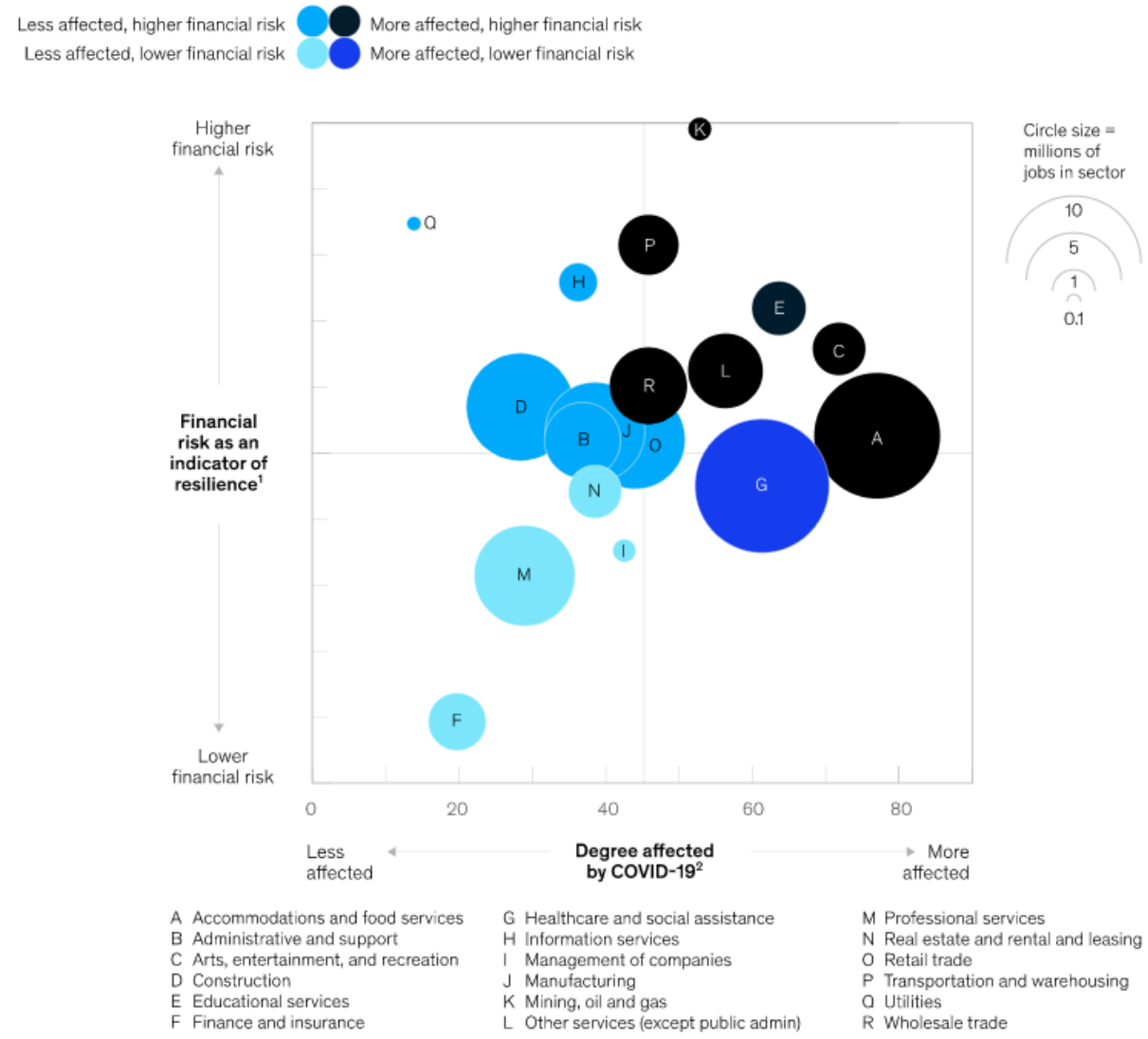

Note: Exhibit from "COVID-19: Implications for business", December 2020, Executive Briefing, McKinsey \& Company, www.mckinsey.com. Copyright (c) 2020 McKinsey \& Company. All rights reserved. Reprinted by permission.

${ }^{1}$ Based on profitability, credit risk and use of retained earnings.

${ }^{2}$ Based on US Census Bureau Pulse Survey of small and medium-sized businesses.

Source: McKinsey \& Company (2020[94]) based on data from Statistics of US Businesses, 2017; Federal Reserve Banks' Small Business Credit Survey, 2019; Annual Business Survey, 2018; Census Bureau Small Business pulse Survey Week 4, 2020; Labor CUBE.

First, the unequal effects during the COVID-19 crisis may result in a widening gap in future innovation performance between those sectors that were most severely hit, more liquidity constrained and less able to benefit from digital tools to mitigate the negative impacts of the crisis, and those that thrived during the pandemic (e.g. large digital tech firms).

Second, the dynamism of some sectors and the demand for certain products may help sustain innovation activities beyond the pandemic and also support the wider STI ecosystem in dealing with the crisis. For instance, the demand for digital services may not only offer opportunities for digital companies but also for firms in traditional sectors to offer innovative services that satisfy new demand. Restaurants and hotels, for instance, may increase the uptake of digital tools to engage in online delivery or air-cleaning technologies to be in a position to operate where social distancing is required.

Third, the unequal effects across and within sectors may have implications for market concentration. The impacts of digitalisation both of processes and products may also 
strengthen the advantages for leading digital providers in traditional sectors or alternatively offer new opportunities for digital start-ups and entrepreneurs. Those shifts may also affect the degree of market competition and consequently innovation dynamics (Guellec and Paunov, 2018[95]).

Fourth, the direction of innovation and technological change may also be affected due to some sectors being more hit than others and the bigger success of certain businesses and firms. Such developments may have important implications for realising wider socioeconomic goals (Acemoglu, 2020 $0_{[96]}$ ). This includes an acceleration in digital innovations - as discussed in section 2.2 - but also possible shifts in the direction of STI in the field of health. Health research and innovation efforts may set greater emphasis on addressing the current and future infectious diseases, possibly reducing investments in other areas such as cardio-vascular diseases and oncology.

\section{Impacts of differences across larger and smaller firms}

The COVID-19 crisis was also highly unequal in its impacts within sectors, providing opportunities disproportionately to larger firms in the economy, notably those in the digital economy. According to data gathered by Goldman Sachs, in April 2020 the top five largest S\&P 500 companies - Microsoft, Apple, Amazon, Alphabet and Facebook - accounted for $20 \%$ of the value of the index and boosted their profits (Phillips, 2020 [97]) (Waters et al., $\left.2020_{[98]}\right]$. More generally, the crisis posed larger challenges for smaller firms across sectors as discussed in detail in Paunov and Planes-Satorra $\left(2021_{[1]}\right)$. Those issues threaten the future inclusiveness of sectors across differently sized firms in the following ways.

First, the crisis risks widening gaps in innovation performance within sectors. SMEs tend to be more vulnerable to liquidity constraints in a context of decreased demand and are relatively less agile than large firms in adopting digital technologies or other innovations to adjust their activities to the new landscape. SMEs affected by the COVID-19 crisis consequently struggled more than their larger counterparts, possibly affecting in particular investments to increase future competitiveness, including those in innovation. The withdrawal or tightening of support policies, a tightening of credit conditions, or both, could set off a wave of bankruptcies, thus far deferred, among SMEs facing the pressure of the crisis (Gourinchas et al., 2021 ${ }_{\text {[99] }}$ ). For those who borrowed heavily to weather the crisis, the large debt accumulated poses a risk of debt overhang that may result in increased bankruptcies in the future (Demmou et al., 2021 [33]).

Second, the unequal preparedness of businesses to take advantage of digital tools may widen the gap between leading firms and those that were further behind and consequently hit more, as they could not immediately implement digital processes to substitute for inperson activities (due to financial or skills constraints). At the same time, COVID-19 was a major push factor that accelerated SME digitisation; evidence from several business surveys conducted in 2020 worldwide by businesses, NGOs, and government agencies suggests that in most countries surveyed a majority of SMEs reported adopting new digital technologies or practices because of the crisis. Some of the greatest accelerations in digital adoption came in the use of e-commerce, cashless payments, online education services, and the use of streaming and teleconferencing software (OECD, 2021 $\left.1_{[100]}\right)$.

Third, the shift to online shopping by consumers during lockdown could further increase the market share of digital retailers at the expense of brick-and-mortar retailers after the crisis. Large players able to successfully adopt hybrid models may also come out strengthened at the expense of smaller ones, increasing market concentration in the sector. Firms' access to consumers may also be affected if large e-commerce platforms (e.g. Amazon) gain permanently in market power. This could force firms - particularly smaller ones - to accept the conditions favourable to platforms to access them and 
consequently markets, even if such conditions were significantly less advantageous than selling their products directly to the final client.

Fourth, if leading firms are emerging from the crisis strengthened while smaller competitors are not in position to resurface or move up, then market concentration may increase, possibly affecting the rate of innovation negatively in the longer run.

Despite the risks of widening gaps between SMEs and larger firms, SMEs could also benefit from changes brought by COVID-19. Changes to global value chains, with an increased emphasis on building a wider base of capabilities and reshoring, could provide new business opportunities for SMEs to take advantage of (Juergensen, Guimón and Narula, $\left.2020_{[101]}\right)$.

\subsubsection{Territorial and global inclusiveness}

At the territorial level, the longer-term impact of the COVID-19 crisis on economic and innovation performance will differ across cities and regions depending on their exposure to global value chains and their reliance on heavily hit sectors such as tourism (OECD, $2020_{[102]}$ ). These effects could widen gaps in innovation performance across regions where the lost revenues in the sectors most affected reduce innovation efforts in those regions across all of their economic activities.

Some factors could however contribute to reducing territorial disparities in innovation performance. The large-scale adoption of new ways of organising work enabled by digital technologies, with work from home becoming more common, could reduce the advantages of agglomeration economies and push towards the "death of distance"; innovation activities could be more evenly spread across regions as individuals can engage in those activities remotely from any location. Some regions have already adopted policies to attract remote workers. In Emilia Romagna, Italy, the regional government launched a scheme to incentivize remote workers to settle in the region (Emilia Romagna Government, $2020_{[103]}$ ).

The possible pushback against globalisation and in particular the incentive to reduce concentration of the global production of certain products among a few producers may also create new opportunities for building more diversified economies and support different regions' to contribute to this objective. This process has already begun in the textile sector of Valencia, Spain, which had struggled in recent years due to competition from Asian textile manufacturers. The Regional Ministry for a Sustainable Economy and the Valencian Institute of Business Competitiveness (Ivace) quickly mobilized the region's textile manufacturers to innovate in response to COVID-19 and shift to production of textiles for personal protection equipment (PPE). Emergency financial instruments have helped regional companies transition to textiles manufacturing for the needs of the COVID-19 pandemic and for preparedness for future pandemics (European Commission, 2020 [104]). In the Grand East Region, France, which has also suffered from deindustrialisation, the regional government has launched an initiative to reshore local capabilities in order to facilitate resilience and economic development after COVID-19. In cooperation with France's Banque des Territoires, its "Reshoring Pact" provides local businesses with free consulting on how to identify risks in their supply chains and relocate them to the region. The goal of this policy is eventually to map the region's supply chains and build resilience through strengthening local alternative manufacturers (Région de Grand Est, 2020 [105]).

The pandemic also risks widening disparities at global level. World Bank estimates (as of January 2021) suggest that the COVID-19 crisis pushed more than 119 million people into extreme poverty in 2020, with the largest share of "new poor" in developing countries particularly in South Asia, followed by Sub-Saharan Africa (Lakner et al., 2021 ${ }_{[106]}$ ). The global economic downturn caused by the COVID-19 crisis is the main driver of this trend, 
as it is leading to a contraction in incomes across developing countries (Kharas, 2020 [107]). A number of factors affected emerging and developing countries in particular. First, the sharp decline in international tourism with travel restrictions severely affected a number of these countries for which tourism is a main source of income. Second, income from remittances - money that migrant workers send to their families at home - also dropped as migrant workers were particularly vulnerable to loss of employment and wages in their host countries during the pandemic (World Bank, 2020 ${ }_{[108]}$ ). Third, the crisis led to a decline in foreign direct investment (FDI) flows to developing countries of around $12 \%$ in 2020 on average, with some regions being significantly affected $(-37 \%$ in Latin America and the Caribbean, $-18 \%$ in Africa), possibly reducing job opportunities for the local population. (UNCTAD, 2021 $\left.1_{[109]}\right)$. A major challenge for future inequalities relates to disruptions to schooling, which on average have been longer than in developed countries, are also likely to disproportionally affect most vulnerable groups in those countries, which could erode earlier gains in human capital development (World Bank, 2021 ${ }_{[110]}$ ). Many low-income countries were already in debt distress before the pandemic, making it harder for them to support the most vulnerable in a context of global turndown (Blake and Wadhwa, 2020 [111]). As a result, the crisis could slow down or even reverse recent advances in economic development in low- and middle-income countries (IMF, 2021 ${ }_{[12]}$ ), possibly hindering capacity building efforts needed to engage in international research and innovation networks.

\section{Will the goals of STI policy change?}

This section discusses how the COVID-19 crisis may lead to changes in the focus of STI policy toward contributing to building systems that are more resilient, environmentally sustainable and inclusive, as these goals gain prominence in policy agendas.

\subsection{Towards a more directional role for STI policy}

The COVID-19 crisis may modify the role of STI policy in the recovery since - as discussed in Section 1.2 above - the pandemic creates new demands as societal preferences may change. In particular, these new policy demands regard "building back better" towards systems that are more environmentally sustainable, inclusive and resilient to shocks. This new role would differ significantly from the main targets STI policy was evaluated against for many decades: its contributions to productivity and competiveness for long-term growth. The shift of STI policy to societal goals (environmental sustainability, health aging, energy security), which was already under way across many countries prior to the COVID19 crisis, may receive an additional push. Such a push may result in those targets gaining larger prominence in the metrics evaluating the success of innovation policy tools in complement of more traditional metrics on productivity and competitiveness.

Pursuing one, several or all of these objectives creates a more directional role for STI policy. This role differs from a focus on addressing market and system failures but not pointing towards preferred technology developments. New focus could be on supporting specific technologies and innovations (e.g. those critical to produce "essential goods" in a crisis situation, or for transition towards green energy and green transportation). The wider use of mission-oriented research and innovation policies (MOIP) over the past years signals a policy shift in this direction, one that may be reinforced by the COVID-19 crisis (Larrue, $2021_{[112]}$ ). Such approaches prioritize research and innovation that contribute to advancement towards "preferred goals" such as carbon neutrality, the development of cancer therapies, or the digitization of manufacturing. One of the largest such examples is the mission-oriented scientific agenda in the Korean New Deal, which set 10 "core 
projects" in health, climate, and digital technologies to be completed by 2025 in response to the COVID-19 pandemic. Importantly, such missions may also rely on generic funding support for business innovation and often require close collaboration within government in charge of those missions, such as ministries of health in the case of health-related missions.

The degree of "directionality" in STI policies can differ substantially based on what is considered the most effective means of reaching societal objectives - that is, whether governments make the choice as to what technologies are pursued, or whether that is left to the STI community to explore. MOIP are defined by a high degree of directionality, i.e. they involve "picking the problem", while offering flexibility to STI actors to decide on the best technology solutions to address it. Successful MOIP set challenges in such a way that a wide set of actors with different approaches to address the challenge engage. They are also sufficiently concrete and well-defined to provide strong orientation that is "actionable" (i.e. that can be translated into and monitored against precise goals and expected deliverables). This challenge-based approach contrasts with policies that target specific sectors or technologies (Larrue, 2021 ${ }_{[112]}$ ). The latter have also gained ground over the past years as many countries have implemented policies to support advances in "enabling" or "general purpose" technologies, such as AI, considered key to enhance countries' future competitiveness as well as to support developments in a wide range of areas, including notably to tackle the abovementioned "missions" (Gonne, Kitazawa and Lalanne, forthcoming $[113])$. Policies directed to specific sectors have been criticized for trying to "pick winners" with much debate as to how to best conduct them. In the current context, these could gain importance if some sectors (e.g. the health industry) are considered strategic to increase future resilience to shocks (see Section 3.4.2).

\subsection{How can STI policy support the transition towards environmentally sustainable futures?}

The COVID-19 crisis provides a context where policies (including STI policies) can accelerate structural change towards more environmentally sustainable systems. As of August 2020, at least 30 OECD and key partner economies had included measures in their recovery packages directed at supporting the transition towards greener economies, including in many cases subsidies for green $R \& D$. These often focus on the field of clean energy and clean transportation (Figure 9) $\left(\right.$ OECD, 2020 $\left.0_{[114]}\right)$. For instance, in July 2020, the UK Government announced a GBP 350 million (USD 452 million) package for a green recovery. This notably includes investments in innovation to decarbonise heavy industry and the construction, transportation and aviation sectors (GOV.UK, 2020 $0_{[15]}$ ). The Korean New Deal, also adopted in July 2020, commits approximately USD 61 billion over five years (2020-25) to boost renewable energy capacity to 42.7 gigawatts (GW) by 2025 , from $12.7 \mathrm{GW}$ in 2019 , and expand the green mobility fleet to 1.33 million electric and hydrogen-powered vehicles. The plan also promises refurbishment of public rental housing and schools to make them eco-friendly, and the transformation of urban areas into smart green cities (Government of Korea, 2020 [116]).

Another way of steering changes has been to make support to carbon-intensive industries or firms conditional on making progress in building more environmentally sustainable processes. An illustration of this is the French Government's bailout package for Air France, which requires the company to cut its emissions by half per passenger and per kilometre by 2030 (from 2005 levels) and use 2\% alternative fuels in its planes by 2025 .

Research and innovation policies to foster green growth are not new. Lessons from policies implemented in the past (Box 1) can provide critical insights for designing green innovation policies in the COVID-19 recovery. 
Figure 9. Number of recovery measures with positive environmental implications, by sector and type

\begin{tabular}{|c|c|c|c|c|c|c|c|c|c|c|}
\hline & Energy & Aviation & $\begin{array}{l}\text { Ground } \\
\text { transport }\end{array}$ & $\begin{array}{l}\text { Maritime } \\
\text { transport }\end{array}$ & $\begin{array}{l}\text { Heavy } \\
\text { industry }\end{array}$ & Buildings & Agriculture & Forestry & $\begin{array}{c}\text { Waste } \\
\text { management }\end{array}$ & Other \\
\hline \multicolumn{11}{|c|}{ Tax reduction / other subsidy } \\
\hline \multicolumn{11}{|c|}{$\begin{array}{l}\text { Grant/Loan (including } \\
\text { interest-free loans) }\end{array}$} \\
\hline \multicolumn{11}{|c|}{ R\&D subsidies } \\
\hline \multicolumn{11}{|c|}{ Regulatory change } \\
\hline \multicolumn{11}{|c|}{ Skills training } \\
\hline Other & & & & & & & & & & \\
\hline
\end{tabular}

Note: Colour shading represents the total number of measures with a clear expected positive environmental impact, tracked across OECD and Key Partner countries in August 2020. Darker cells indicate a larger number of measures.

Source: OECD (2020[114]).

\section{Box 1. Research and innovation policies for sustainable development}

Innovation supports growth and job creation and also helps address a wide range of social and environmental challenges that are reflected in the Sustainable Development Goals (SDGs) adopted by the United Nations. Overcoming the barriers to green innovation - such as the dominance of existing technologies and systems, regulatory frameworks that may favour incumbents, or barriers to access capital - can significantly spur innovation in this area (Table 1) (OECD, 2011 $1_{[19]}$; Borowiecki et al., 2019 $\left.9_{[117]}\right)$.

\section{Table 1. Fostering green innovation: challenges and policy options}

\begin{tabular}{|c|c|}
\hline Policy challenge & Policy options \\
\hline Insufficient demand for green innovation & $\begin{array}{l}\text { - Demand-side policies, such as public procurement, standards and } \\
\text { regulations, in specific markets and circumstances } \\
\text { - Market-based instruments to price externalities and enhance incentives }\end{array}$ \\
\hline Lack of innovation capability & - Broad-based policies to strengthen innovation \\
\hline $\begin{array}{l}\text { Technological roadblocks and lack of } \\
\text { radical innovation }\end{array}$ & $\begin{array}{l}\text { - Investment in relevant R\&D, incl. thematic and mission-oriented research } \\
\text { - International cooperation }\end{array}$ \\
\hline $\begin{array}{l}\text { Research and investment bias to } \\
\text { incumbent technology }\end{array}$ & $\begin{array}{l}\text { - R\&D support, tax incentives } \\
\text { - Adoption incentives/subsidies } \\
\text { - Technology prizes }\end{array}$ \\
\hline Lack of finance & $\begin{array}{l}\text { - Co-investment funds } \\
\text { - Market development }\end{array}$ \\
\hline Regulatory barriers to new firms & $\begin{array}{l}\text { - Regulatory reform } \\
\text { - Competition policy } \\
\text { - Front-runner approaches }\end{array}$ \\
\hline
\end{tabular}




\begin{tabular}{l|l}
\hline Lack of capabilities in SMEs to adopt & - Access to finance \\
green innovation & - Skills development \\
& - Linking SMEs to knowledge networks \\
& - Improving information supply \\
& - Reducing regulatory burdens \\
\hline Non-technological innovation & - City and transport planning \\
& - Regulatory reform \\
\hline International technology transfer & - Development of capabilities \\
& - Trade and investment policies \\
& - IPR protection and enforcement \\
& - Voluntary patent pools and collaborative mechanisms \\
\hline Source: OECD $\left(2011_{[19])}\right.$
\end{tabular}

Borowiecki et al. $\left(2019_{[117]}\right)$ explore specific policy initiatives in support of research and innovation for sustainable development. These programmes set specific environmental sustainability targets jointly with targets on research excellence, industry competitiveness and/or addressing societal challenges, and combine financial and nonfinancial support for research and innovation. Relevant aspects that contributed to the success of these initiatives included the following:

- Involving the wider innovation community and civil society in addressing sustainability challenges. The Environmental Technology Development and Demonstration Programme (MUDP) in Denmark, for instance, promotes the creation of innovation partnerships, where enterprises, researchers and public institutions get together to discuss around specific environmental challenges, possibilities for developing better solutions, as well as regulation-related issues.

- Supporting the private sector in adopting sustainable business strategies. The Swedish Foundation for Strategic Environmental Research (MISTRA) follows up the sustainability focus of its investments by supporting firms in adapting their business strategies to achieve sustainable development goals.

- Promoting international collaboration in research to address global sustainability challenges. The Science and Technology Research Partnership for Sustainable Development (SATREPS) in Japan supports research collaborations between Japanese researchers and researchers in developing countries, with the objective of both providing new solutions to environmental problems and at strengthening research capacities in developing countries.

Source: Borowiecki et al. (2019[117])

\subsection{How can STI policy support future inclusiveness?}

STI policy can contribute in important ways to an inclusive recovery after COVID-19 (OECD, 2017 $7_{[18]}$; Planes-Satorra and Paunov, 2017[85]; Paunov, 2013 $3_{[119]}$ ). Inclusive innovation policies - i.e. those that aim to remove barriers to the participation of individuals, social groups, firms, sectors and regions underrepresented in innovation activities - are particularly relevant here. They tackle the misallocation of human resources (and to a certain extent technologies) across the economy due to the limited opportunities of some groups or firms to participate in innovation activities. Historically, such misallocations stem from a diversity of factors, including labour market discrimination and barriers to access to funding for innovation activities that particularly affect smaller players. 
As explored in Section 2.5 and in Paunov and Planes-Satorra $\left(2021_{[1]}\right)$, the pandemic risks aggravating existing inclusiveness challenges, since individuals and firms in most vulnerable positions (e.g. early-career and women researchers, students from disadvantaged backgrounds, SMEs and early-stage start-ups) are disproportionally affected.

Inclusive innovation policy approaches can thus prove highly relevant in the COVID-19 context, as they support both innovation and inclusiveness. Table 2 presents an overview of policy examples classified by the primary inclusiveness dimension they address (social, industrial or territorial), although they often directly or indirectly tackle more than one of those dimension (Error! Reference source not found.). 


\section{Table 2. Overview of innovation policy approaches to foster inclusiveness}

\section{By inclusiveness type}

\begin{tabular}{|c|c|c|}
\hline Social inclusiveness & Industrial inclusiveness & Territorial inclusiveness \\
\hline $\begin{array}{l}\text { These policies aim to broaden the group of } \\
\text { innovators by including in research, } \\
\text { entrepreneurial and innovation activities } \\
\text { individuals and groups that do not usually } \\
\text { participate in those activities. Policies } \\
\text { addressing social inclusiveness proceed } \\
\text { either by building the innovation capabilities } \\
\text { of disadvantaged groups, or by facilitating } \\
\text { their access to opportunities to participate in } \\
\text { innovative activities. }\end{array}$ & $\begin{array}{l}\text { These policies aim to support innovation } \\
\text { activities in less innovative firms (including } \\
\text { micro-entrepreneurs, small and medium-sized } \\
\text { enterprises and start-ups) and traditional } \\
\text { sectors. The focus is on strengthening their } \\
\text { innovation capacities, as well as on building the } \\
\text { adequate business environment for innovation. }\end{array}$ & $\begin{array}{l}\text { These policies target lagging and less } \\
\text { innovative regions with the aim of } \\
\text { narrowing the performance gap with } \\
\text { leading innovation regions. They foster } \\
\text { the innovation capacity of individuals } \\
\text { and firms located in peripheral regions, } \\
\text { as well as in disadvantaged } \\
\text { neighbourhoods within large urban } \\
\text { areas. }\end{array}$ \\
\hline $\begin{array}{l}\text { Building capacities } \\
\text { - Access to high-quality science education } \\
\text { for disadvantaged groups } \\
\text { - Schemes for communication and } \\
\text { popularisation of S\&T } \\
\text { - Entrepreneurship education } \\
\text { - Grants for researchers from disadvantaged } \\
\text { groups } \\
\text { - Funds to research institutions for } \\
\text { implementing plans to improve the research } \\
\text { environment for disadvantaged groups }\end{array}$ & $\begin{array}{l}\text { Providing support for business development } \\
\text { - Information to entrepreneurs } \\
\text { - Coaching and mentoring } \\
\text { - Business counselling/advice to entrepreneurs } \\
\text { - Assistance to access new markets } \\
\text { - Technology transfer assistance }\end{array}$ & $\begin{array}{l}\text { Facilitating access to global } \\
\text { knowledge and technology } \\
\text { - Demonstration of new technologies } \\
\text { and training by S\&T specialists } \\
\text { - Financial support to projects that use } \\
\text { STI solutions to address local } \\
\text { challenges }\end{array}$ \\
\hline $\begin{array}{l}\text { Addressing discrimination and } \\
\text { stereotypes } \\
\text { - Campaigns to raise awareness of the } \\
\text { business potential of activities of } \\
\text { disadvantaged groups } \\
\text { - Mentoring programmes and provision of } \\
\text { role models to incentivise disadvantaged } \\
\text { groups }\end{array}$ & $\begin{array}{l}\text { Facilitating access to finance } \\
\text { - Microcredit (micro-loans) } \\
\text { - Equity financing } \\
\text { - Educating in finance }\end{array}$ & $\begin{array}{l}\text { Maximising the potential of existing } \\
\text { assets } \\
\text { - Identification of sectors with potential } \\
\text { in a region and training of potential } \\
\text { regional entrepreneurs in those sectors } \\
\text { - Intellectual property protection in } \\
\text { traditional sectors } \\
\text { - Support for regional governments to } \\
\text { implement STI projects and develop } \\
\text { research capabilities }\end{array}$ \\
\hline \multirow[t]{2}{*}{$\begin{array}{l}\text { Providing incentives to invest in } \\
\text { (inclusive) innovation } \\
\text { - Grants } \\
\text { - Repayable grants }\end{array}$} & $\begin{array}{l}\text { Promoting networks involving industry, } \\
\text { academia and the financial sector } \\
\text { - Innovation vouchers } \\
\text { - Entrepreneurial networks }\end{array}$ & $\begin{array}{l}\text { Attracting innovative firms to } \\
\text { peripheral regions } \\
\text { - Technology parks } \\
\text { - Special economic zones } \\
\text { - Grants for business R\&D in } \\
\text { peripheral regions }\end{array}$ \\
\hline & $\begin{array}{l}\text { Improving access to talent by small } \\
\text { businesses } \\
\text { - Grants to SMEs to recruit researchers/experts } \\
\text { to implement innovation projects } \\
\text { - Providing SMEs with access to specialised } \\
\text { online job portals }\end{array}$ & \\
\hline
\end{tabular}

Source: Planes-Satorra and Paunov (2017[85]). 
Figure 10. Interactions among social, industrial and territorial inclusiveness

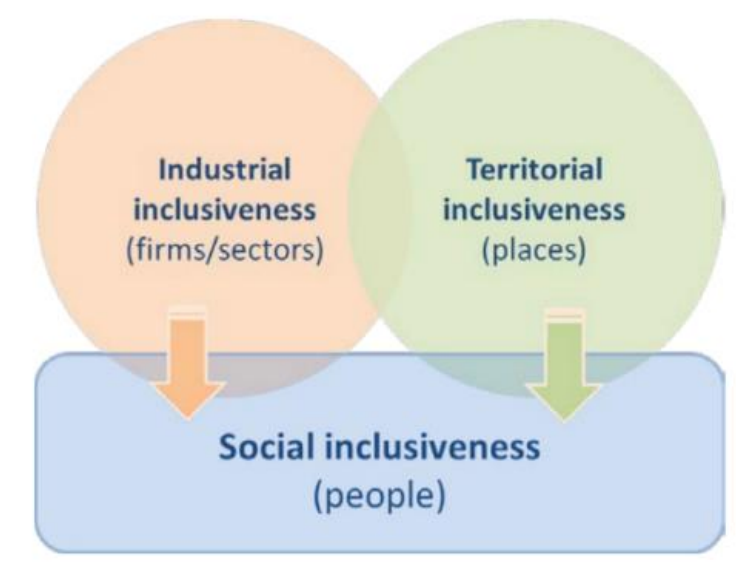

Source: Planes-Satorra and Paunov $\left(2017_{[85]}\right)$.

\subsection{How can STI policy help build greater resilience?}

This section discusses STI policy's potential areas of application to build resilience - "the ability to anticipate, absorb, recover and adapt to unexpected shocks" (OECD, 2020 [120]). Since the onset of the COVID-19 crisis, achieving greater resilience was raised as a priority by several countries, as reflected in the OECD Survey on STI Policy Responses to COVID19. Similarly, other policy domains have discussed strengthening resilience with proposals ranging from applying stress tests to the real economy (mimicking those applied to the financial sector), to building stocks of essential goods and reshoring their production.

Work by the OECD New Approaches to Economic Challenges (NAEC) emphasises the need to enhance systems' capacity not only to anticipate and prevent shocks, but also to recover and adapt in the aftermath of disruption, taking advantage of emerging opportunities following the crisis to "bounce forward" towards better systems instead of "bouncing back".

This section explores how STI can contribute to two dimensions of resilience (Figure 11). The first is anticipation, which has to do with STI preventing, or enhancing preparedness for, future shocks. The second is agility and responsiveness to shocks - that is, the capacity to adjust quickly in the event of a shock in order to mitigate its negative impacts and take advantage of emerging opportunities. 
Figure 11. Dimensions of systems' resilience

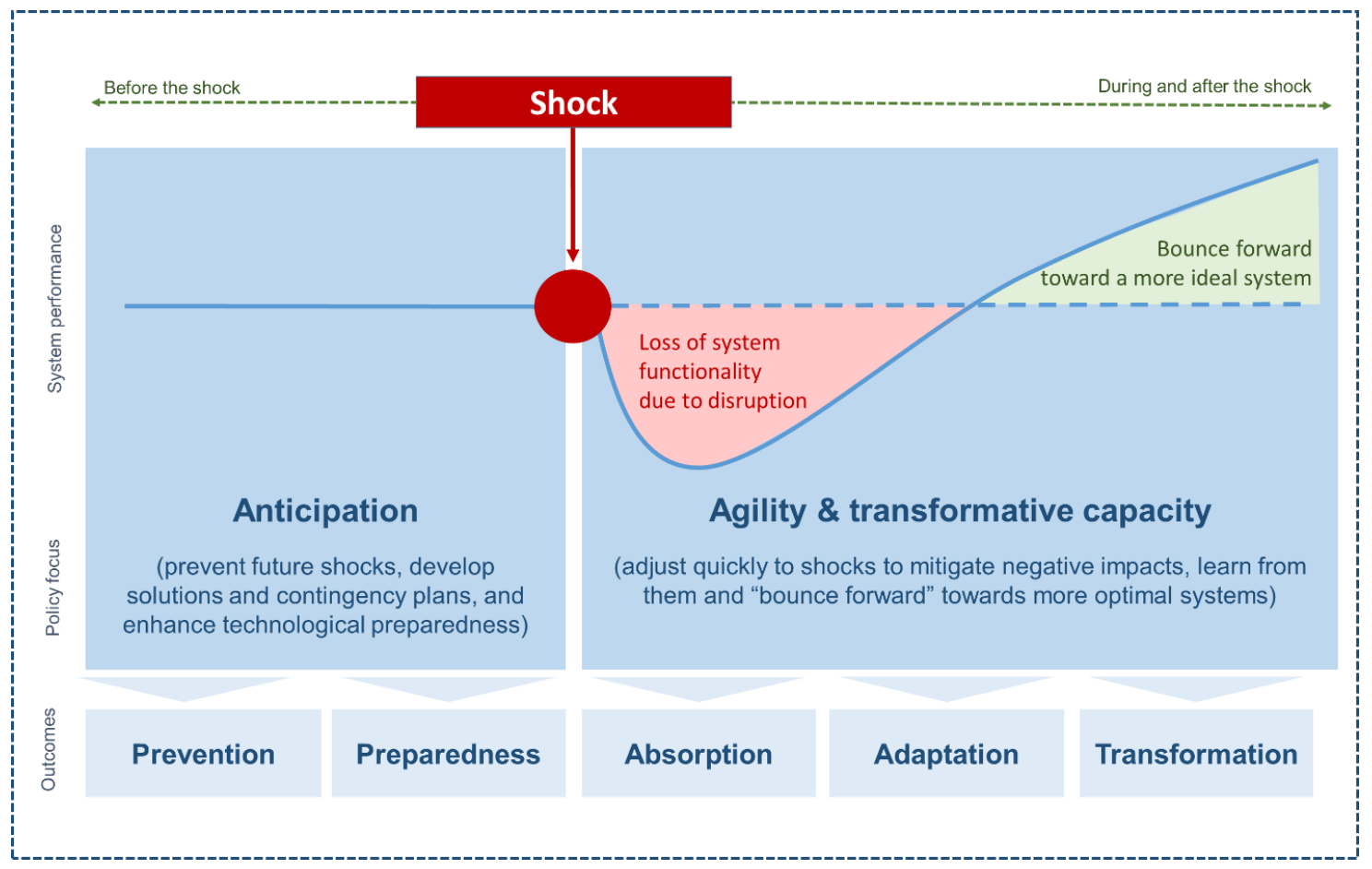

Source: Authors' elaboration based on Hynes et al. (2020[16]) and Bené et al. (2012[121]).

\subsubsection{STI's core role in anticipation, agility and transformative capacities}

STI can help anticipate future crises by engaging in preventive action and improving preparedness for them in the following three ways:

First, STI can identify the underlying factors behind certain threats that are well known to pose risks for the future, such as climate change or cybersecurity attacks. STI can develop the technological capacities and solutions to either prevent them or, when this is not possible, best tackle them. An example would be the development of green technologies to mitigate global warming.

Second, technological capacities in STI systems - including research and innovation capacities - strengthen anticipation and preparedness for future shocks as they make STI systems more responsive to such shocks. The lack of production capabilities in core goods such as test kits, masks and medical equipment in the early phase of the COVID-19 crisis was put forward as factor that weakened countries' immediate responses to the pandemic (Aghion et al., 2020 ${ }_{[122]}$; OECD, 2020 $0_{[123]}$ ). STI infrastructures and process innovations also provide the flexibility to make STI systems responsive and resilient to future shocks. Prior STI infrastructure investments that proved essential during the COVID-19 crisis included investments in broadband connectivity, critical for remote working. The ability to produce and manage rapidly data on, for instance, the number of new COVID-19 cases, the availability of intensive care unit beds, the amount of COVID-19 product supplies and the mobility of individuals also proved important in managing the pandemic. Moreover, firms with more advanced production technologies (such as robotics to automate production and 3D printing that allows switching production across a wide array of items) were also less vulnerable to the shock in labour supply (Shih, 2020 $[124]$ ).

Third, innovation in policy processes towards more anticipatory governance, defined as the application of foresight planning on policy making, can support resilience. Foresight and 
scenario analysis coupled with monitoring could allow policy makers to anticipate possible future developments (which may bring both opportunities and challenges) and prepare strategies and contingency plans to be able to rapidly and effectively respond to them, including by taking preventive actions to avoid possible future shocks (see section 4.2.1).

STI systems can also help respond to crises by providing for countries' agility and responsiveness and help "bounce forward". A strong scientific base; a vibrant and innovative business sector; fluid interactions between industry and science; and international research and innovation networks are well-known factors of an innovation ecosystem that can respond most effectively to shocks, such as future health crises and other shocks. During the COVID-19 crisis, STI ecosystems were rapidly mobilised to develop vaccines, treatments and solutions to social distancing, attenuating the detrimental effects of the pandemic (Paunov and Planes-Satorra, 2021 ${ }_{[1]}$ ). The better the underlying conditions of STI ecosystems in place, the more powerful and rapid were the responses. Those capacities are also important for plans to "bounce forward" to different futures by introducing the breakthrough and incremental innovations needed for transformations.

\subsubsection{Policy actions to support STI's contributions to resilience}

Certain policy actions can support STI ecosystems' contributions to resilience. A key policy priority is to enhance skills, capacities and core infrastructures. Technology advances, but also their successful widespread adoption and rapid adaptation in case of disruption, highly depend on the research base and the levels of skills and capacities in the economy in core fields, including health, essential goods - such as food - but also other core capacities, such as digital infrastructure and skills. Strengthening such capacities, and ensuring that all segments of society have opportunities to develop them in order to contribute to and benefit from innovation, enhances resilience (see also Section 3.3 on inclusive innovation policies). This includes the need for more effective reskilling processes across all levels of qualification. An example of accelerated change in the context of COVID-19 was the need for adopting digital technologies by government, industry, workers and citizens. Where capacities were lacking, the crisis resulted in costly delays in the delivery of public services (such as emergency help), shortfalls in production (incl. from reduced labor inputs were home office functionalities were not fully available) and exclusion in a context of social distancing (with all social activities being virtual).

Another policy priority is to strengthen the preparedness and flexibility of the public sector (including research and innovation funding agencies) to respond to future shocks. Emergency R\&D funding allocations and other measures introduced during the pandemic (e.g. fast-track open innovation calls, flexibilities to grant holders and new applicants, etc.) should be assessed, in order to identify good practices as well as weaknesses and the main challenges faced (e.g. shortages in evaluation capacities due to heavy increments in numbers of proposals). During the early phase of the COVID-19 crisis in 2020, concerns were raised about the risks of allocating large amounts of funding to well-known researchers and research groups in specific disciplines (i.e. those that were already well established in the system) as a way of accelerating disbursement of support, leaving little scope for multi-disciplinary approaches and unexpected solutions coming from a more diverse range of researchers and innovators. Special attention may thus be given to reviewing emergency R\&D funding allocation processes, to ensure they reward both the quality and diversity of approaches. Existing emergency procedures of regulatory bodies (e.g. regarding the approval process for developing new products) should also be examined to ensure they are optimised and draw on lessons learned during the pandemic. Such mechanisms need to ensure compliance with ethical and scientific quality standards to safeguard the rights, safety and well-being of consumers. 
Enhancing the preparedness of the public sector also involves reviewing STI governance systems to ensure they are agile in implementing co-ordinated STI-related measures across national and sub-national levels of government (and in their alignment with policies in other areas) (OECD, 2020 $\left.{ }_{[125]}\right)$. The processes to designate the composition and responsibilities of crisis task forces or councils; information-sharing mechanisms across levels of governments and other actors in the STI ecosystem; and science advice and communication processes should also be strengthened when necessary.

A third policy priority is to support international connectedness of research and innovation systems. As pointed to by Brazil in the OECD Survey on STI Policy Responses to COVID19 , identifying better ways of rapidly mobilising and interconnecting research and innovation capabilities can also help build effective response capabilities for resilience. Not all countries have the research base or scientific expertise at the cutting edge of all the areas that are relevant to respond to a specific crisis - ranging from epidemiology and seismology to artificial intelligence. In addition, as experienced during the COVID-19 crisis, international collaboration can accelerate responses and avoid duplication of effort, taking a cue from experiences in other countries. There is much to be gained from international sharing of experiences and lessons learned during the pandemic regarding successful policy practices as well.

With the vulnerabilities the COVID-19 crisis exposed, achieving wider resilience by mobilising STI systems has received wider policy attention. The context of geopolitical uncertainties and the threat of global trade conflicts, questions of "strategic autonomy" and "technology sovereignty" - which Edler et al. $\left(2020_{[126]}\right)$ define as "the ability of a state or a federation of states to develop the technologies it deems critical for its welfare, competitiveness, and ability to act, or source them from other economic areas without onesided structural dependency" - have come onto policy agendas (Kelly, 2020 ${ }_{[127]}$ ).

Several recovery plans to the COVID-19 crisis explicitly refer to resilience as a core goal. At European level, enhancing strategic autonomy is included as a priority in the EU recovery plan and the 2020 Strategic Foresight Report of the European Commission to secure EU competitiveness in the future and strengthen its resilience to future shocks. This includes strengthening key technological capacities that will enable digital and green transitions (European Commission, 2020 $[128]$; European Commission, 2020 $\left.{ }_{[129]}\right)$. In France, a High Commissioner for Planning (Haut-Commissaire au Plan) was appointed in September 2020 to lead and co-ordinate prospective reflection and inform the choices of public authorities with regard to future economic, social, technological, health and environmental challenges. This includes reflection on the country's independence in the production of essential health products (Gouvernement.fr, 2020 [130] $)$.

The increased policy attention to strengthening technological capacities may contribute to a revival of technology policy across countries, which was already happening in recent years as AI strategies and other policies to support advances in cutting-edge digital technologies were widely adopted to enhance national competitiveness in the digital age (Planes-Satorra and Paunov, 2019 $\left.9_{[56]}\right)$. An illustration of the renewed interest in technology policy in the time of the pandemic is the Korean "Post-COVID-19 Science and Technology Policy Direction for the Future", which identifies high-priority technologies for R\&D funding based on the assessment of scientific and technological experts (Figure 12).

Sector-specific innovation and technology policies, undertaken previously to build capacities in industries with high-growth potential, could also in the near future be pursued to strengthen systems resilience, by prioritising those sectors in which capabilities are judged essential to be prepared for future shocks. This could involve, for instance, capabilities to produce essential medical products to reduce over-reliance on a single or a few suppliers in the event of another global health threat. Initial steps have been taken in 
that direction. The national science research agency in Australia, CSIRO, has announced a plan to partner with industry and academia to deliver innovations in 12 target areas including several related to sustainability, resilience, and future economic competitiveness. CSIRO expects to spend at least AUD 100 million (USD 77 million) annually on these twelve missions (Marshall, 2020 [131]; CSIRO, 2021 $1_{[132]}$. However, the success of strategies is not straightforward as mapping existing and desirable technology capabilities is complex, especially when it comes to capturing emerging technology areas that are very much evolving.

\section{Figure 12. Technology priorities identified in the Korean Post-COVID-19 Science and Technology Policy Direction for the Future}

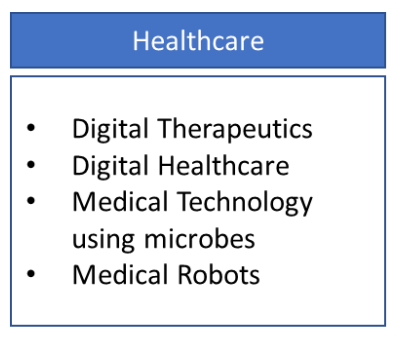

Transformation \& Logistics

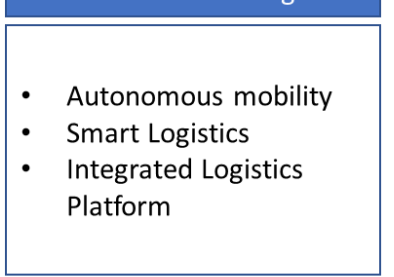

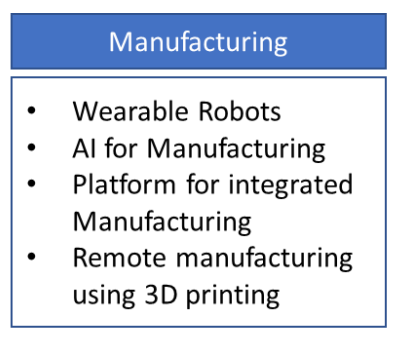

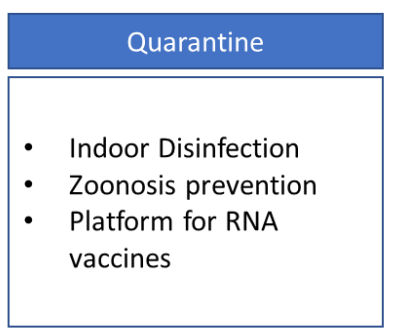

Education \& Culture

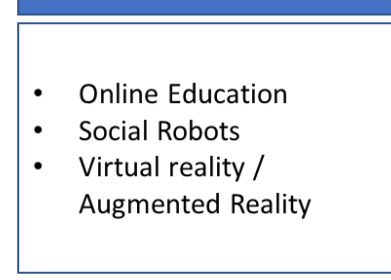

Energy \& Environment

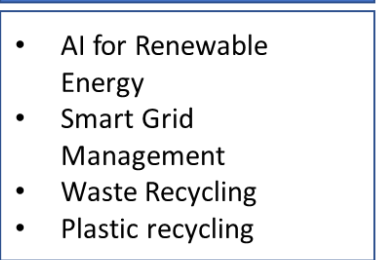

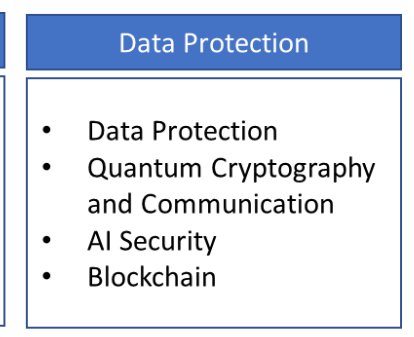

\begin{tabular}{|ll|}
\hline \multicolumn{1}{|c|}{ Digital } \\
\hline- & Digital Twins \\
- & Next generation \\
& Internet of Things \\
- & Next generation \\
& Communication \\
- & Next generation \\
& batteries \\
\hline
\end{tabular}

Source: Presentation of Ms Myong Hwa Lee during the OECD Workshop "Mobilising science in response to COVID-19", held virtually on 21 October 2020.

\subsection{Open questions on the new policy goals}

Setting policy goals in a context of the multiple objectives (which are supporting the economic recovery and contributing to build more resilient, sustainable and inclusive systems) requires identifying (or building) complementarities and decide on priority goals where trade-offs emerge. Just-in-time production illustrates the case of existing trade-offs between efficiency and resilience. While it increased efficiency in normal times and supported industrial competitiveness, some have argued this very success may have rendered value chains less resilient to the COVID-19 shock (Javorcik, 2020 [133]). Systematically mapping complementarities and trade-offs among policy goals is a first critical step towards making informed policy choices. Those policy choices will differ across countries as societal preferences may set different priorities.

The prioritization of specific goals is also needed to allow for decisions on the portfolio of public STI investments. Should there be no major increase in public STI funding in the future, the choice for more support in one research/technology area or sector implies necessarily less support for other research/technology areas or sectors. This relative choice is much harder to make than an absolute choice. In the aftermath of the COVID-19 crisis, health research on infectious diseases may be considered for more investments to be better prepared for future pandemics. If so, however, the question emerges as to whether this investment should be incurred if it reduces resources available for research in other fields 
such as cancer. Trade-offs also arise across fields: if overall funding for health research is increased, then research in other fields, such as research supporting more environmentally sustainable production mechanisms, may receive less funding. Concretely mapping the portfolio of public STI support and its priorities is consequently an important step.

Moreover, operationalising the new set of policy goals requires building metrics and lead indicators, particularly on resilience. The toolbox on indicators, while far from perfect, was built for efficiency and growth targets, notably productivity measures but also employment and turnover gains related to innovation. There are also many different ways to account for different dimensions related to "environmental sustainability". Targets range widely, and encompass a diversity of objectives including those related to greenhouse gas (GHG) emissions, air quality, energy use, water quality, waste generation and treatment, land use and biodiversity loss. Inclusiveness measures often include indicators on the distribution of income, including the Gini index, as well as indicators on the performance of disadvantaged socio-economic groups in socio-economic activities. Resilience, however, has so far not featured as a core policy objective in itself, except within the financial sector where a set of measures have been set up to build banks' resilience. This, however, does not easily translate into a target for the real economy. Key resilience targets need to be defined, and that will depend on what type of crisis resilience is sought and what approach is adopted towards reaching this resilience (for instance, measures tracking capacities in key technologies or the ability to adapt production to supply key essential goods).

Finally, another major question for implementation is about what mix of policy instruments and policy processes are most effective to reach those goals. The policy toolbox offers a variety of instruments that can be leveraged, most of which have been tested regarding their success in reaching productivity targets. Among those that are more directional, such as mission-oriented, industrial policy and smart specialisation strategies, the choice over those instruments also depends on what the optimal division of tasks across government, industry, research institutions and citizens is. The ideal policy aims to steer industry, research and citizens towards transitions while engaging in constant dialogue to solicit citizens' views to constantly refine specific objectives. Importantly, it also aims to allow research institutions and industry to experiment with different approaches (and technologies) to identify breakthroughs to advance the diverse societal missions. The model of the DARPA, a US research and defence agency that has been very successful in funding breakthrough innovation, is an example of how to achieve the latter. Copying the model to other country contexts has often been challenging.

\section{New ways of conducting STI policy}

The need for quick responses to the COVID-19 shock led to unprecedented experimentation with new approaches, tools and data sources for policy. These have distinct advantages and, if applied successfully, promise more effective and agile policies for the future.

\subsection{New data and better data analytics tools for STI policy}

The innovative tools used in the policy space reviewed in this section build on digital technologies, benefiting from the reduced costs of producing and handling information and the increased "fluidity" provided by these tools (Guellec and Paunov, 2018[95]). This "fluidity" (i.e. the fact that data can circulate and be reproduced, shared or manipulated instantaneously, on a huge scale and at little cost) was essential in the context of the pandemic, as policy decisions relied on the real-time data on the effects of the pandemic 
(incl. the incidence of new cases, hospitalisations) and also required quick policy responses. Moreover, digital communication tools have offered distinct opportunities for exchange, in spite of social distancing.

While some innovative tools revised here have not been yet applied to STI policy directly, they are nonetheless illustrative of the potential that these new applications offer in terms of providing 1) more granular, behavioural and timely data and 2) more opportunities for leveraging those data by using semantic analysis, big data analytics and visualisation tools.

\subsubsection{Granular, behavioural and timely data}

More granular, behavioural and timely data were used during the COVID-19 crisis to explore a wide range of impacts of the pandemic. An example is Google's mobility data, which - based on the profile of Google's Android platform users - revealed how lockdown measures affected mobility patterns in specific locations across countries. The data are interesting in that they provide information on actual behaviour, since they track movement based on mobile phone devices rather than (as would be the case with a survey) statements made by people regarding their mobility. In addition, data from job portals were used to provide more speedy information on how hiring across sectors and professions was evolving in the context of the COVID-19 pandemic. Social media data (e.g. from Twitter) were also exploited to gather insights on citizens' well-being and concerns during COVID19 (see examples in Section 4.1.2).

Provided privacy and security concerns are addressed, collecting and exploiting granular data on topics related to innovation is relevant to better inform STI policy. Insights gathered through such exercises could range from understanding citizens' views on STI based on social media data, to understanding the evolution of local employment in STI in response to STI policy actions, such as the implementation of specific regional smart specialisation policies, based on job portal information. Behavioural data on innovative firms includes tracking the evolution of operational expenditures - such as electricity - to learn about whether they ceased operations before identifying filing for bankruptcy to emerge on official statistics (e.g. see Crane et al. $\left(2020_{[134]}\right)$. Granular information on impacts can spur experimentation for policy purposes and support better understanding of the challenges related to inclusive STI. Having more granular and real-time information regarding the impacts of the crisis across people, sectors and regions would allow for more targeted policy responses.

Since the start of the pandemic, the wealth of information on COVID-19 has also resulted in the wider use of new tools to track developments related to the pandemic, leveraging the potential of web crawlers. This included efforts to provide such data in machine-readable format to facilitate the use of data science techniques to analyse those data. An immediate set of applications pooled various information sources to track COVID-19 cases, hospitalisations and deaths. One such tool was the COVID-19 Data Repository, developed by the Centre for Systems Science and Engineering at John Hopkins University, which since early 2020 has used mostly automated processes to aggregate daily data on cases and deaths from public health authorities worldwide (Dong, Du and Gardner, 2020 ${ }_{[135]}$ ). This came to be of central importance as the evolution of case numbers directly affected social distancing measures, including lockdown decisions. Also, numerous policy trackers have been launched to provide information on country responses in different policy areas, as reported in the Oxford Supertracker - an online directory of policy trackers related to COVID-19 across countries (Daly et al., 2020 $0_{[136]}$ ). Such trackers differ significantly in terms of policy fields, country coverage and the type of information given. Some of them provide structured information on policy measures adopted across countries in (qualitative) text-based format (such as the OECD's STIP COVID-19 Tracker) while others provide 
quantitative information through indicators of inputs (expenditure, benefit generosity) or outcomes (unemployment rate, poverty rate, GDP decline). Some of these trackers, such as COVID Scholar, use automated search engines to generate daily statistics; others, like the Oxford Government Response Tracker, are updated on a weekly basis by volunteer students and researchers. Governments have used data from these trackers to better understand the impact of COVID-19 response policies. For instance, the COVID-19 Stringency Index developed by the Oxford Government Response Tracker which gathers data on lockdown measures was used by the UK's Office for National Statistics to evaluate the impact of containment measures on retail turnover in the EU and G7 (Khaliq, $2021_{[137]}$ ). Structured machine-readable open datasets of government interventions, such as the one produced by Desvars-Larrive et al. $\left(2020_{[138]}\right)$, offer opportunities for applying data science techniques to cross-country policy analysis.

The COVID-19 crisis has also resulted in more experimentation with rapid surveys of firms and citizens, leveraging the possibilities of digital tools to reach out to respondents and collect and analyse responses. Pulse surveys (or rapid response surveys) with a reduced number of targeted questions became more common during the pandemic as a means of collecting near-real-time snapshots of the impact of the crisis, and tracking their evolution over time. For instance, the US Census Bureau launched the Small Business Pulse Survey to collect weekly information on the challenges faced by small businesses during the pandemic, with a high level of geographical and sectoral detail (US Census Bureau, $\left.2020_{[139]}\right)$. Responses are linked to statistical information about the respondents (e.g. location, firm size and sector of activity) collected previously through traditional census or business surveys.

There have also been survey efforts across many countries that produced timely and very granular information on how people's social and economic lives were affected by the pandemic, including surveys of researchers. An example on the social effects is the Household Pulse Survey of the US Census Bureau, which tracks the mental, social and economic health of citizens $\left(\mathrm{CDC}, 2020_{[140]}\right)$. More closely to STI, many surveys were implemented at different stages of the COVID-19 crisis to learn more about the impacts of the crisis on researchers, such as the OECD Science Flash Survey 2020 (OECD, 2020 [54]). These surveys looked into effects across different fields including medicine, neuroscience and STEM disciplines (Tiesmaki, 2020 [141] ; BNA, 2020 [142] ; Krukowski, Jagsi and Cardel, $\left.2021_{[143]}\right)$. Many also focused on understanding the effects across different socio-economic groups (Myers et al., 2020 $0_{[92]}$ ), including notably women (Deryugina, Shurchkov and Stearns, 2021 $1_{[144]}$; OWSD, 2020 ${ }_{[145]}$; Torres et al., $\left.2020_{[146]}\right)$, but also young researchers (Woolston, 2020 [147]).

Similarly, many quick surveys of entrepreneurs, start-ups and workers were conducted to learn about impacts, expectations and views on relief programmes, supporting immediate evidence to adjust policies as needed. For instance, an online survey conducted between March and April 2020 gathered information from 5,800 small businesses in the United States on the impacts of the COVID-19 crisis on businesses, their expectations as to future developments and their views on relief programmes. The researchers conducting the study partnered with Alignable -a network-based platform of 4.6 million small businesseswhich helped them contact its subscribers and invite them to complete the survey online (Bartik et al., 2020 $0_{[148]}$ ). Other surveys gathered perspectives from employees regarding possibly accelerated automation and shifts in skills needs. Deloitte, a consultancy, used an online tool to survey over 10,000 employees across seven European countries (France, Germany, Italy, Portugal, Poland, Spain and the United Kingdom) in July 2020. They gathered information on the impacts of the COVID-19 crisis on their work and what permanent changes they expected (e.g. the prevalence of flexible work arrangements, the potential further digitalisation of their work, the application of AI as well as skills 
requirements) (Gosling, Coppola and McCarthy, 2020 $\left.0_{[149]}\right)$. The Environics Institute for Survey Research, a Canadian non-profit, in partnership with the Future Skills Centre, an independent research institute affiliated with Ryerson University, and the Diversity Institute at Ryerson University, also surveyed 5,000 employees in early 2020 on how they perceived their employment situation but also their perspectives on new more flexible work arrangements, such as the wider use of digital tools for remote work, as well as their access to skills training to build stronger capabilities with modified workplace demands (Environics Institute for Survey Research, 2020[150]).

The types of data made available offer opportunities for better policies, providing, however, that there are efficient tools to build actionable policy evidence based on those data. We turn to those tools in the next section.

\subsubsection{Semantic analysis, big data analytics and visualisation of big data}

Among the tools to transform data into actionable policy evidence are semantic analysis, big data analysis and visualisation tools for big data, all of which have been used in the context of the COVID-19 crisis.

Visualisation tools to render large amounts of very granular data useful to policy have already been applied in the field of STI. For example, the US National Science Foundation developed a visualisation tool that clusters all NSF-funded research projects addressing the COVID-19 pandemic into groups of similar topics, based on the application of machinelearning techniques to abstracts of project proposals (Figure 13). The objective was to reduce risks of duplication in grant awards, facilitate the identification of synergies across projects, and offer a complete picture of the research areas being funded and their relative importance (Columbia University, 2020 ${ }_{[151]}$ ). Another example is SciSight, a visualisation tool that allows exploring a fast-evolving literature network on the pandemic posted on the COVID-19 Open Research Dataset (CORD-19). At the end of September 2020 this dataset contained over 200000 machine-readable scholarly articles on COVID-19 and related coronaviruses, including over 100000 with full text. The SciSight visualisation tool reveals which research groups are working in which directions, and their connections with each other.

Turning data into policy-relevant evidence, however, often is not simply a matter of visualisation, particularly as regards large qualitative information, but requires applications of semantic analysis. A group of researchers in Stanford University and Stony Brook University have applied large-scale analysis of linguistic patterns in Twitter to track the impacts of COVID-19 social distancing measures on mental health and affective well-being at the county level across the United States (SBU, 2020 $\left.{ }_{[152]}\right)$. In Japan, NTT Data and Citibeats -two data analytics companies- use artificial intelligence algorithms to analyse large-scale real-time qualitative data on opinions and concerns expressed by citizens on Twitter with regard to the COVID-19 pandemic, and track them over time (NTT Data, $\left.2020_{[153]}\right)$. 
Figure 13. Clusters map of NSF-funded research addressing the COVID-19 pandemic

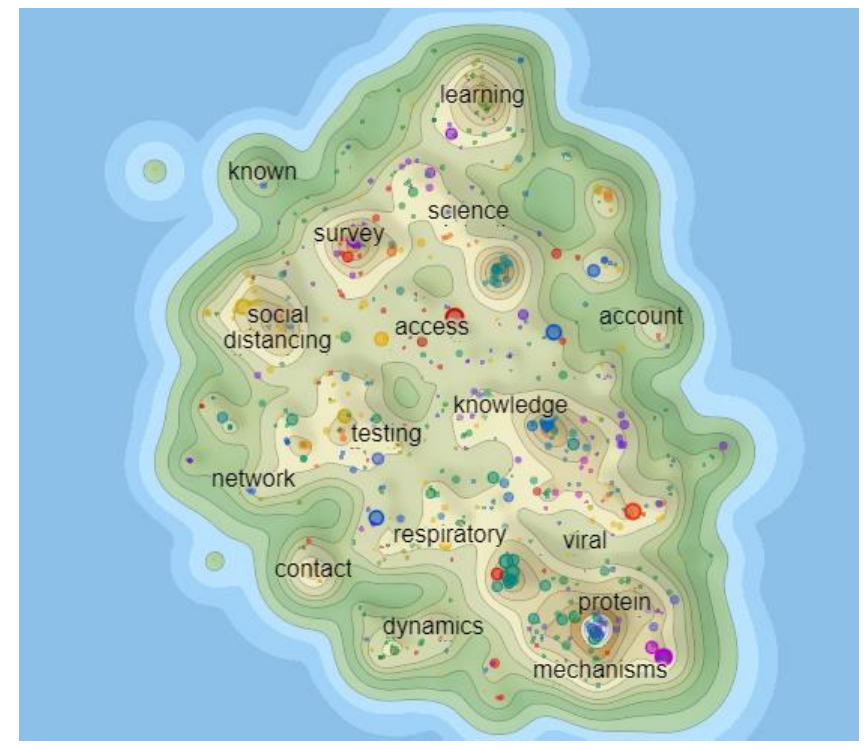

Note: The 2-dimensional map presents groups of related NSF-funded research projects addressing the COVID19 pandemic. The map was downloaded from the COVID Information Commons platform on 21 October 2020. The figure draws on 723 documents and 359 labels. Based on this exercise, 67 clusters have been identified. The platform allows exploring those different clusters.

Source: Columbia University $\left(2020_{[151]}\right)$.

In addition, new tools from data science, computer science and machine learning were also used to draw policy-relevant evidence from new big data sources. For instance, researchers at the Bank of England use machine learning for mining new data sources (e.g. restaurant bookings, public transportation apps, flight data, electricity use, job advertisement portals) to better understand the interaction between the macroeconomy and the pandemic. Using agent-based modelling frameworks, they simulate how the economic choices of individuals may change their risks of coming in contact with the virus (Gibney, 2020 $\left.0_{[154]}\right)$. In Austria, Invenium - a spinoff of the Graz University of Technology that works in partnership with the A1 Telekom Austria Group - developed a motion analysis application that models human mobility flows based on anonymised mobile phone data to inform about traffic congestion trends and tourist flows. In the COVID-19 context, the application was applied to assess the effectiveness of social distancing and restricted mobility measures introduced by governments (Invenium, 2020 $0_{[155]}$ ).

\subsection{Alternative policy approaches: Strategic foresight, systems transformation, and tracking applications}

A number of alternative policy approaches have also been experimented with more as a result of the COVID-19 crisis. They include strategic foresight, systems transformation approaches and the use of mobile apps for policy.

\subsubsection{Strategic foresight}

Strategic foresight, a structured way of exploring ideas about the future to anticipate and better prepare for change, may become more embedded in policy-making processes for better preparedness to future crises. The approach, which uses a range of methodologies, such as scanning the horizon for emerging changes, analysing megatrends and developing multiple scenarios $\left(\mathrm{OECD}, 2021_{[156]}\right)$, allows taking policy decisions and actions based on 
an understanding of the range of possible future developments (which may provide opportunities or challenges) and allows to future-proof strategies under rapidly changing conditions (OECD, 2020[157]).

In the COVID-19 context of high uncertainty, rapid change and growing complexity, several new strategic foresight initiatives are being implemented to inform policy making. For instance, the International Science Council -a non-governmental organisation representing science organisations across the world- launched in February 2021 a COVID19 scenarios project to explore a range of possible scenarios for the next 3 to 5 years, and on the implications of choices made by governments. The analysis will be conducted by a multidisciplinary oversight panel composed of international experts in relevant disciplines that will work with a technical team to produce the scenario map (Skegg et al., 2021 $1_{[158]}$ ).

While strategic foresight exercises are not new tools in the STI policy domain, their focus and their role in informing policy may change. In the past, their main focus in the field of STI has often been on forecasting emerging technology and research fields to support strategic planning and less so policy orientations in view of possible future socio-economic trends. The crisis may increase incentives for using them more systematically in STI policy to help policy makers prepare to strategically respond to a wide range of challenges that may emerge in the future, and detect early signals of those developments to provide timely responses.

A key objective in implementing strategic foresight would be to assess and monitor systems' vulnerabilities at regional, national and international levels and their interlinkages. The vulnerabilities can be at the social, economic, environmental, geopolitical and technological levels (e.g. biodiversity loss, pockets of poverty, infectious diseases, concentration of production of essential goods in a few suppliers, natural disasters and extreme weather events, water and food crises, aging populations, social unrest, cyber attacks), and are often highly interrelated. Detecting where vulnerabilities exist would help identify potential sources of future crises. The European Commission Expert Group on Economic and Societal Impact of Research \& Innovation (ESIR) recommended developing detailed "crisis maps" based on specialised knowledge and robust risk-assessment exercises (Dixson-Declève et al., 2020[159]).

Mini-scenarios could also be developed around key uncertainties (an expanded list of possible turning points, for example). These would offer plausible yet sufficiently divergent visions of the future that would aim to capture a wide range of possible developments. Such scenarios can be explored to identify possible STI system developments to inform STI policy responses. In addition, if combined with a monitoring tool built around key indicators, such an exercise can operate as an early warning system that alerts policy makers (and others) to possible future risks. It also allows decision makers to keep sight of the alternative pathways and outcomes they could pursue or would want to avoid. Indeed, the course of uncertainty is shaped by choices and in most cases it is possible to choose the direction to take to avoid some obviously bad choices and to pursue much more promising ones. Using multiple scenarios, the exercise should help governments systematically appraise a wide range of policy options for positively shaping the future state and dynamics of STI landscapes.

\subsubsection{Systems transformation approaches}

The COVID-19 crisis - as well as the 2008-09 global financial crisis - highlights the need for new approaches to better understand the nature of global challenges and articulate appropriate policy responses that take into account the complexity and interconnectedness of systems. Systems approach consists in setting policies considering that they are addressing issues that are part of a complex system of systems (economic, social, political, 
environmental, etc.), and that changes in one component may directly or indirectly shape impacts in other parts of the system (Hynes, Lees and Müller, 2020 ${ }_{[17]}$ ).

Efforts aimed at articulating policies in terms of systems rather than autonomous individual entities (or policy "silos") may consequently gain in importance, drawing on the new tools and data approaches discussed above. In May 2020, the European Commission expert group on ESIR - which brings together 15 European experts working on the links of R\&I policy to global and European social, economic, environmental and digital transformation - released a list of recommendations in view of implementing a systemic transformation. The group advocated that "the COVID-19 fiscal stimulus should be combined with the European Green Deal package and public policy across the board to craft an equitable, secure and sustainable system, fit for purpose in a digital age" (Dixson-Declève et al., $\left.2020_{[159]}\right)$.

Such systems approaches are not new to STI policy thinking; they form part of the major contributions of the OECD-TIP group since its very beginning (OECD, 2015 [11]; OECD, $2002_{[160]} ;$ OECD, 2001 ${ }_{[161]} ;$ OECD, 2001 $1_{[162]} ;$ OECD, 1999 [163]] $)$ However, applying systems perspectives to the post-COVID-19 STI policy agenda is not straightforward in practice. New approaches to policy that effectively account for system dependencies and enable real-time STI policy making to respond to future shocks have yet to be developed (Campolongo et al., 2020 [164]; Hynes, Lees and Müller, 2020 ${ }_{[17]}$ ).

Bringing about systems transformation requires a different type of government action, aimed at setting incentives to steer the economy towards different trajectories. STI policies have traditionally been implemented in response to a number of "failures" that affect research and innovation ecosystems, and that may result in weaker innovation performance than would be desirable from a societal perspective. The shock of COVID-19 has drawn greater attention to other emerging crises, notably the risks of climate change, and demonstrated that more needs to be done than just supporting business conditions and addressing market failures.

Developing balanced and well-aligned policy mixes is critical in this regard, as discrete policy interventions are unlikely to steer systems change on their own. Even when single instruments succeed, they may result in unintended consequences and shift problems elsewhere in the system. Alignment is needed not only among innovation policies but also with other policy domains (e.g. research, education, competition, tax). In the past, intergovernmental committees and platforms have been used in many countries to ensure co-ordination among multiple policy instruments.

The implementation of systems approaches will also require using the new tools and data outlined in the previous section. In particular, combining different new (and old) data to map entire systems at granular levels and in real time would allow capturing system dependencies. Detecting where vulnerabilities exist would help identify sources of future crises, complementing foresight activities. Such mapping would also help understanding how policies targeting one area affect others. While such mappings exist they are currently models, while in principle big data capacities would allow mapping the actual system.

International co-operation in policy making will also be critical in implementing systems transformation. The COVID-19 pandemic has shown that countries cannot tackle global challenges on their own and that responses will not be effective unless implemented in a co-ordinated fashion across borders, as systems are closely interconnected. Such collaboration is critical if global public goods (e.g. global public health, the environment) are to be protected. At the same time, sharing experiences internationally can also facilitate policy learning, extend policy horizons, and improve impact over time. 


\subsubsection{Mobile applications as a model for new granular policy action}

New policy approaches included investment in contact tracing applications, which follow the movement of people and allow identifying those that may have been in contact with an infected individual. These were developed in many countries to monitor and thereby contain the spread of the virus, although the apps were not widely adopted (Howell O'Neill, Ryan-Mosley and Johnson, 2020 [165] $)$.

The use of such tools by policy makers opens a wide range of options. Possible types of data that could be applied to STI include tracking the purchase of core technologies across companies and consumers to understand technology diffusion and barriers to such diffusion. Such tracking could also reveal what happens to diffusion in times of shocks and when there are mechanisms in place to resolve possible bottlenecks.

Low uptake rates of these applications point to the diverse set of socio-technical challenges that need to be addressed before their effective use. Major reasons for low uptake rates were prospective users' privacy concerns about sharing health and location information and the limited integration of applications to national health-care systems was another challenge (e.g. when users are tested positive, they need to manually introduce this information in the app for close contacts to be notified) (Lewis, 2020 [166]; Lewis, 2021 ${ }_{[167]}$ ).

\subsection{New governance models and the importance of civil society engagement}

Governance models for STI may change based on the COVID-19 experience, as the pandemic led to more intensive civil society and industry involvement compared to the preCOVID-19 period and highlighted the importance of improving intergovernmental coordination and science communication.

Civil society participation in STI policy is different from the pre-COVID-19 experience. First, private foundations - such as the Bill and Melinda Gates Foundation and the Wellcome Trust - were prominent actors with financial and social leverage regarding vaccine and treatment development, and helped articulate societal demands in national and international debates. Second, civil society actions - such as implementing social distancing and community engagement in grassroots innovation to respond to emergency supply shortages - proved critical since the start of the COVID-19 crisis in complementing the actions by markets and governments to fight the pandemic (Figure 14) (Bowles and Carlin, 2020 $\left.0_{[168]}\right)$. For instance, Coronavirusmakers was an open source community in Spain founded in March 2020 by civil society that gathered more than 20000 volunteer researchers, developers and engineers. With the support of firms, public administration and foundations, by 15 May 2020 the group had produced more than 840000 face shields and 123000 hands-free door openers.

Industry also played a prominent role during COVID-19, by engaging in research and innovation efforts to develop vaccines, treatments and diagnostics, but also in responding to COVID-19-related challenges such as shortages in critical medical equipment due to disruptions in global supply chains. New governance models in the post-pandemic period should enhance collaboration between governments and industry, further exploiting possibilities to set up public-private partnerships that allow pooling resources and capacities as well as sharing risks and rewards. This will be particularly critical given constrained public budgets. Industry will also play a central role in shaping transitions towards more resilient and sustainable systems.

Establishing mechanisms for multi-stakeholder engagement can be key to overcoming resistance to change, often an important barrier to systems transformation. Such mechanisms help build trust, create a shared and comprehensive vision of the 
transformation, and facilitate the co-ordination of actions in the right direction (PlanesSatorra and Paunov, 2019[56]). This could include involving key stakeholders (including from industry, academia, philanthropies and citizens) in roadmapping in multi-stakeholder platforms or forums for discussion (e.g. Plattform Industrie 4.0 in Austria and Germany), and involving citizens in the process of validating new technology solutions. For instance, the development of the Automotive Technology Roadmap to foster the transition towards low-carbon vehicles in the United Kingdom involved the senior level from business and research institutes to ensure that the outcome represented an industry-wide view (Automotive Council UK, 2018 ${ }_{[169]}$ ). The strategic innovation programme Bioinnovation in Sweden - aimed at fostering the transition towards a bio-based economy by 2050 promotes the active engagement of users to ensure the market relevance of innovation projects (BioInnovation, 2018 ${ }_{[170]}$ ).

Figure 14. An expanded space for policy and economic discourse

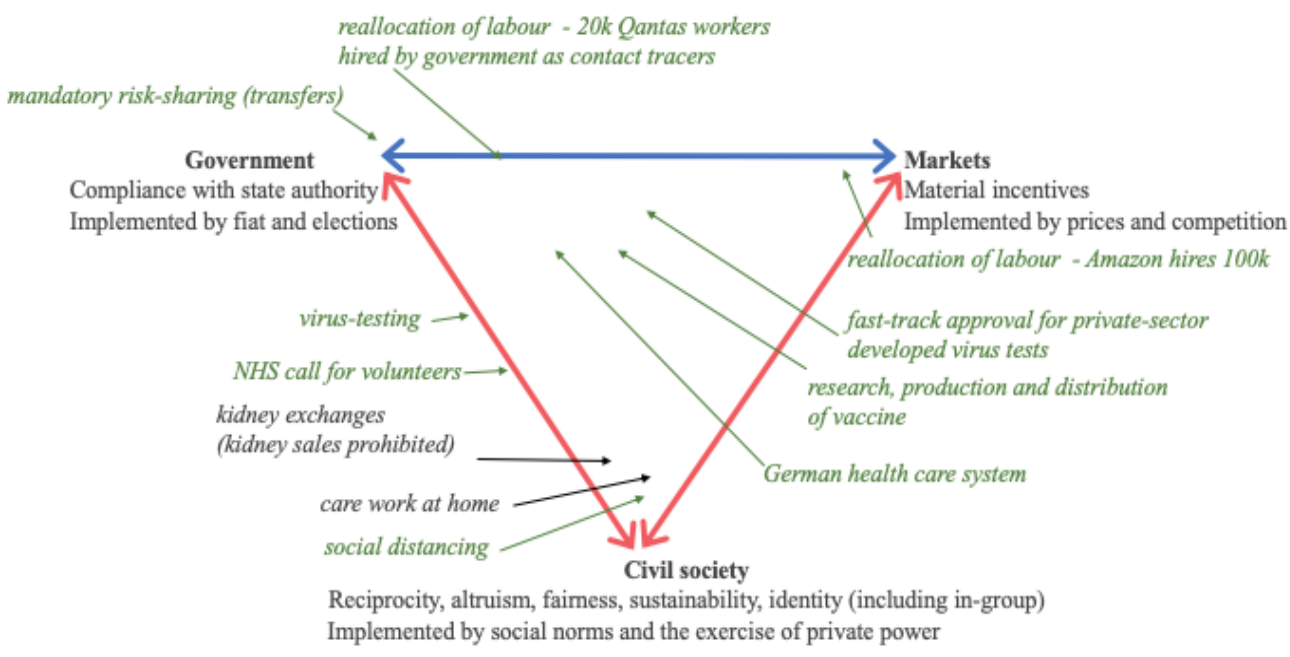

Note: The figure illustrates the location in "institution-space" of different responses to the epidemic. The blue line at the top is the government-versus-market continuum of choices that has dominated policy debates over the past century. The green arrows place COVID-19 related policies in the space; the black arrows are other examples. At the top left is the government as the insurer of last resort. Closer to the civil society pole are social distancing policies implemented through consent. An example is the public-spirited mobilisation by universities and small private labs of efforts to undertake production and processing of tests and to develop new machines to substitute for scarce ventilators.

Source: Bowles and Carlin (2020[168]).

The importance of intergovernmental co-ordination and collaboration at vertical and horizontal levels has also been made evident during the pandemic. At the vertical level, articulating policy decisions at local, regional, national, transnational and international levels was a major task. Municipalities, public utilities, public hospitals, national regulatory agencies, philanthropies and citizens play key roles in bringing new technological and innovative solutions to life, particularly those aimed at addressing societal challenges. Similarly, the COVID-19 crisis also required whole-of-government approaches to respond optimally. While the ministries of health played a central role in managing the crisis, the widespread impacts required close co-ordination with other areas of government and other institutions.

Moreover, citizen engagement is also critical to ensure that policy measures have their intended effects, and thus establishing mechanisms for dialogue with civil society actors is essential. For instance, the success of many "social confinement" measures implemented 
by governments - such as home confinement, curfews, and obligatory use of masks in public spaces - depends on the engagement of civil society. So does the successful roll-out of vaccines as these become available (Ann Burgess et al., 2020 ${ }_{[171]}$ ). Addressing public mistrust in government institutions and on science is a key priority in this regard. In the aftermath of the crisis, new governance models may emerge especially in view of the need to engage diverse actors of the STI ecosystem in building more resilient, environmentally sustainability and inclusive systems. Lessons from experimental approaches that allow the participation of civil society in systems' innovation processes could be explored, such as:

- Citizens' assemblies - These are representative groups of citizens who are selected at random from the population to learn about, deliberate upon, and make recommendations in relation to particular issues or a set of issues. In response to the crisis, citizens' assemblies were convened in many countries at local and regional levels. For instance, Climate Assembly UK, a national citizens' assembly convened before the crisis to discuss climate change, passed an additional suite of recommendations on sustainability in the context of the country's recovery from COVID-19.

- Deep demonstration programmes ${ }^{4}$ - These are test beds for systemic innovation led by EIT Climate-KIC. They start with a demand-led approach, working with city authorities, regional bodies, governments or industry leaders committed to zero-net emissions and resilient futures. Through a systems innovation approach, EIT Climate-KIC matches this demand with supply, bringing together different stakeholders to tackle multiple levers of change simultaneously through rapid experiments (EIT Climate-KIC, 2020 [172]).

- Warm data $l a b s^{5}$ - These are group processes, which highlight interdependency and generate understanding of systemic patterns for people with no previous exposure to systems theory. As a tool for revealing relationships that are integral and woven into the complex fabric of the issues worked on, the Warm Data Lab process allows participants to see new patterns and causations, and to respond to them with a much broader comprehension. In this way, the Warm Data Lab enables new societal responses to complex challenges (Warm Data, 2020 $0_{[173]}$ ).

As suggested by Sandrine Dixson-Declève, Chair of the European Commission Expert Group on ESIR, pilot programmes could be implemented at local and national levels, equipped with appropriate reporting, monitoring and feedback mechanisms in place to enable continuous policy learning and improvements.

\subsection{Implementation challenges for new policy tools}

As illustrated by the experiments during the COVID-19 crisis discussed above, new big data and digital tools can allow collecting and gather better data (e.g. granular timely behavioural data) to detect, monitor and communicate developments and produce timely policy-relevant evidence. These data and tools could help map system dependencies, alert to shocks, and communicate real-time impacts of possible future shocks at a granular level. These data and tools could also support the application of unconventional policy approaches, such as strategic foresight and systems transformation as well as the use of mobile apps.

Leveraging new data and tools to implement more agile and responsive policies to reach the new goals requires however important investments. This includes investments in the right infrastructure of data management systems and information services. Such infrastructure needs to be fine-tuned to best serve policy needs. It also needs to be 
technically and scientifically sound to ensure its legitimacy. Guaranteeing data privacy and safety as well as the security of tools from manipulation is also an important dimension (Letouzé et al., 2020[174]). Training of government officials in how to use those data and tools is another critical component of infrastructure investments.

Building these policy infrastructures requires collaborations across government, research institutions and industry. This implies finding effective ways to exchange across different fields of expertise ranging from thematic policy knowledge to technical know-how, and constitutes an important challenge for the development of AI-based policy applications (Mateos-Garcia, Klinger and Stathoulopoulos, 2020 $\left.0_{[175]}\right)$. Moreover, effective publicprivate partnerships are needed in view of applying the capacities of the private sector to optimise tools for policy purposes and leveraging data collected by the private sector. This may involve developing clear, sustainable business models that create incentives for the private sector to generate reliable data and indicators (e.g. offering fiscal incentives for indicator sharing) of relevance to the public sector.

Initial public investments in accelerating the adoption of new data and tools in response to COVID-19 have been undertaken. In March 2020 for example, the Portuguese Foundation for Science and Technology (FCT) launched the AI 4 COVID19, a competition with a budget of EUR 3 million (USD 3.6 million) for R\&D projects in the field of data science and AI that help improve the response of public administration bodies to the impact of COVID-19 and future pandemics.

Finally, applying such technologies for policy purposes will also require ensuring building trust and societal acceptance around them. Decisions taken with the support of AI tools should be explainable and transparent to citizens. Such tools should not replace but support human evidence-based decision-making, and should be permanently monitored to ensure they do not reproduce biases or pose risks for data privacy and safety.

\section{Conclusion: What speed and directions for innovation in the future?}

This paper discusses the effects that the COVID-19 crisis could have on the future of STI and its policies. It illustrates the array of possible future scenarios for STI and the direct or indirect effects these could have for different actors and the functioning of STI systems. These will in turn critically affect the speed and directions of innovation in the future as well as its impacts on wellbeing and market dynamics.

The direction of developments will be shaped by the evolution across the different dimensions explored in this paper. These include the effects of the crisis on future STI spending, with implications for businesses, public research institutions and the STI labour force; the accelerated digitalisation of science and innovation; the future openess and inclusiveness of STI ecosystems, with implications at social, industrial and territorial level; the role of global collaborations; possible changes in STI policy goals and priorities, with sustainability, inclusiveness and resilience gaining relevance in policy agendas but possibly facing trade-offs; the increased experimentation with data and tools used for policy purposes, as well as the implementation of new policy approaches and governance models.

While some developments remain highly uncertain, such as the duration of the pandemic or its longer term effects on individuals' consumption patterns and preferences, the STI systems of the future will largely be shaped by the policy choices made today and in the months to come. In this context, STI policy making should be based on a comprehensive vision of the complexity of ongoing developments and intertwined effects across different parts of the system. 
Future work should continue to explore the possible long-term impacts of ongoing developments to best inform policy today. Efforts should also continue to be devoted to monitor the immediate effects of the crisis on the multiple dimensions and actors that conform STI systems, as done by Paunov and Planes-Satorra $\left(2021_{[1]}\right)$ for the 2020 period. In-depth assessments of the impacts of the crisis on STI systems embedded in a forwardlooking perspective will also be important to optimise future STI policies. 


\section{References}

Acemoglu, D. (2020), Antitrust Alone Won't Fix the Innovation Problem by Daron Acemoglu, Project Syndicate, https://www.project-syndicate.org/commentary/google-antitrust-big-tech-hurdle-toinnovation-by-daron-acemoglu-2020-10 (accessed on 5 November 2020).

Aghion, P. et al. (2020), Masques, respirateurs, tests... Pourquoi la France doit repenser sa politique industrielle après la crise du coronavirus | la vie n'est pas un cadeau!, https://eldiabloisakiller.blogspot.com/2020/04/masques-respirateurs-tests-pourquoi-la.html (accessed on 29 May 2020).

Agrawal, M. et al. (2020), "Industry 4.0: Reimagining manufacturing operations after COVID-19", McKinsey, https://www.mckinsey.com/business-functions/operations/our-insights/industry-40reimagining-manufacturing-operations-after-covid-19 (accessed on 28 October 2020).

Ann Burgess, R. et al. (2020), "The COVID-19 vaccines rush: participatory community engagement matters more than ever", The Lancet, Vol. 397, pp. 8-10, http://dx.doi.org/10.1016/So140-6736(20)32642-8.

ASAPbio (2020), Preprints and Rapid Communication of COVID-19 research, https://asapbio.org/preprints-and-covid-19 (accessed on 22 October 2020).

Australian Government (2020), Budget Paper No. 1 | Budget 202O-21, https://budget.gov.au/202021/content/bp1/index.htm (accessed on 10 March 2021).

Automotive Council UK (2018), New Automotive Technology Roadmap Launched, https://www.automotivecouncil.co.uk/2018/07/new-automotive-technology-roadmap-launched/ (accessed on 19 November 2020).

Bank of Japan (2021), Bank of Japan Accounts (Every Ten Days), https://www.boj.or.jp/en/statistics/boj/other/acmai/index.htm/ (accessed on 26 March 2021).

Bartik, A. et al. (2020), The impact of COVID-19 on small business outcomes and expectations, National Academy of Sciences, http://dx.doi.org/10.1073/pnas.2006991117.

Be the business (2020), The UK's technology moment - why 2020 can be the year that changed our trajectory on tech - Be the Business, Be the business and McKinsey, https://www.bethebusiness.com/media/the-uks-technology-moment-why-2020-can-be-the-year-thatchanged-our-trajectory-on-tech/ (accessed on 5 October 2020).

Béné, C. et al. (2012), "Resilience: New Utopia or New Tyranny? Reflection about the Potentials and Limits of the Concept of Resilience in Relation to Vulnerability Reduction Programmes", IDS Working Papers, Vol. 2012/405, pp. 1-61, http://dx.doi.org/10.1111/i.2040-0209.2012.00405.x.

BioInnovation (2018), BioInnovation, https://www.bioinnovation.se/in-english/ (accessed on 15 February 2019).

Blake, P. and D. Wadhwa (2020), 2020 Year in Review: The impact of COVID-19 in 12 charts, World Bank Blogs, https://blogs.worldbank.org/voices/2020-year-review-impact-covid-19-12-charts (accessed on 11 January 2021).

BNA (2020), The future of neuroscience research after COVID-19 - Summary of survey results, 18 June 202O, British Neuroscience Association, https://www.bna.org.uk/resources/258/download/ (accessed on 10 March 2021).

Borowiecki, M. et al. (2019), "Supporting research for sustainable development”, OECD Science, Technology and Industry Policy Papers, No. 78, OECD Publishing, Paris, https://www.oecd-ilibrary.org/scienceand-technology/supporting-research-for-sustainable-development 6c9b7be4-en (accessed on 16 October 2020).

Bowles, S. and W. Carlin (2020), The coming battle for the COVID-19 narrative, VOX, CEPR Policy Portal, 
https://voxeu.org/article/coming-battle-covid-19-narrative (accessed on 3 June 2020).

Brunnermeier, M. (2009), "Deciphering the Liquidity and Credit Crunch 2007-2008”, Journal of Economic Perspectives, Vol. 23/1, pp. 77-100, http://dx.doi.org/10.1257/jep.23.1.77.

Bryan, K., J. Lemus and G. Marshall (2020), Innovation During a Crisis: Evidence from Covid-19, https://papers.ssrn.com/sol3/papers.cfm?abstract id=3587973 (accessed on 20 May 2020).

Brynjolfsson, E., X. Hui and M. Liu (2018), "Does Machine Translation Affect International Trade? Evidence from a Large Digital Platform", NBER Working Papers, No. 24917, National Bureau of Economic Research, Cambridge, MA, http://dx.doi.org/10.3386/w24917.

Buchheim, L. et al. (2020), Sentiment and Firm Behavior During the COVID-19 Pandemic, https://covid19.iza.org/wp-content/uploads/2020/10/Sentiment-and-Firm-Behavior-During-the-COVID-19Pandemic.pdf (accessed on 16 March 2021).

Byrne, P., N. Kraemer and E. Gunter (2020), Market Liquidity In A Crisis: Five Key Lessons From COVID19 | S\&P Global Ratings, https://www.spglobal.com/ratings/en/research/articles/200716-marketliquidity-in-a-crisis-five-key-lessons-from-covid-19-11573666 (accessed on 10 March 2021).

Campolongo, F. et al. (2020), Time for transformative resilience: The COVID-19 emergency, Publications Office of the European Union, Luxembourg, https://op.europa.eu/en/publication-detail/Lpublication/fa410do3-8379-11ea-bf12-01aa75ed71a1/language-en (accessed on 19 May 2020).

CDC (2020), Novel COVID-19 survey takes nation's social, mental "Pulse”, https://www.cdc.gov/coronavirus/2019-ncov/communication/accomplishments/pulse-survey.html (accessed on 4 November 2020).

Chen, H. et al. (2021), "A cross-country core strategy comparison in China, Japan, Singapore and South Korea during the early COVID-19 pandemic”, Globalization and Health, Vol. 17/1, p. 22, http://dx.doi.org/10.1186/s12992-021-00672-w.

Chopoorian, R. and D. Gross (2021), Pfizer's vaccine machine, strategy+business, https://www.strategybusiness.com/article/Pfizers-vaccine-machine?gko=b14bo (accessed on 1 March 2021).

Columbia University (2020), Covid Information Commons, https://covidinfocommons.datascience.columbia.edu/ (accessed on 21 October 2020).

Committee for a Responsible Federal Budget (2020), How Does COVID Relief Compare to Great Recession Stimulus?, http://www.crfb.org/blogs/how-does-covid-relief-compare-great-recession-stimulus (accessed on 19 October 2020).

Committee for a Responsible Federal Budget (2020), The Fiscal Response to COVID-19 Will be Larger than the Great Recession Response, https://www.crfb.org/blogs/fiscal-response-covid-19-will-be-largergreat-recession-response (accessed on 31 March 2021).

Company, M. (2020), COVID-19: Implications for business, December 202O, Executive briefing, McKinsey \& Company, https://www.mckinsey.com/business-functions/risk/our-insights/covid-19-implicationsfor-business (accessed on 9 October 2020).

Crane, L. et al. (2020), "Business Exit During the COVID-19 Pandemic: Non-Traditional Measures in Historical Context”, Finance and Economics Discussion Series, No. 089, Board of Governors of the Federal Reserve System, Washington, http://dx.doi.org/10.17016/feds.2020.089.

CSIRO (2021), Partner with us to tackle Australia's greatest challenges - CSIRO, CSIRO, https://www.csiro.au/en/about/challenges-missions (accessed on 22 March 2021).

Daimler (2021), Annual report \& full year results 2020, https://www.daimler.com/investors/reportsnews/annual-reports/2020/ (accessed on 26 February 2021).

Dai, Q., E. Shin and C. Smith (2018), “Open and inclusive collaboration in science: A framework”, OECD Science, Technology and Industry Working Papers, No. 2018/07, OECD Publishing, Paris, https://dx.doi.org/10.1787/2dbff737-en.

Daly, M. et al. (2020), Oxford Supertracker: The Global Directory for COVID Policy Trackers and Surveys, [136] Department of Social Policy and Intervention., https://supertracker.spi.ox.ac.uk/ (accessed on 
4 September 2020).

Demmou, L. et al. (2021), Insolvency and debt overhang following the COVID-19 outbreak, VOX, CEPR Policy Portal, https://voxeu.org/article/insolvency-and-debt-overhang-following-covid-19-outbreak (accessed on 10 March 2021).

Deryugina, T., O. Shurchkov and J. Stearns (2021), “COVID-19 Disruptions Disproportionately Affect Female Academics”, NBER Working Papers, No. 28360, National Bureau of Economic Research, Cambridge, MA.

Desvars-Larrive, A. et al. (2020), "A structured open dataset of government interventions in response to COVID-19”, Scientific Data, Vol. 7/1, p. 285, http://dx.doi.org/10.1038/s41597-020-00609-9.

Dixson-Declève, S. et al. (2020), "Protect, prepare and transform Europe: Recovery and resilience post Covid-19”, ESIR Policy Brief, No. 1, European Commission - Directorate-General for Research and Innovation, Brussels, https://ec.europa.eu/info/sites/info/files/research_and_innovation/groups/esir/ec_rtd_esir-recoveryresilience-covid19.pdf (accessed on 9 June 2020).

Dong, E., H. Du and L. Gardner (2020), "An interactive web-based dashboard to track COVID-19 in real time”, The Lancet Infectious Diseases, Vol. 20/5, pp. 533-534, https://doi.org/10.1016/S14733099(20)30120-1.

Eastermann, T. (2020), University funding amid the coronavirus pandemic: lessons learnt from the 2008 global economic crisis, https://www.eua.eu/resources/expert-voices/165-university-funding-amid-thecoronavirus-pandemic-lessons-learnt-from-the-2008-global-economiccrisis.html?utm source=social\&utm medium=Twitter\&utm name=Twitter-social-23-4-2020 (accessed on 7 May 2020).

Edler, J. et al. (2020), Technology sovereignty. From demand to concept, Fraunhofer Institute for Systems and Innovation Research ISI, Karlsruhe, https://www.isi.fraunhofer.de/content/dam/isi/dokumente/publikationen/technology_sovereignty.pdf (accessed on 9 October 2020).

EIT Climate-KIC (2020), Deep Demonstrations, https://www.climate-kic.org/programmes/deepdemonstrations/ (accessed on 18 November 2020).

Elgin, C., G. Basbug and A. Yalaman (2020), "Economic policy responses to a pandemic: Developing the COVID-19 Economic Stimulus Index", Covid Economics. Vetted and Real-time Papers, Vol. 3, pp. 50-54, http://web.boun.edu.tr/elgin/COVID 19.pdf (accessed on 10 March 2021).

Emilia Romagna Government (2020), Montagna 2020, https://territorio.regione.emilia-romagna.it/bandidi-gara/montagna-2020 (accessed on 22 March 2021).

Environics Institute for Survey Research (2020), Canadians'Shifting Outlook on Employment 202O: Survey on Employment and Skills (Preliminary Report), https://fsc-ccf.ca/wpcontent/uploads/2020/06/Skills-report-ENG-June-3.pdf (accessed on 10 March 2021).

European Central Bank (2021), Eurosystem consolidated statement - Eurosystem balance sheet - ECB Statistical Data Warehouse, https://sdw.ecb.europa.eu/browse.do?node $=9691294$ (accessed on 26 March 2021).

European Commission (2021), Preparing Europe for the increased threat of variants, https://ec.europa.eu/commission/presscorner/detail/en/ip_21_641 (accessed on 25 February 2021)

European Commission (2020), 2020 Strategic Foresight Report: Charting the course towards a more resilient Europe, https://ec.europa.eu/info/strategy/priorities-2019-2024/new-push-europeandemocracy/strategic-foresight/2020-strategic-foresight-report en (accessed on 18 November 2020).

European Commission (2020), Europe's moment: Repair and Prepare for the Next Generation [COM(2020) 456 final], European Commission, Brussels, https://eur-lex.europa.eu/legalcontent/EN/TXT/PDF/?uri=CELEX:52020DC0456\&from=EN (accessed on 13 November 2020).

European Commission (2020), EUvsVirus: from ideas to solutions, European Commission, https://www.euvsvirus.org/finalreport.pdf (accessed on 4 June 2020). 
European Commission (2020), Smart Story: Turning the COVID-19 threat into an opportunity for $S_{3}$ : transformation of industrial sectors in the Valencian Community, https://s3platform.jrc.ec.europa.eu//turning-the-covid-19-threat-into-an-opportunity-for-s3-transformation-of-industrial-sectors-in-thevalencian-community?inheritRedirect=true (accessed on 22 March 2021).

European Committee of the Regions (2020), The Coronavirus crisis and the role of EU regions and cities, European Committee of the Regions, https://cor.europa.eu/en/ourwork/EURegionalBarometerDocs/CoR_Report_final.pdf (accessed on 16 October 2020).

Federal Reserve Bank of Atlanta (2020), Businesses Anticipate Slashing Postpandemic Travel Budgets, https://www.frbatlanta.org/blogs/macroblog/2020/08/04/businesses-anticipate-slashingpostpandemic-travel-budgets.aspx (accessed on 8 October 2020).

Federal Reserve Board (2021), Federal Reserve Board - Recent balance sheet trends, https://www.federalreserve.gov/monetarypolicy/bst_recenttrends.htm (accessed on 26 March 2021).

Fernald, J., H. Li and M. Ochse (2021), Future Output Loss from COVID-Induced School Closures, Federal Reserve Bank of San Francisco Economic Letter, https://www.frbsf.org/economicresearch/publications/economic-letter/2021/february/future-output-loss-from-covid-induced-schoolclosures/ (accessed on 10 March 2021).

Fitter, E. and K. Kelly (2020), Bank Earnings Show Diverging Fortunes on Wall Street and Main Street The New York Times, The New York Times, https://www.nytimes.com/2020/10/14/business/bankearnings-wall-street-coronavirus.html (accessed on 6 November 2020).

Gibney, E. (2020), “This physicist-turned-economist is modelling the pandemic's financial fallout”, Nature, Vol. 581/7807, https://doi.org/10.1038/d41586-020-01338-o (accessed on 3 June 2020).

Goedhart, M., T. Koller and P. Stumpner (2020), Wall Street versus Main Street: Why the disconnect?, McKinsey \& Company, https://www.mckinsey.com/business-functions/strategy-and-corporatefinance/our-insights/wall-street-versus-main-street-why-the-disconnect (accessed on 10 March 2021).

Gonne, N., K. Kitazawa and G. Lalanne (forthcoming), “A fresh look at industrial policies: old debates, new perspectives”, Science, Technology and Industry Policy Papers, OECD Publishing, Paris, https://www.oecd-ilibrary.org/science-and-technology/oecd-science-technology-and-industry-policypapers_23074957 (accessed on 29 March 2021).

Gosling, W., M. Coppola and K. McCarthy (2020), May the workforce be with you The voice of the European workforce 2020, Deloitte Insights, https://www2.deloitte.com/xe/en/insights/focus/technology-and-the-future-of-work/impact-covid-19european-workforce.html (accessed on 10 March 2021).

Gourinchas, P. et al. (2021), COVID-19 and SMEs: A 2021 "Time Bomb"?, National Bureau of Economic Research, Cambridge, MA, http://dx.doi.org/10.3386/w28418.

Gouvernement.fr (2020), Présentation du Haut-Commissariat au Plan, https://www.gouvernement.fr/haut-commissariat-au-plan/presentation (accessed on 18 November 2020).

GOV.UK (2020), PM commits $£ 35$ o million to fuel green recovery, https://www.gov.uk/government/news/pm-commits-350-million-to-fuel-green-recovery (accessed on 2 November 2020).

Government of Korea (2020), Korean New Deal: National Strategy for a Great Transformation, Ministry of Economy and Finance, http://english.moef.go.kr/pc/selectTbPressCenterDtl.do?boardCd=Noo01\&seq $=4948$ (accessed on 21 October 2020).

Guellec, D. and C. Paunov (2018), "Innovation policies in the digital age”, OECD Science, Technology and Industry Policy Papers, No. (forthcoming).

Guellec, D. and C. Paunov (2018), "Innovation policies in the digital age”, OECD Science, Technology and Industry Policy Papers, No. 59, OECD Publishing, Paris, https://www.oecd-ilibrary.org/science-andtechnology/innovation-policies-in-the-digital-age eadd1094-en (accessed on 16 February 2021).

Guellec, D. and S. Wunsch-Vincent (2009), "Policy Responses to the Economic Crisis: Investing in 
Innovation for Long-Term Growth”, OECD Digital Economy Papers, No. 159, OECD Publishing, Paris.

Hanushek, E. and L. Woessmann (2020), “The economic impacts of learning losses”, Education Working Papers, No. 25, OECD Publishing, Paris, https://www.oecd-ilibrary.org/education/the-economicimpacts-of-learning-losses 21908d74-en (accessed on 10 March 2021).

Harris, M. et al. (2020), Fast and frugal innovations in response to the COVID-19 pandemic, Nature Research, http://dx.doi.org/10.1038/s41591-020-0889-1.

HBR (2020), Recreating Work as a Blend of Virtual and Physical Experiences, Harvard Business Review Analaytic Services, https://hbr.org/resources/pdfs/comm/verizon/RecreatingWorkAsABlendOfVirtualandPhysicalExperie nces.pdf (accessed on 12 November 2020).

Hershbein, B. and L. Kahn (2018), "Do recessions accelerate routine-biased technological change? evidence from vacancy postings”, American Economic Review, Vol. 108/7, pp. 1737-1772, http://dx.doi.org/10.1257/aer.20161570.

Howell O’Neill, P., T. Ryan-Mosley and B. Johnson (2020), “A flood of coronavirus apps are tracking us. Now it's time to keep track of them.", MIT Technology Review, https://www.technologyreview.com/2020/05/07/1000961/launching-mittr-covid-tracing-tracker/ (accessed on 18 November 2020).

Hynes, W., M. Lees and J. Müller (eds.) (2020), Systemic Thinking for Policy Making: The Potential of Systems Analysis for Addressing Global Policy Challenges in the 21st Century, New Approaches to Economic Challenges, OECD Publishing, Paris, https://dx.doi.org/10.1787/879c4f7a-en.

Hynes, W. et al. (2020), "Bouncing forward: a resilience approach to dealing with COVID-19 and future systemic shocks”, Environment Systems and Decisions, Vol. 40/2, pp. 174-184, http://dx.doi.org/10.1007/s10669-020-09776-x.

ILO (2021), COVID-19 Pandemic in the World of Work: ILO Monitor: COVID-19 and the world of work. 7th edition, International Labour Organization, https://www.ilo.org/global/topics/coronavirus/impactsand-responses/WCMS 767028/lang--en/index.htm (accessed on 10 March 2021).

IMF (2021), Fiscal Monitor Update, January 2021, International Monetary Fund, https://www.imf.org/en/Publications/FM/Issues/2021/01/20/fiscal-monitor-update-january-2021 (accessed on 26 February 2021).

IMF (2021), Transcript of the World Economic Outlook Update Press Briefing - 28 January 2021, International Monetary Fund, https://www.imf.org/en/News/Articles/2021/01/28/tro12621-transcriptof-the-world-economic-outlook-update-press-briefing (accessed on 17 March 2021).

IMF (2020), Fiscal Monitor - April 2020, Inernational Monetary Fund, https://www.imf.org/en/Publications/FM/Issues/2020/04/06/fiscal-monitor-april-2020 (accessed on 28 September 2020).

IMF (2020), IMF Fiscal Monitor: Policies for the Recovery - October 202O, https://www.imf.org/en/Publications/FM/Issues/2020/09/30/october-2020-fiscal-monitor (accessed on 25 April 2018).

IMF (2020), World Economic Outlook, October 2020: A Long and Difficult Ascent, International Monetary Fund, https://www.imf.org/en/Publications/WEO/Issues/2020/o9/30/world-economic-outlookoctober-2020 (accessed on 26 February 2021).

Interpol (2020), COVID-19: Cybercrime Analysis Report - August 2020, https://www.interpol.int/Newsand-Events/News/2020/INTERPOL-report-shows-alarming-rate-of-cyberattacks-during-COVID-19 (accessed on 26 October 2020).

Invenium (2020), Helping in the COVID crisis, https://invenium.io/en/blog/2020-03-15-here-to-help/ (accessed on 18 November 2020).

Izsak, K. et al. (2013), Impact of the Crisis on Research and Innovation Policies, Study for the European Commission DG Research, Directorate C - Research and Innovation under the framework contract Lot 2, https://ec.europa.eu/research/innovation-union/pdf/expert-groups/ERIAB pb- 
Impact_of_financial_crisis.pdf (accessed on 5 November 2020).

Javorcik, B. (2020), "Global supply chains will not be the same in the post-COVID-19 world", in Baldwin, R. and S. Evenett (eds.), COVID-19 and Trade Policy: Why Turning Inward Won't Work, A CEPR Press VoxEU.org eBook, https://voxeu.org/content/covid-19-and-trade-policy-why-turning-inward-won-twork (accessed on 4 June 2020).

Johns Hopkins University (2021), COVID-19 Map, Johns Hopkins Coronavirus Resource Center, https://coronavirus.jhu.edu/map.html (accessed on 25 March 2021).

Juergensen, J., J. Guimón and R. Narula (2020), "European SMEs amidst the COVID-19 crisis: assessing impact and policy responses", Journal of Industrial and Business Economics, Vol. 47/3, pp. 499-510, http://dx.doi.org/10.1007/s40812-020-00169-4.

Kelly, E. (2020), Decoding Europe's new fascination with 'tech sovereignty', ScienceBusiness, https://sciencebusiness.net/news/decoding-europes-new-fascination-tech-sovereignty (accessed on 18 February 2021)

Khaliq, M. (2021), Impact of the coronavirus (COVID-19) pandemic on retail sales in 2020 , Office for National Statistics, https://www.ons.gov.uk/economy/grossdomesticproductgdp/articles/impactofthecoronaviruscovid19p andemiconretailsalesin2020/2021-01-28 (accessed on 18 February 2021).

Kharas, H. (2020), The impact of COVID-19 on global extreme poverty, Brookings, https://www.brookings.edu/blog/future-development/2020/10/21/the-impact-of-covid-19-on-globalextreme-poverty/ (accessed on 31 March 2021).

Khurshid, A. (2020), "Applying Blockchain Technology to Address the Crisis of Trust During the COVID-19 Pandemic”, JMIR Medical Informatics, Vol. 8/9, p. e20477, http://dx.doi.org/10.2196/20477.

Korean Ministry of Economy and Finance (2021), 2021 Budget Drawn up to Speed up Turnaround and Prepare for the Future - Press Release, https://english.moef.go.kr/pc/selectTbPressCenterDtl.do?boardCd=No001\&seq=4967 (accessed on 10 March 2021).

Krukowski, R., R. Jagsi and M. Cardel (2021), “Academic Productivity Differences by Gender and Child Age in Science, Technology, Engineering, Mathematics, and Medicine Faculty During the COVID-19 Pandemic", Journal of Women's Health, Vol. 30/3, pp. 341-347, http://dx.doi.org/10.1089/jwh.2020.8710.

Lakner, C. et al. (2021), Updated estimates of the impact of COVID-19 on global poverty: Looking back at 2020 and the outlook for 2021, World Bank Blog, https://blogs.worldbank.org/opendata/updatedestimates-impact-covid-19-global-poverty-looking-back-2020-and-outlook2021\#: : :text=As\%2oreported\%20above\%2C\%20the\%2opandemic,between\%20143\%20and\%20163\%2 omillion. (accessed on 11 January 2021).

Larrue, P. (2021), "The design and implementation of mission-oriented innovation policies: A new systemic policy approach to address societal challenges”, OECD Science, Technology and Industry Policy Papers, No. 100, OECD Publishing, Paris, https://www.oecd-ilibrary.org/fr/science-and-technology/the-designand-implementation-of-mission-oriented-innovation-policies_3f6c76a4-en (accessed on 10 March 2021).

Letouzé, E. et al. (2020), "Using data to fight COVID-19 and build back better”, Paper Series, No. 2, DataPop Alliance and the Vodafone Institute for Society and Communications, http://dx.doi.org/10.1016/So140-6736(20)32000-6.

Lewis, D. (2021), Contact-tracing apps help reduce COVID infections, data suggest, NLM (Medline), http://dx.doi.org/10.1038/d41586-021-00451-y.

Lewis, D. (2020), "Why many countries failed at COVID contact-tracing - but some got it right", Nature, Vol. 588/7838, pp. 384-387, http://dx.doi.org/10.1038/d41586-020-03518-4.

Marshall, L. (2020), Mission possible - A vision for Australia's recovery and future resilience, CSIRO Newsroom, https://www.csiro.au/en/News/News-releases/2020/Speech-to-the-National-Press-Club (accessed on 22 March 2021). 
Mateos-Garcia, J., J. Klinger and K. Stathoulopoulos (2020), Artificial Intelligence and the Fight Against COVID-19, Nesta, https://www.nesta.org.uk/report/artificial-intelligence-and-fight-against-covid-19/ (accessed on 11 September 2020).

Maxmen, A. (2021), “Massive Google-funded COVID database will track variants and immunity.", Nature, http://dx.doi.org/10.1038/d41586-021-00490-5.

McGrail, S. (2021), IBM, Moderna Explore AI, Blockchain for COVID-19 Vaccine Management, HITInfrastructure - Xtelligent Healthcare Media, https://hitinfrastructure.com/news/ibm-modernaexplore-ai-blockchain-for-covid-19-vaccine-management (accessed on 22 March 2021).

Myers, K. et al. (2020), Unequal effects of the COVID-19 pandemic on scientists, Nature Research, http://dx.doi.org/10.1038/s41562-020-0921-y.

Nasdaq (2021), 2020 Review and Outlook for 2021, https://www.nasdaq.com/articles/2020-review-andoutlook-for-2021-2021-01-04 (accessed on 10 March 2021).

NSF (2020), Dear Colleague Letter: Future of International Research Collaboration Post COVID-19 (nsf20132), National Science Foundation, https://www.nsf.gov/pubs/2020/nsf20132/nsf20132.jsp?WT.mc id=USNSF 25\&WT.mc ev=click (accessed on 21 October 2020).

NTT Data (2020), What are citizens saying during the COVID-19 pandemic?, NTT Data and Citibeats, https://covid19-japan.citibeats.com/\#/CAT/4 (accessed on 18 November 2020).

OECD (2021), “COVID-19: A pivot point for science, technology and innovation?”, in OECD Science, Technology and Innovation Outlook 2021: Times of Crisis and Opportunity, OECD Publishing, Paris, https://doi.org/10.1787/8eao17be-en (accessed on 23 October 2020).

OECD (2021), OECD Science, Technology and Innovation Outlook 2021: Times of Crisis and Opportunity, OECD Publishing, Paris, https://dx.doi.org/10.1787/75f79015-en.

OECD (2021), Quarterly GDP, https://www.oecd-ilibrary.org/economics/quarterlygdp/indicator/english b86d1fc8-en (accessed on 26 February 2021).

OECD (2021), Recommendation of the OECD Council concerning Access to Research Data from Public Funding, http://www.oecd.org/sti/recommendation-access-to-research-data-from-public-funding.htm (accessed on 16 February 2021).

OECD (2021), Strategic Foresight, https://www.oecd.org/strategic-foresight/ (accessed on 19 February 2021).

OECD (2021), The Digital Transformation of SMEs, OECD Studies on SMEs and Entrepreneurship, OECD Publishing, Paris, https://dx.doi.org/10.1787/bdb9256a-en.

OECD (2020), "A systemic resilience approach to dealing with Covid-19 and future shocks", No. OECD Tackling Coronavirus (COVID-19), OECD Publishing, Paris, http://www.oecd.org/coronavirus/policyresponses/a-systemic-resilience-approach-to-dealing-with-covid-19-and-future-shocks-36a5bdfb/ (accessed on 4 November 2020).

OECD (2020), "COVID-19 and global value chains: Policy options to build more resilient production networks”, OECD Policy Responses to Coronavirus (COVID-19), OECD Publishing, Paris, http://www.oecd.org/coronavirus/policy-responses/covid-19-and-global-value-chains-policy-optionsto-build-more-resilient-production-networks-04934ef4/ (accessed on 9 February 2021).

OECD (2020), "Dealing with digital security risk during the Coronavirus (COVID-19) crisis", OECD Policy Responses to Coronavirus (COVID-19), OECD Publishing, Paris, http://www.oecd.org/coronavirus/policy-responses/dealing-with-digital-security-risk-during-thecoronavirus-covid-19-crisis-c9d3fe8e/ (accessed on 16 November 2020).

OECD (2020), "Education and COVID-19: Focusing on the long-term impact of school closures", $O E C D$ Policy Responses to Coronavirus (COVID-19), OECD, Paris, https://www.oecd.org/coronavirus/policyresponses/education-and-covid-19-focusing-on-the-long-term-impact-of-school-closures-2ceag26e/ (accessed on 10 March 2021).

OECD (2020), Enhanced Access to Publicly Funded Data for Science, Technology and Innovation, OECD 
Publishing, Paris, https://dx.doi.org/10.1787/947717bc-en.

OECD (2020), "Ensuring data privacy as we battle COVID-19”, OECD Policy Responses to Coronavirus (COVID-19), OECD Publishing, Paris, http://www.oecd.org/coronavirus/policy-responses/ensuringdata-privacy-as-we-battle-covid-19-36c2f31e/ (accessed on 16 November 2020).

OECD (2020), "Making the green recovery work for jobs, income and growth", OECD Policy Responses to Coronavirus (COVID-19), OECD Publishing, Paris, http://www.oecd.org/coronavirus/policyresponses/making-the-green-recovery-work-for-jobs-income-and-growth-a505f3e7/\#section-d1e176 (accessed on 29 October 2020).

OECD (2020), OECD Science Flash Survey 2020: Science in the face of the Covid-19 crisis, https://oecdsciencesurveys.github.io/2020flashsciencecovid/ (accessed on 3 August 2020).

OECD (2020), "Productivity gains from teleworking in the post COVID-19 era: How can public policies make it happen?”, OECD Policy Responses to Coronavirus (COVID-19), OECD Publishing, Paris, http://www.oecd.org/coronavirus/policy-responses/productivity-gains-from-teleworking-in-the-postcovid-19-era-a5d52e99/ (accessed on 16 November 2020).

OECD (2020), "Science, technology and innovation: How co-ordination at home can help the global fight against COVID-19”, OECD Policy Responses to Coronavirus (COVID-19), http://www.oecd.org/coronavirus/policy-responses/science-technology-and-innovation-how-coordination-at-home-can-help-the-global-fight-against-covid-19-aa547c11/ (accessed on 8 September 2020).

OECD (2020), "Seven lessons learned about digital security during the COVID-19 crisis", OECD Tackling Coronavirus (COVID-19), OECD Publishing, Paris, http://www.oecd.org/coronavirus/policyresponses/seven-lessons-learned-about-digital-security-during-the-covid-19-crisis-e55a6b9a/ (accessed on 16 November 2020).

OECD (2020), "Strategic foresight for the COVID-19 crisis and beyond: Using futures thinking to design better public policies", OECD Tackling Coronavirus (COVID-19), OECD Publishing, Paris, http://www.oecd.org/coronavirus/policy-responses/strategic-foresight-for-the-covid-19-crisis-andbeyond-using-futures-thinking-to-design-better-public-policies-c3448fa5/ (accessed on 8 October 2020)

OECD (2020), The Financial System, New Approaches to Economic Challenges, OECD Publishing, Paris, https://dx.doi.org/10.1787/d45f979e-en.

OECD (2020), "The territorial impact of COVID-19: Managing the crisis across levels of government", OECD Policy Responses to Coronavirus (COVID-19), OECD Publishing, Paris, https://www.oecd.org/coronavirus/policy-responses/the-territorial-impact-of-covid-19-managing-thecrisis-across-levels-of-government-d3e314e1/ (accessed on 26 October 2020).

OECD (2020), "Tracking and tracing COVID: Protecting privacy and data while using apps and biometrics", OECD Tackling Coronavirus (COVID-19), OECD Publishing, Paris, http://www.oecd.org/coronavirus/policy-responses/tracking-and-tracing-covid-protecting-privacy-anddata-while-using-apps-and-biometrics-8f394636/ (accessed on 16 November 2020).

OECD (2020), Trade interdependencies in Covid-19 goods, OECD Policy Responses to Coronavirus (COVID-19), http://www.oecd.org/coronavirus/policy-responses/trade-interdependencies-in-covid-19goods-79aaa1d6/ (accessed on 3 June 2020).

OECD (2020), Why open science is critical to combatting COVID-19, https://www.oecd.org/coronavirus/policy-responses/why-open-science-is-critical-to-combatting-covid19/ (accessed on 5 May 2020).

OECD (2019), Digital Innovation: Seizing Policy Opportunities, OECD Publishing, Paris, https://dx.doi.org/10.1787/a298dc87-en.

OECD (2019), University-Industry Collaboration : New Evidence and Policy Options, OECD Publishing, Paris, https://dx.doi.org/10.1787/egc1e648-en.

OECD (2017), Making Innovation Benefit All: Policies for Inclusive Grow th, https://www.innovationpolicyplatform.org/system/files/Inclusive\%20Growth\%20publication\%20FULL 
\%20for\%20web.pdf (accessed on 17 January 2019).

OECD (2015), "Making Open Science a Reality”, OECD Science, Technology and Industry Policy Papers, No. 25, OECD Publishing, Paris, https://dx.doi.org/10.1787/5jrs2f963zs1-en.

OECD (2015), System Innovation: Synthesis Report, http://www.innovationpolicyplatform.org/www.innovationpolicyplatform.org/sites/default/files/gener al/SYSTEMINNOVATION_FINALREPORT_o/index.pdf (accessed on 3 June 2020).

OECD (2012), OECD Science, Technology and Industry Outlook 2012, OECD Publishing, Paris, https://www.oecd-ilibrary.org/science-and-technology/oecd-science-technology-and-industry-outlook2012_sti_outlook-2012-en (accessed on 1 June 2020).

OECD (2012), OECD Science, Technology and Industry Outlook 2012, OECD Publishing, Paris, https://dx.doi.org/10.1787/sti_outlook-2012-en.

OECD (2011), “Towards Green Growth”, OECD Green Growth Studies, OECD Publishing, pp. 1-146, http://dx.doi.org/10.1787/22229523.

OECD (2002), Dynamising National Innovation Systems, OECD Publishing, Paris, https://dx.doi.org/10.1787/9789264194465-en.

OECD (2001), Innovative Networks: Co-operation in National Innovation Systems, OECD Publishing, Paris, https://dx.doi.org/10.1787/9789264195660-en.

OECD (2001), Innovative People: Mobility of Skilled Personnel in National Innovation Systems, OECD Publishing, Paris, https://dx.doi.org/10.1787/9789264195585-en.

OECD (1999), Managing National Innovation Systems, OECD Publishing, Paris, https://dx.doi.org/10.1787/9789264189416-en.

Our World in Data (2021), Coronavirus (COVID-19) Vaccinations - Statistics and Research, https://ourworldindata.org/covid-vaccinations (accessed on 26 March 2021).

OWSD (2020), The impact of COVID-19 on women scientists from developing countries: Results from an OWSD member survey, Organization for Women in Science for the Developing World, https://owsd.net/news/news-events/impact-covid-19-women-scientists-developing-countries-resultsowsd-member (accessed on 10 March 2021).

Paunov, C. (2013), "Innovation and Inclusive Development: A Discussion of the Main Policy Issues", OECD Science, Technology and Industry Working Papers, No. 2013/1, OECD Publishing, Paris, https://dx.doi.org/10.1787/5k4dd1rvsnjj-en

Paunov, C. et al. (2019), "On the concentration of innovation in top cities in the digital age", OECD Science, Technology and Industry Policy Papers, No. 85, OECD Publishing, Paris, https://www.oecdilibrary.org/science-and-technology/on-the-concentration-of-innovation-in-top-cities-in-the-digitalage_f184732a-en (accessed on 19 May 2020).

Paunov, C. and S. Planes-Satorra (2021), "Science, technology and innovation in the time of COVID-19", OECD Science, Technology and Industry Policy Papers, No. 99, OECD Publishing, Paris, https://doi.org/10.1787/234aooe5-en (accessed on 14 February 2021).

Paunov, C. and S. Planes-Satorra (2019), "How are digital technologies changing innovation? : Evidence from agriculture, the automotive industry and retail”, OECD Science, Technology and Industry Policy Papers, No. 74, OECD Publishing, Paris, https://dx.doi.org/10.1787/67bbcafe-en.

Pfizer (2021), Real-World Evidence Confirms High Effectiveness of Pfizer-BioNTech COVID-19 Vaccine and Profound Public Health Impact of Vaccination One Year After Pandemic Declared, Pfizer News, https://www.pfizer.com/news/press-release/press-release-detail/real-world-evidence-confirms-higheffectiveness-pfizer (accessed on 22 March 2021).

Phillips, M. (2020), Investors Bet Giant Companies Will Dominate After Crisis - The New York Times, The New York TImes, https://www.nytimes.com/2020/04/28/business/coronavirus-stocks.html (accessed on 2 June 2020).

Planes-Satorra, S. and C. Paunov (2019), “The digital innovation policy landscape in 2019”, OECD Science, 
Technology and Industry Policy Papers, No. 71, OECD Publishing, Paris, https://www.oecdilibrary.org/science-and-technology/the-digital-innovation-policy-landscape-in-2019 6171f649-en (accessed on 1 July 2019).

Planes-Satorra, S. and C. Paunov (2017), "Inclusive innovation policies: Lessons from international case studies”, OECD Science, Technology and Industry Working Papers, No. 2017/2, OECD Publishing, Paris, https://dx.doi.org/10.1787/a09a3a5d-en.

Région de Grand Est (2020), Pacte de relocalisation des approvisionnements - GrandEst, https://www.grandest.fr/vos-aides-regionales/pacte-de-relocalisation-des-approvisionnements/ (accessed on 22 March 2021).

Riom, C. and A. Valero (2020), "The business response to Covid-19: The CEP-CBI survey on technology adoption”, A CEP Covid-19 analysis, No. 009, Centre for Economic Performance, London, http://cep.lse.ac.uk/pubs/download/cepcovid-19-009.pdf (accessed on 30 September 2020).

SBU (2020), Stony Brook Led Team Using Twitter to Measure and Forecast Changes in COVID-19 Symptoms and Mental Health, Stony Brook University - Department of Computer Science, https://www.cs.stonybrook.edu/about-us/News/Stony-Brook-Led-Team-Using-Twitter-Measure-andForecast-Changes-COVID-19-Symptoms-and (accessed on 18 November 2020).

Seric, A. and D. Winkler (2020), "Managing COVID-19: Could the coronavirus spur automation and reverse globalization? | Industrial Analytics Platform", Industrial Analytics Platform - Unido.org, https://iap.unido.org/articles/managing-covid-19-could-coronavirus-spur-automation-and-reverseglobalization (accessed on 2 June 2020).

Shakil, M. et al. (2020), "COVID-19 and the environment: A critical review and research agenda”, Science of the Total Environment, Vol. 745, p. 141022, http://dx.doi.org/10.1016/j.scitotenv.2020.141022.

Shih, W. (2020), “Global Supply Chains in a Post-Pandemic World”, Global Business Review, https://hbr.org/2020/o9/global-supply-chains-in-a-post-pandemic-world (accessed on 12 October 2020).

Skegg, D. et al. (2021), "Future scenarios for the COVID-19 pandemic", The Lancet, Vol. o/o, http://dx.doi.org/10.1016/So140-6736(21)00424-4.

Spanish Government (2020), Government approves Spanish Science, Technology and Innovation Strategy for 2021 to 2027, La Moncloa, https://www.lamoncloa.gob.es/lang/en/gobierno/councilministers/Paginas/2020/20200908council.as px (accessed on 7 October 2020).

Spinney, L. (2020), The World Changed Its Approach to Health After the 1918 Flu, Time, https://time.com/5797629/health-1918-flu-epidemic/ (accessed on 23 October 2020).

Stokstad, E. (2020), "UK cues up big funding increases for R\&D”, Science, http://dx.doi.org/10.1126/science.abb6928.

Swedish Government (2020), Considerable boost for Swedish research - Press release, https://www.government.se/press-releases/2020/12/considerable-boost-for-swedish-research/.

Tiesmaki, M. (2020), Supporting health researchers during a pandemic: A research funder's response to COVID-19, Michael Smith Foundation for Health Research, https://www.msfhr.org/news/forwardthinking-supporting-health-researchers-during-pandemic (accessed on 10 March 2021).

Tirole, J. (2019), Regulating the Disrupters,

https://www.livemint.com/Technology/XsgWUgygtR4uaoME7xtITI/Regulating-the-disrupters-JeanTirole.html (accessed on 10 November 2020).

Torres, I. et al. (2020), COVID Has Laid Bare the Inequities That Face Mothers in STEM, Scientific American, https://www.scientificamerican.com/article/covid-has-laid-bare-the-inequities-that-facemothers-in-stem/ (accessed on 10 March 2021).

UNCTAD (2021), Global foreign direct investment fell by $42 \%$ in 2020 , outlook remains weak, United Nations Conference on Trade and Development, https://unctad.org/news/global-foreign-directinvestment-fell-42-2020-outlook-remains-weak (accessed on 31 March 2021). 
US Census Bureau (2020), Small Business Pulse Survey: Tracking Changes During The Coronavirus Pandemic, https://www.census.gov/businesspulsedata (accessed on 4 November 2020).

Vincent-Lamarre, P., C. Sugimoto and V. Larivière (2020), The decline of women's research production during the coronavirus pandemic | Nature Index, Nature Index, https://www.natureindex.com/newsblog/decline-women-scientist-research-publishing-production-coronavirus-pandemic (accessed on 19 May 2020).

Warm Data (2020), Warm Data Lab, https://www.warmdatalab.net/warm-data-lab (accessed on 18 November 2020).

Waters, R. et al. (2020), Big Tech shows its resilience to pandemic and politics, Elsevier, https://www.ft.com/content/ac8c0714-151b-4c2f-8eb4-2e5c48ofgdec.

Wolinetz, C. (2020), NIH Releases New Policy for Data Management and Sharing - Office of Science Policy, Office of Science Policy - National Institutes of Health, https://osp.od.nih.gov/2020/10/29/nihreleases-new-policy-data-management-and-sharing/ (accessed on 9 November 2020).

Woolston, C. (2020), “Pandemic darkens postdocs' work and career hopes”, Nature, Vol. 585/7824, pp. 309-312, http://dx.doi.org/10.1038/d41586-020-02548-2.

World Bank (2021), Global Economic Prospects (January 2021), The World Bank Group, https://www.worldbank.org/en/publication/global-economic-prospects (accessed on 31 March 2021).

World Bank (2020), World Bank Predicts Sharpest Decline of Remittances in Recent History, https://www.worldbank.org/en/news/press-release/2020/04/22/world-bank-predicts-sharpestdecline-of-remittances-in-recent-history (accessed on 31 March 2021).

World Economic Forum (2018), The Future of Jobs Report 2018, World Economic Forum, https://www.weforum.org/reports/the-future-of-jobs-report-2018 (accessed on 10 March 2021).

Zolas, N. et al. (2020), Advanced Technologies Adoption and Use by U.S. Firms: Evidence from the Annual Business Survey, National Bureau of Economic Research, Cambridge, MA, http://dx.doi.org/10.3386/w28290. 


\section{Endnotes}

${ }^{1}$ In October 2020 the CSTP organised two webinars to coincide with the launch of STI Outlook 2020: "STI Policy in times of uncertainty" (5 October 2020), and "Mobilising science in response to COVID-19" (21 October 2020).

2 Between September and November 2020, the OECD's TIP Working Party organised a series of online talks and discussions: 1) "What role does technology play in building resilience to systemic shocks?" (2 October 2020); 2) "Learning about the future with scenarios: Innovation in a post-coronavirus world" (7 October 2020); 3) "How to co-create successfully? Developing lessons from the TIP co-creation case studies" (15 October); 4) "The shifting geography of innovation: Funding for innovation in times of COVID-19" (29 October); 5) "What's next for STI policies in times of the COVID-19 crisis and after? A perspective from Sweden" (12 November). Find all information at: http://oe.cd/tipone.

${ }^{3}$ Figures refer to the number of COVID-19 vaccination doses administered per 100 people within a given population. This is counted as a single dose, and may not equal the total number of people vaccinated, depending on the specific dose regime (e.g. people that receive multiple doses).

${ }^{4}$ Find more at www.climate-kic.org/programmes/deep-demonstrations/.

${ }^{5}$ Find more at www.warmdatalab.net/warm-data-lab. 